


\section{CONNECT WITH US}

wbg.org/Malaysia

f @WorldBankMalaysia

@WB_AsiaPacific

http://bit.ly/WB_blogsMY 


\section{MALAYSIA ECONOMIC MONITOR}




\section{(C) 2019 International Bank for Reconstruction and Development / The World Bank}

Sasana Kijang, 2 Jalan Dato Onn, Kuala Lumpur 50480, Malaysia

Some rights reserved.

This work is a product of the staff of The World Bank with external contributions. The findings, interpretations, and conclusions expressed in this work do not necessarily reflect the views of The World Bank, its Board of Executive Directors, or the governments they represent. The World Bank does not guarantee the accuracy of the data included in this work. The boundaries, colors, denominations, and other information shown on any map in this work do not imply any judgment on the part of The World Bank concerning the legal status of any territory or the endorsement or acceptance of such boundaries.

Nothing herein shall constitute or be considered to be a limitation upon or waiver of the privileges and immunities of The World Bank, all of which are specifically reserved.

\section{Rights and Permissions}

This work is available under the Creative Commons Attribution 3.0 IGO license (CC BY 3.0 IGO) http://creativecommons.org/licenses/by/3.0/igo. Under the Creative Commons Attribution license, you are free to copy, distribute, transmit, and adapt this work, including for commercial purposes, under the following conditions:

Attribution: Please cite the work as follows: World Bank (2019) "Re-energizing the Public Service" Malaysia Economic Monitor (June), World Bank, Washington, DC.

Translations: If you create a translation of this work, please add the following disclaimer along with the attribution: This translation was not created by The World Bank and should not be considered an official World Bank translation. The World Bank shall not be liable for any content or error in this translation.

Adaptations: If you create an adaptation of this work, please add the following disclaimer along with the attribution: This is an adaptation of an original work by The World Bank. Views and opinions expressed in the adaptation are the sole responsibility of the author or authors of the adaptation and are not endorsed by The World Bank.

Third-party content: The World Bank does not necessarily own each component of the content contained within the work. The World Bank therefore does not warrant that the use of any thirdparty-owned individual component or part contained in the work will not infringe on the rights of those third parties. The risk of claims resulting from such infringement rests solely with you. If you wish to re-use a component of the work, it is your responsibility to determine whether permission is needed for that re-use and to obtain permission from the copyright owner. Examples of components can include, but are not limited to, tables, figures, or images.

All queries on rights and licenses should be addressed to World Bank Publications, The World Bank, 1818 H Street NW, Washington, DC 20433, USA; e-mail: pubrights@worldbank.org 


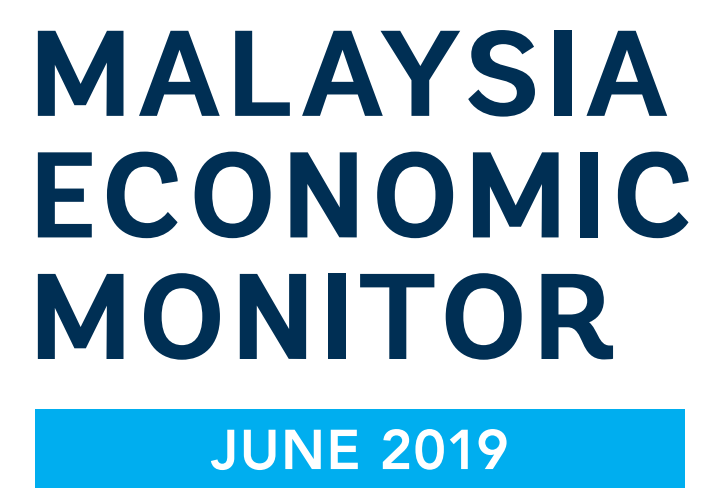

\section{Re-energizing the Public Service}




\section{Acknowledgements}

This edition of the Malaysia Economic Monitor was prepared by Richard Record (Task Team Leader), Yew Keat Chong, Shakira Teh Sharifuddin, Rajni Bajpai (Task Team Leader for Part 2) and Jeeva Govindasamy. Kenneth Simler, Achim Schmillen, Wei San Loh, Deryck Brown, Bernard Myers, Samuel Fraiberger, Maryla Maliszewska, Carmen Loo, Cristina Constantinescu, Taufiq Zin, Anton Prokopyev, Amanina Abdur Rahman, Siddhartha Raja, Jorge Guzman, Steven Pennings, Norman Loayza, Young Kim, Sharmila Devadas, Willy McCourt, Sergio Schmukler, Abdullah Maamor Ibrahim, Facundo Abraham and Shahrul Natasha Halid provided additional contributions.

Mara Warwick, Firas Raad, Ndiame Diop, George Larbi and Souleymane Coulibaly provided overall guidance. The team is grateful to Andrew Mason, Ekaterine Vashakmadze, Ergys Islamaj and Francesca de Nicola for their constructive input.

This report benefited from productive discussions with staff from the Ministry of Economic Affairs, the Ministry of Finance, the Prime Minister's Department, Bank Negara Malaysia, the National Centre for Governance, Integrity and Anti-Corruption Anti-corruption, Public Service Department, Malaysian Administrative Modernization and Management Planning Unit and many other government ministries and agencies, relevant organizations and individuals, all of whom provided valuable information and useful feedback.

In particular, the team would like to thank the Strategic Planning and International Cooperation Division of the Ministry of Economic Affairs and the Economics Department of Bank Negara Malaysia for close ongoing collaboration with the World Bank and for the crucial support to the launch of this report. The team would like to express its gratitude to analysts at several private financial firms and rating institutions, whose participation in a constructive dialogue also informed the analysis.

Joshua Foong and Min Hui Lee led external communications and the production and design of the report. Irfan Kortschak provided editing assistance, while Aziaton Ahmad provided administrative support. Kane Chong designed the report and its cover.

Photography: Samuel Goh

The report is based on information current as of June 21, 2019.

Please contact Richard Record (rrecord@worldbank.org), Yew Keat Chong (ychong@worldbank.org) or Shakira Teh Sharifuddin (stehsharifuddin@worldbank.org) if you have any questions or comments regarding the Malaysia Economic Monitor. 


\section{Abbreviations}

\begin{tabular}{|c|c|}
\hline $1 M D B$ & 1 Malaysia Development Berhad \\
\hline ASEAN & Association of Southeast Asian Nations \\
\hline ASR & Adult Survival Rate \\
\hline ATI & Access to Information \\
\hline ATM & Automated Teller Machine \\
\hline B40 & Bottom 40 percent (of the population) \\
\hline BNM & Bank Negara Malaysia \\
\hline BSH & Cost of Living Aid (Bantuan Sara Hidup Rakyat) \\
\hline CPI & Consumer Price Index \\
\hline DGCCR & $\begin{array}{l}\text { Digital Government Competency and Capability } \\
\text { Readiness }\end{array}$ \\
\hline DMO & Debt Management Office \\
\hline DOSM & Department of Statistics Malaysia \\
\hline E\&E & Electrical and Electronics \\
\hline EAP & East Asia and Pacific \\
\hline ECRL & East Coast Rail Link \\
\hline EG & Electronic Government \\
\hline EM & Emerging Market \\
\hline EMDE & Emerging Market and Developing Economies \\
\hline FBM KLCl & FTSE Bursa Malaysia Index \\
\hline FDI & Foreign Direct Investment \\
\hline FM & Frontier Market \\
\hline G2G & Government to Government \\
\hline GDP & Gross Domestic Product \\
\hline GFCF & Gross Fixed Capital Formation \\
\hline GIACC & $\begin{array}{l}\text { National Centre for Governance, Integrity and Anti- } \\
\text { Corruption }\end{array}$ \\
\hline GLC & Government-linked Company \\
\hline GLIC & Government-linked Investment Company \\
\hline GNI & Gross National Income \\
\hline GST & Goods and Services Tax \\
\hline $\mathrm{HCl}$ & Human Capital Index \\
\hline HIES & Household Income and Expenditure Survey \\
\hline HRM & Human Resource Management \\
\hline ICT & Information Communications Technology \\
\hline IMF & International Monetary Fund \\
\hline IPI & Industrial Production Index \\
\hline IR4.0 & Industrial Revolution 4.0 \\
\hline ISP & Internet Service Provider \\
\hline JKKMAR & Cabinet Special Committee on Anti-Corruption \\
\hline
\end{tabular}

\begin{tabular}{|c|c|}
\hline KRI & Khazanah Research Institute \\
\hline LTGM & Long Term Growth Model \\
\hline M40 & Middle 40 percent (of the population) \\
\hline MAMPU & $\begin{array}{l}\text { Malaysian Administrative Modernization and } \\
\text { Management Planning Unit }\end{array}$ \\
\hline MASCO & Malaysia Standard Classification of Occupations \\
\hline MCMC & $\begin{array}{l}\text { Malaysian Communications and Multimedia } \\
\text { Commission }\end{array}$ \\
\hline MEM & Malaysia Economic Monitor \\
\hline MGS & Malaysian Government Securities \\
\hline MIER & Malaysian Institute of Economic Research \\
\hline MODUG & Malaysian Open Data Users Group \\
\hline MOF & Ministry of Finance Malaysia \\
\hline MSAP & Mandatory Standard on Access Pricing \\
\hline MTR & Mid-term Review \\
\hline NACP & National Anti-Corruption Plan \\
\hline OBI & Open Budget Index \\
\hline ODB & Open Data Barometer \\
\hline ODRA & Open Data Readiness Assessment \\
\hline OECD & $\begin{array}{l}\text { Organization for Economic Cooperation and } \\
\text { Development }\end{array}$ \\
\hline OGI & Open Government Index \\
\hline OPR & Overnight Policy Rate \\
\hline OSA & Official Secrets Act \\
\hline PER & Public Expenditure Review \\
\hline PSC & Public Service Commission \\
\hline PSD & Public Service Department \\
\hline PTD & Administrative and Diplomatic Service \\
\hline Q/Q & Quarter-on-Quarter \\
\hline QoG & Quality of Government \\
\hline RMKe-11 & Eleventh Malaysia Plan \\
\hline RMKe-12 & Twelfth Malaysia Plan \\
\hline SAAR & Seasonally Adjusted Annual Rate \\
\hline SDGs & Sustainable Development Goals \\
\hline SST & Sales and Services Tax \\
\hline T20 & Top 20 percent (of the population) \\
\hline TFP & Total Factor Productivity \\
\hline TM & Telekom Malaysia \\
\hline WGBI & World Government Bond Index \\
\hline $\mathrm{Y} / \mathrm{Y}$ & Year-on-Year \\
\hline
\end{tabular}





\section{Table of Contents}

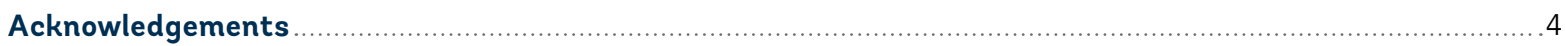

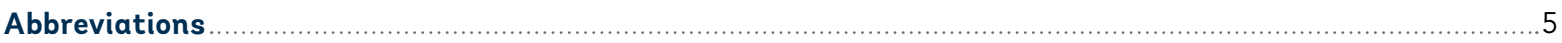

Summary

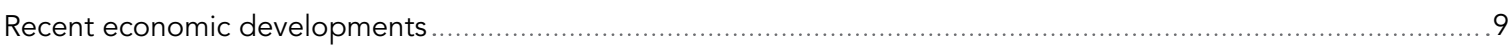

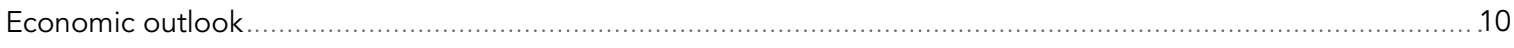

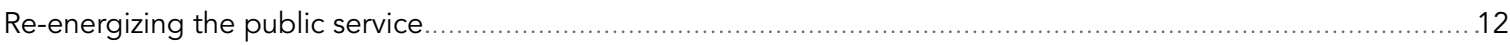

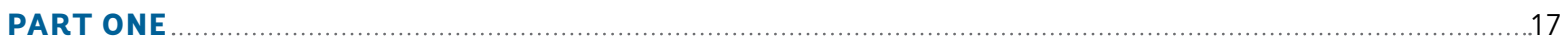

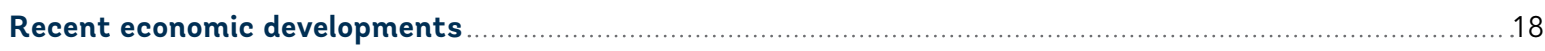

Regional growth has moderated amid increased headwinds ..................................................................... 18

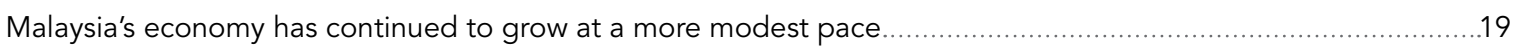

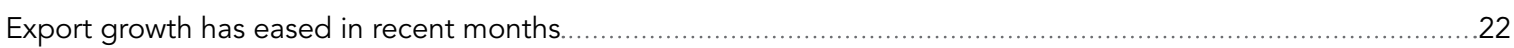

Inflation turned temporarily negative due to several policy-related factors . . ...................................................23

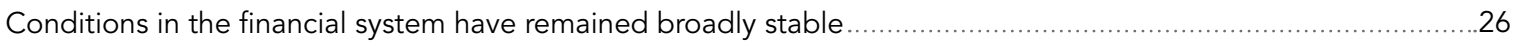

Federal government debt as a share of GDP has increased slightly ............................................................... 30

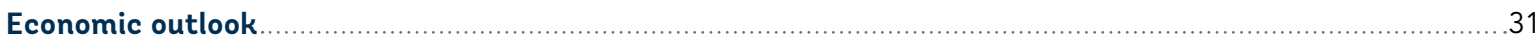

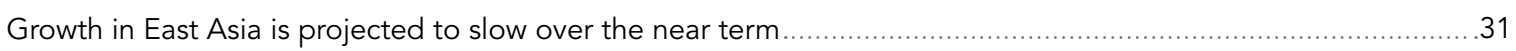

Malaysia's economy is expected to expand at a relatively modest pace .......................................................32

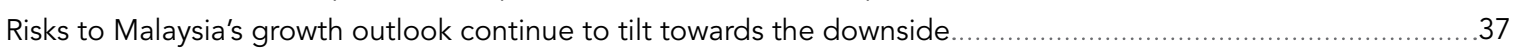

Near-term policies should focus on boosting resilience and protecting the vulnerable ....................................37

PART TWO

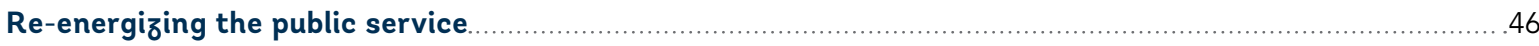

The public service plays a vital role in Malaysia's transition to a high-income and developed economy …............46

Malaysia's public service performs at par or ahead of the region, but shows a stagnant or declining trend

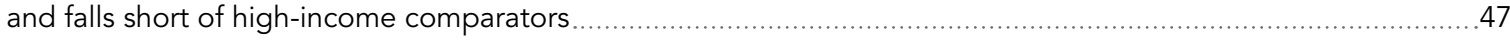

The public service faces challenges in fulfilling the emerging expectations of the people ...............................50

Malaysia's public sector size and wage bill has been an issue of concern …...................................................52

So, how can Malaysia re-energize the public service to achieve shared prosperity? $\ldots \ldots \ldots \ldots \ldots \ldots \ldots \ldots \ldots \ldots \ldots \ldots \ldots \ldots . . \ldots 57$

Merit-based recruitment, decentralization, and the use of competency frameworks to induct the best talent .........57

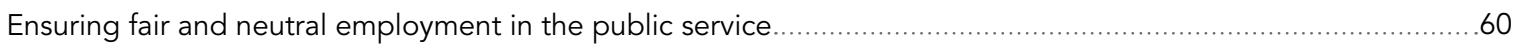

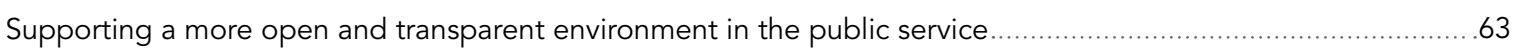

Embracing new technologies and skills to digitalize and automate for improved public service delivery ..............66

References 


\section{Summary}

\section{Malaysia's economy has continued to grow at a more modest pace}

Growth moderated in Q1 2019, owing to weaker investment growth and inventory drawdowns. Domestically, an easing of export growth, together with a decline in investment, has resulted in Malaysia's economic growth becoming more dependent on consumption.

In 2019, Malaysia's economy is expected to expand at a relatively moderate rate, with risks tilted towards the downside. The GDP growth rate is projected to reach 4.6 percent in 2019, 0.1 percentage points lower than in the previous forecast, reflecting weaker-than-expected investment and export activity observed in Q1 2019. Potential risks to growth include those related to escalating trade tensions, a sharperthan-expected slowdown in major economies, as well as volatility in financial and commodity markets. Relatively high levels of private and public debt also pose risks to growth.

In the short term, policies should focus on boosting resilience and protecting the vulnerable. In an environment of growing uncertainty, it is particularly important to rebuild fiscal policy buffers, to facilitate private investment, and to ensure adequate social protection for low-income and vulnerable households.

In the medium term, bold reforms will be needed to boost human capital and to raise productivity. As Malaysia proceeds on its transition to a high-income and developed economy, incremental growth in incomes will be increasingly dependent on improvements in human capital and productivity. In turn, this will require a multi-year reform agenda to improve the quality of workforce skills and learning outcomes from the education system.
The Malaysia Economic Monitor (MEM) consists of two parts. Part 1 presents a review of recent economic developments and a macroeconomic outlook. Part 2 focuses on a selected special topic that is key to Malaysia's medium-term development prospects and the achievement of shared prosperity. In this edition, the focus of the special topic is on re-energizing the public service to better enable it to facilitate Malaysia's future development.

While Malaysia's public service performs well or at par with regional standards, its performance has been largely stagnant and falls short relative to high-income aspirational comparators. Malaysia is one of the top performers in the region according to the World Bank's Doing Business index, but it's performance on the Government Effectiveness indicator has remained stagnant or fallen in recent years. It also lags behind both high-income and other upper middle-income countries in terms of openness and transparency. Malaysia's index for voice and accountability is well below what would be expected, given its level of per-capita income, and some indicators like political stability and the rule of law have worsened over time, with a widening gap with OECD comparators.

Building capacity in the public service is vital for Malaysia's successful transition to a high-income and developed nation. To enable the public service to fully realize its potential, Malaysia will need to invest in the management of human resources in the public service; to encourage and develop a more open, transparent environment; and to manage the impact of new and emerging trends, including those related to rapidly-evolving technological innovations and digitalization. 


\section{Recent economic developments}

Malaysia's economy has continued to expand, but at a more modest pace of $\mathbf{4 . 5}$ percent in Q1 2019. The expansion has been largely supported by sustained consumption spending in both the private and public sectors. Overall economic activity, however, has been weighed down by weaker-than-expected investment growth and continued inventory drawdowns.

Private consumption growth has remained strong, at the rate of 7.6 percent in Q1 2019. This strong expansion has been supported by continued growth in real incomes, with stable employment and wage growth as well as lower consumer price inflation. Public consumption also accelerated, at the rate of 6.3 percent in Q1, mainly due to increased expenditure on supplies and services.

By contrast, investment registered its first quarterly decline in nearly four years, with the growth rate at $\mathbf{- 3 . 5}$ percent in Q1 2019. Capital expenditure in the private sector slowed materially to 0.4 percent in Q1, with increased uncertainty appearing to have weighed on business confidence. With a review of major infrastructure projects and with the near completion of several multi-year projects, public investment contracted by -13.2 percent in Q1.

On the supply side, growth has moderated in most economic sectors except agriculture. Growth in the services sector moderated to 6.4 percent in Q1 2019, mainly due to the normalization in the retail sector following the largely tax policy-induced expansion in 2018. Growth in the manufacturing sector also slowed, in line with weaker export demand, to 4.2 percent in $\mathrm{Q} 1$. With weaker investment, growth in construction activity decelerated to 0.3 percent in Q1. Unplanned closures of key oil and gas facilities also affected the mining sector, which contracted by -2.1 percent in Q1. Meanwhile, the agriculture sector experienced a significant turnaround, expanding at the rate of 5.6 percent in Q1, largely due to a recovery in palm oil production.

Export growth slowed to 0.1 percent in Q1 2019, with softening external demand for manufactured exports. There is evidence to indicate that Malaysia has increased its market share for exports to both the US and to China following the imposition of tariffs between the two countries. This points to the underlying competitive strength of the Malaysian economy. However, weakening external demand and a maturing global technology cycle have weighed on Malaysia's aggregate export performance.

The current account surplus widened appreciably to 4.5 percent of GDP in Q1 2019, reflecting a larger trade balance and a narrower primary income deficit. The increase in the goods surplus, to 9.4 percent of GDP in Q1, was mainly due to declining imports more than offsetting the slower pace of export growth.

\section{Malaysia's GDP growth rate is forecast to moderate to 4.6 percent in 2019 , with increased headwinds}

Headline inflation briefly turned negative in early 2019 , with the rate standing at -0.3 percent in Q1 2019 due to several policy-related factors. The continued effects of lower fuel prices and the goods and services tax (GST) to the sales and services tax (SST) transition were the main drivers of the temporary deflation. Consumer price inflation has returned to positive territory since March. Core inflation, which measures underlying inflation, has remained positive and stable.

Labor markets have remained stable and supportive of economic growth. The labor force participation rate remained stable at 68.5 percent in Q1 2019. The overall unemployment rate was unchanged at 3.3 percent, albeit with substantially higher rates for younger cohorts, with the rate for the 15-24 years age group at 10.4 percent. Wage growth in the manufacturing sector continues to significantly outstrip growth in services.

In line with concerns regarding decelerating global growth, Malaysia's monetary policy committee reduced the overnight policy rate to 3.0 percent in May 2019. Bank Negara Malaysia, in announcing the rate cut of 25 basis points, also highlighted the considerable downside risks to the global economic environment. While domestic monetary and financial conditions remain supportive of growth, there are some signs of tightening of financial conditions. 
Household debt has continued to decline, standing at 83.0 percent of GDP at the end of 2018 , in a context of tighter mortgage lending conditions. Although household debt levels remain comparatively high, the bulk of household debt is secured by residential property and securities. The overall quality of lending by both banks and non-banks has remained sound, with the aggregate impairment ratio improving to 1.2 percent.

Domestic financial markets have been affected by heightened risk aversion, related to both domestic and external factors. Concerns regarding US-China trade tensions, slowing global growth and a more moderate economic activity domestically, have seen portfolio outflows by non-resident investors in an environment of heightened risk aversion. This trend may continue if Malaysia's weighting in the World Global Bond Index is reduced. Similarly, the Ringgit has been on a broad depreciating trend against the US dollar since April 2019, mainly reflecting outflows from the domestic bond market.

Federal government debt increased to $\mathbf{5 1 . 2}$ percent of GDP at the end of 2018. The fiscal deficit increased to 3.7 percent of GDP in 2018 to accommodate new policy directions and short-term adjustments. The vast majority of federal government debt remains denominated in the domestic currency, with most issuances having a remaining maturity period of more than three years, limiting both currency and rollover risks. The review of the government's outstanding public private partnership commitments has seen a reduction in the aggregate stock of the government's liabilities. However, the share of committed government guarantees has increased to 9.2 percent of GDP.

A number of new revenue and expenditure measures have been introduced. Taxes on sugar-sweetened beverages and a tourism departure levy are expected to come into effect during 2019. The extension of the SST to cover imported digital services from nonresident suppliers will commence on January 1, 2020. Efforts are also underway to reduce tax leakages. On the expenditure side, the new fuel subsidy framework is also expected to be rolled out by mid-2019. A more targeted framework and the gradual removal of untargeted subsidies could contribute to decreased subsidy spending, potentially freeing up space for more efficient targeted cash payments. In 2019, the government is committed to achieving a fiscal deficit target of 3.4 percent of GDP.

\section{Economic outlook}

Malaysia's GDP growth rate is forecast to moderate to 4.6 percent in 2019 , with increased headwinds. This is 0.1 percentage points lower than in the previous forecast, reflecting weaker-thanexpected investment and export activity. While private consumption is expected to continue to support

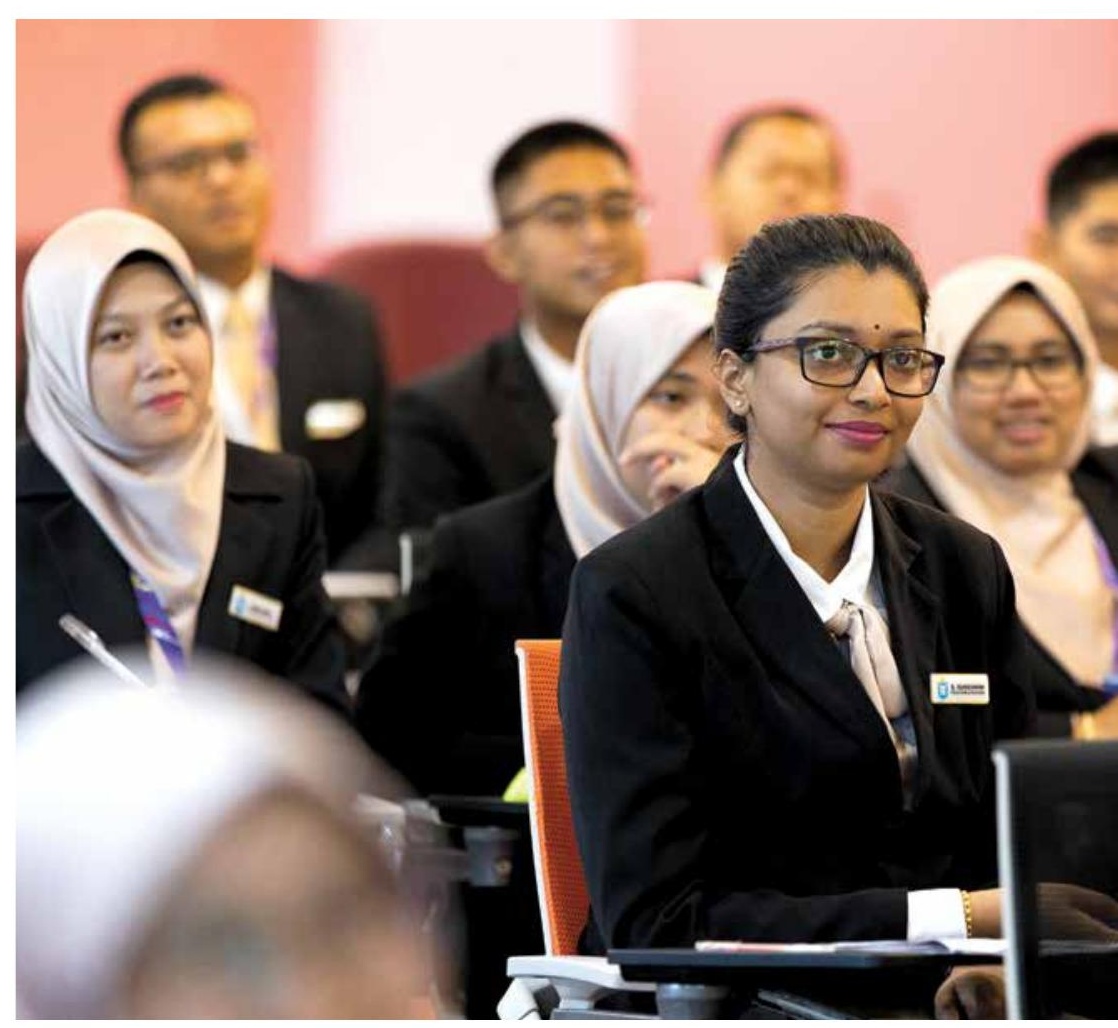

domestic demand, its growth is projected to decelerate to 6.6 percent this year. This follows a robust expansion in 2018, especially during the zero-rated GST period. In the public sector, the continued rationalization of government expenditure will continue to weigh on its contribution, with the growth rate projected to stand at 1.8 percent for the year. Sentiment-based forecasts of GDP growth continue to track below consensus estimates, suggesting that confidence remains weak.

Investment is projected to remain subdued over the near term, with both the public and private sectors continuing to adopt a cautious stance. Softening external demand, together with weaker business sentiment, are likely to result in continued slow growth in private investment, with the rate projected 
to stand at 2.9 percent in 2019. Public investment is projected to continue to contract in 2019 , to -7.0 percent, with major projects nearing completion and the government maintaining a cautious approach towards new infrastructure investment, given concerns regarding public debt levels and available fiscal space. Over the medium term, investment may start to pick up as selected large-scale capital projects resume.

The weakness in the external sector is likely to persist in the near term, with softening global demand constraining export growth. Malaysia's exports are projected to grow at the more moderate pace of 0.7 percent in 2019. Continued global uncertainty and prolonged domestic supply constraints will affect Malaysia's manufactured and commodity exports. The former will be exacerbated by the dip in the global technology cycle.

Headline inflation is expected to increase modestly in 2019, with the effects of transitory policy-related factors dissipating. The consumer price inflation rate is projected to average at about 1 percent for 2019, mainly due to the diminishing effects of the changes to consumption tax policy towards H2 2019. Underlying inflation is expected to be broadly contained over the near team in the absence of immediate domestic cost pressures.

Looking further ahead, Malaysia remains on track to achieve high-income economy status by 2024. Malaysia's GNI per capita stood at US $\$ 10,460$ in 2018, US $\$ 1,915$ below the threshold level of US $\$ 12,375$ that the World Bank currently sets to define high-income country status.

Risks to Malaysia's growth outlook continue to tilt towards the downside. A further escalation of trade tensions between the US and China, as well as sharper-than-expected slowdowns in major economies and the technology cycle could weigh on Malaysia's growth in the near term. A continued cycle of slowing global growth, weak business sentiment, and subdued investment is another key risk factor for Malaysia's open economy. Further, the country's comparatively high levels of public debt will continue to exert constraints on fiscal space available in the event of macroeconomic shocks.

In the short term, the focus of government policies should be on rebuilding fiscal buffers, supporting private investment, and ensuring adequate social protection for low-income households. In an environment of growing uncertainty, with heightened downside risks, there is a clear need to increase policy space and maneuverability. More could be done to diversify sources of revenue, including through a realignment of tax incentives, an expansion of personal incomes taxes, and a broadening of the sales and services tax.

A widening of the government's revenue base should also be accompanied by efforts to expand and improve the social protection system to achieve greater overall progressivity. The government's planned move to a more targeted fuel subsidy framework could lead to potential savings for reinvestment in core social welfare programs. In addition, evidence from across the world has shown that progressive taxes and social transfers can be very effective at reducing income inequality. Compared to other countries in the region, the depth of Malaysia's social safety net system remains underdeveloped.

Further, as Malaysia continues on its path towards becoming a high-income and developed economy, it will need to implement reforms to boost human capital and to accelerate productivity growth. To ensure greater shared prosperity and inclusive growth, it will be necessary to increase labor productivity, which in turn depends on improved human capital development. While Malaysia performs well in this regard compared to other middle-income countries, its performance falls well short of that of aspirational comparators. To improve human capital outcomes, priority should be given to measures to enhance learning outcomes; to reduce child stunting and malnutrition; and to strengthen social protection systems to enable households to invest in and to protect human capital. To boost income per capita over the long term, Malaysia should also intensify its efforts to close the gaps between economic opportunities for men and women.

To accelerate productivity growth, it is also necessary to increase efforts to boost investor confidence; to increase competition; and to address market distortions. This is particularly important in areas where government linked companies continue to play a disproportionate role, stifling competition and resulting in many potentially productive private sector firms operating below their optimal levels. 


\section{Re-energizing the public service}

There is a well-established connection between the quality of state institutions and economic growth. With increased affluence, societal expectations regarding the range and quality of services delivered by the state also tend to grow. Therefore, enhancing the effectiveness of state institutions is an integral part of a successful transition to a higher level of economic and social development. To achieve this, it is necessary to improve the capacity of government agencies and institutions both to set objectives and priorities and to attain them. The 11th Malaysia Plan is intended to facilitate the achievement of the aspirations outlined in Vision 2020, particularly the one of transitioning to an industrialized and developed country. In the Mid-term Review (MTR) of the Plan, the government identified a number of constraints to improving public services. To address these constraints, the MTR outlined reforms that would help rebuild the public service by strengthening its human resources and institutions, to enable it to implement the measures necessary to facilitate the achievement of the national vision, in accordance with the principles of good governance.

While Malaysia's public service performs relatively well or is at par on a number of governance indicators compared to other countries in the region, it lags behind high-income aspirational comparators. Malaysia is one of the top performers in the region in terms of the Doing Business rankings, but it's performance on the Government Efficiency indicators has been largely stagnant. It lags behind the OECD average, a gap that is large and widening, and behind other high-income countries. It also lags behind both high-income and other upper-middle income countries in terms of openness and transparency, not just in public service employment, but in overall governance. Malaysia fares poorly in terms of citizen perceptions related to equal treatment in public sector employment and ranks below regional and OECD comparators in terms of the impartiality of its public administration. However, it has done well on measures related to gender equality, with women constituting nearly 50 percent of employees in the public service.

Like other East Asian countries with a growing middle class, Malaysia faces rising expectations and increased demands from citizens for betterquality public service delivery and a more responsive public service. The instrumental role of Malaysia's public service in facilitating the country's socioeconomic development since independence is widely acknowledged. Thus, people's expectations regarding the public service and delivery of public services remain high, with the current Prime Minister often articulating his desire to restore the public service to its "glory days" in his speeches. Various efforts have been made to improve the quality of public service delivery, monitor its performance, and implement corrective measures. However, over recent years and despite these efforts, there is a perception that the quality of the public service has remained stagnant, with a failure to keep pace with the country's transformation.

Looking to the future, how can Malaysia re-energize the public service to achieve higher levels of shared prosperity? This report takes a closer look at the most important elements of public sector governance, these being: (i) the management of the public service itself; (ii) the government's role in encouraging an open and transparent environment in the public sector through the establishment of an appropriate institutional and legal framework; and (iii) the impact of new and emerging trends, including technological innovations and digitalization on employment in the public service.

\section{With increased affluence, societal expectations regarding the range and quality of services delivered by the state tend to grow}

There is ample evidence to support the proposition that bureaucracies characterized by meritocratic recruitment and predictable, rewarding career paths are associated with higher economic growth rates. However, Malaysia's public service continues to be characterized by a rigid, over-centralized HRM system, with a lengthy recruitment process and other suboptimal practices. The over-centralization of the system limits the strategic role that central agencies should play to detect, strategize and respond to emerging issues and challenges that may affect the capabilities of the public service. Recruitment is based on "schemes of service" that are very well established, but that are predominantly career-based rather than position-based. By contrast, advanced countries increasingly utilize competency frameworks to recruit candidates with the appropriate level of skills, 


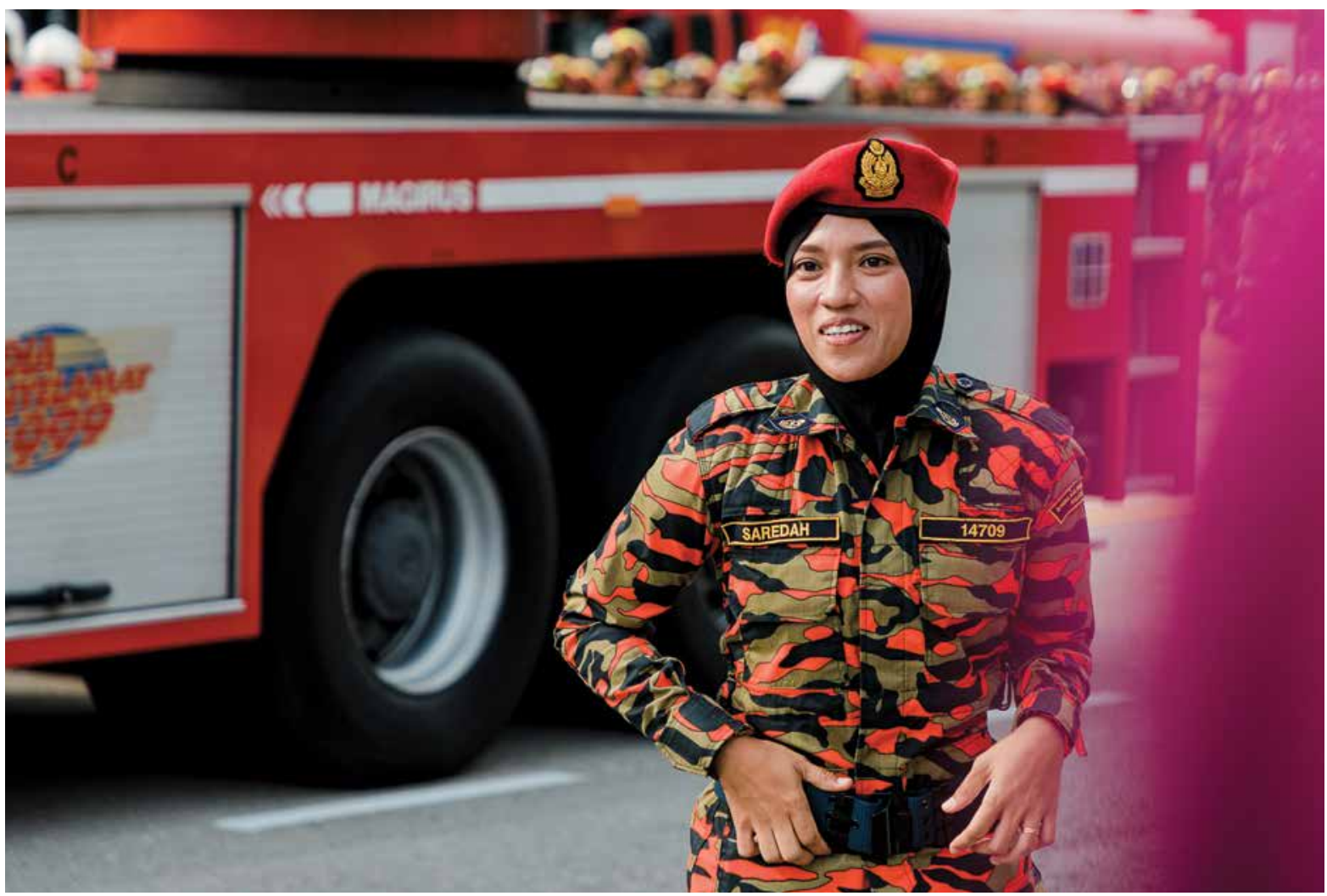

knowledge and capabilities into the public service and to ensure adherence to high moral and ethical standards for their appointment and promotion.

Malaysia needs to intensify its efforts to ensure equal treatment in the area of public sector employment and to improve public perceptions regarding the impartiality of public administration. Fair and neutral employment practices result in a more diverse, resilient and innovative workforce that is more responsive to market demands and the needs of the country. In its election manifesto, the government committed to measures to ensure fair and neutral employment, including through the establishment of the Equal Opportunity Commission to address discriminatory work practices in both the public and private sector.

Malaysia should facilitate the emergence of an open environment in the public service. To achieve this, it is necessary to build an institutional and legal framework that encourages pro-active sharing of information and data in a user-friendly and impactful manner. In Malaysia, there are still significant constraints on access to data, creating challenges for the potential users of such data and hampering effective coordination. The achievement of Malaysia's policy goals of a more transparent and citizen-centric government requires a range of agencies and departments to coordinate their activities more effectively. When government agencies and departments work in silos, they are unable to engage in the kind of collaboration that is critical to deliver on the government's commitments. To facilitate increased transparency and improved coordination, Malaysia will need to not just invest in improving its behavioral, technical or financial resources, but also to strengthen the institutional and legal framework to support greater openness in the public service, particularly with respect to access and sharing of data.

Megatrends related to digitalization and automation pose challenges for the management of the public service, with significant changes to the nature of jobs. Unlike the routine manual skills that are currently required of a large proportion of public servants, the public sector workforce of the future will require advanced cognitive, socio-behavioral and interpersonal skills. It will also require adaptability to perform non-routine cognitive and analytical tasks in an ever-evolving context. A large share of jobs in Malaysia, including in the public sector, are susceptible to automation. From the perspective of managing the future public sector workforce, the main challenge relates to maximizing the potential gains from technological change while at the same time mitigating the negative impact of these changes. 


\section{Recent economic developments and outlook}

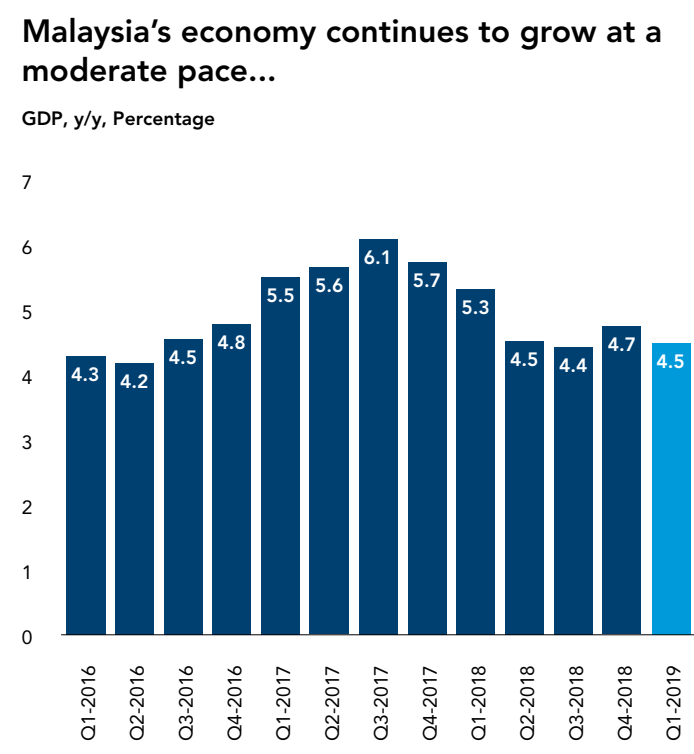

Export growth has slowed amid softening global demand...

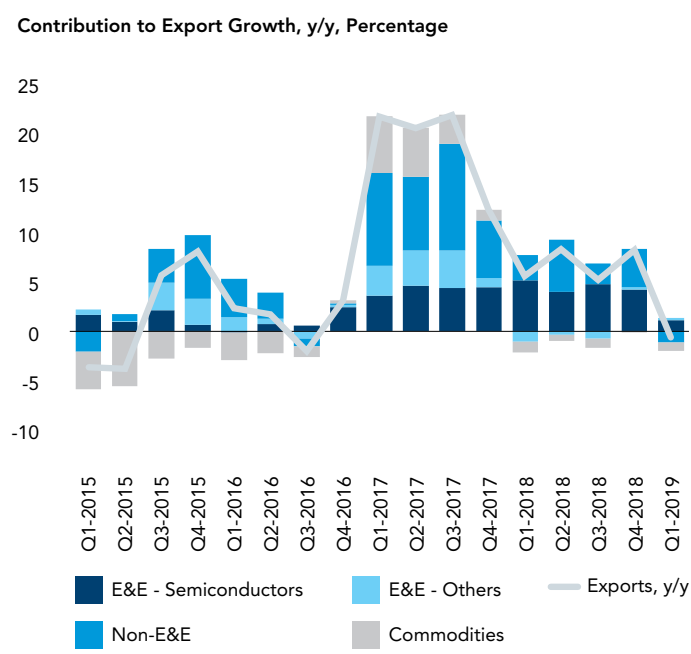

Malaysia's economy is forecast to grow at 4.6 percent in 2019 ...

GDP, y/y, Percentage

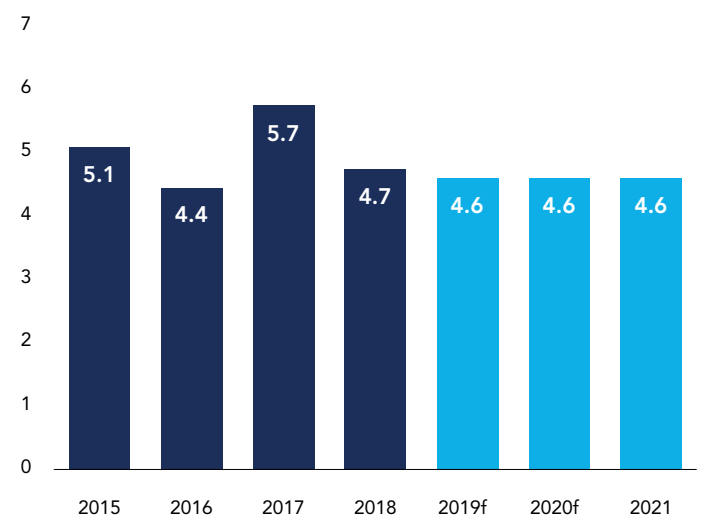

...but has been weighed down by weakerthan-expected investment

Contribution to GDP, $y / y$, Percentage

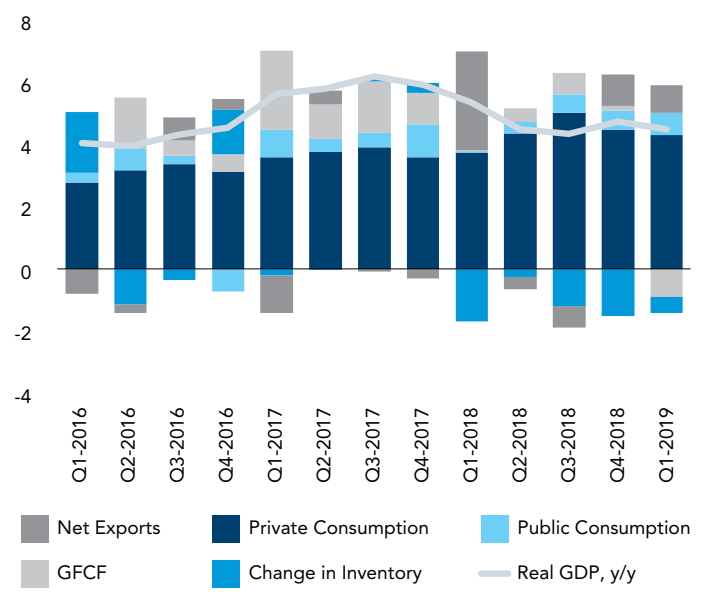

....and domestic financial markets have been affected by heightened risk aversion

Non-resident Portfolio Flows, RM Billion

15

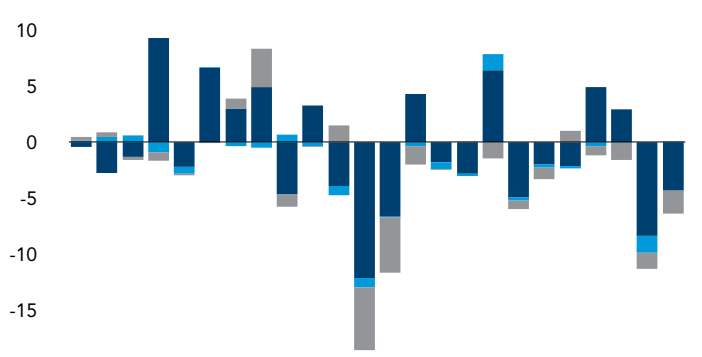

$-20$

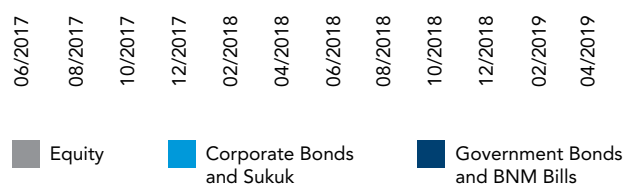

...while sentiment-based forecasts highlight downside risks to the growth outlook

GDP, 2019f, y/y, Percentage

6.0

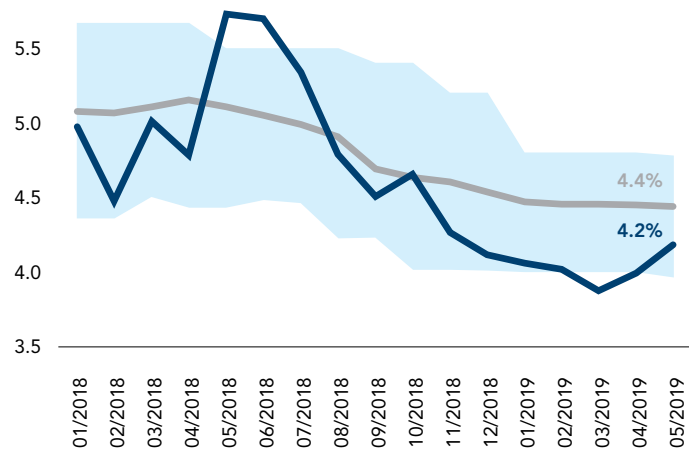

$\begin{array}{ll}\text { Consensus } & \text { Mean Consensus } \\ \text { Forecast Range } & \text { Forecast }\end{array}$ Sentiment 


\section{Re-energizing the public service}

Malaysia scores comparatively well in terms of overall government effectiveness, but has been on a declining trend...

Government Effectiveness Ranking, 2018

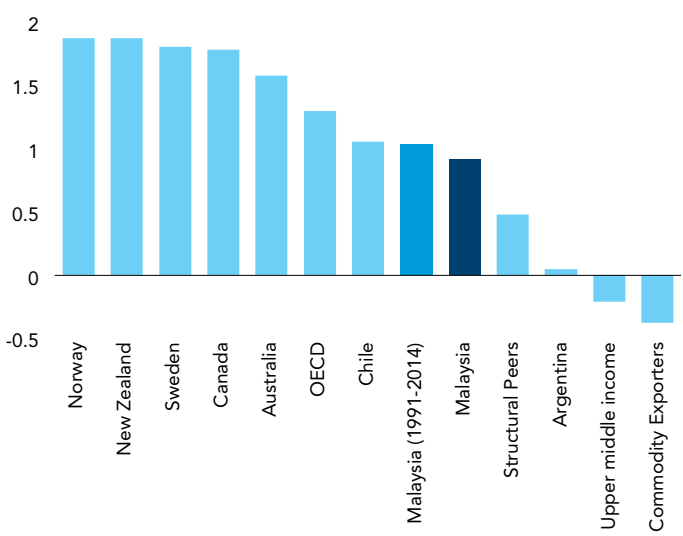

Malaysia's government wage bill has been tracking below the average of comparators...

Central Government Wage Bill as a Percentage of GDP Plotted Against Log of GDP per Capita, Malaysia: 2000-18 and Comparator Countries for Most Recent Year Available
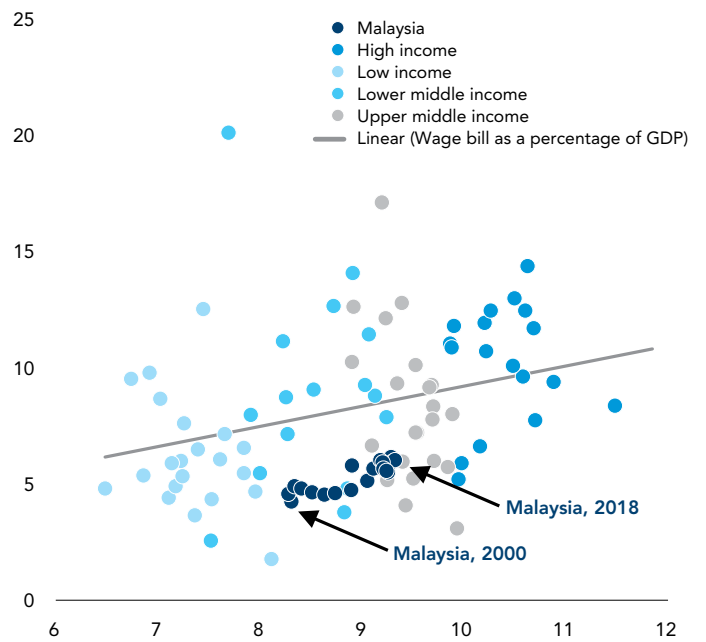

Re-energizing the public service will require competency-based and transparent recruitment...

Citizen Perceptions on Equal Treatment with Regard to Access to Public Employment, 2016

5

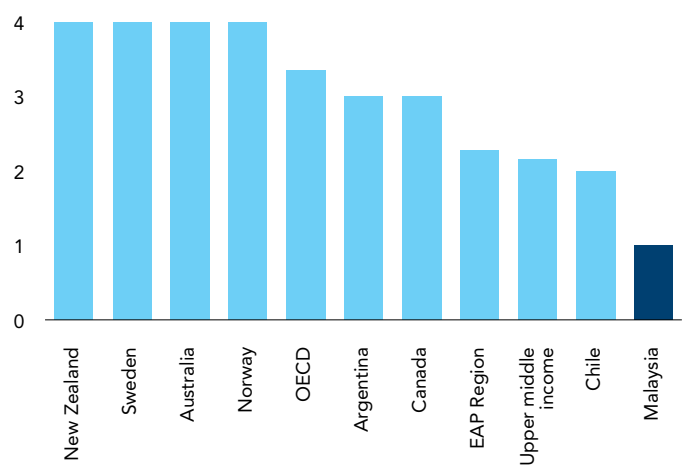

...and compares poorly in measures of open government, especially compared to highincome economies

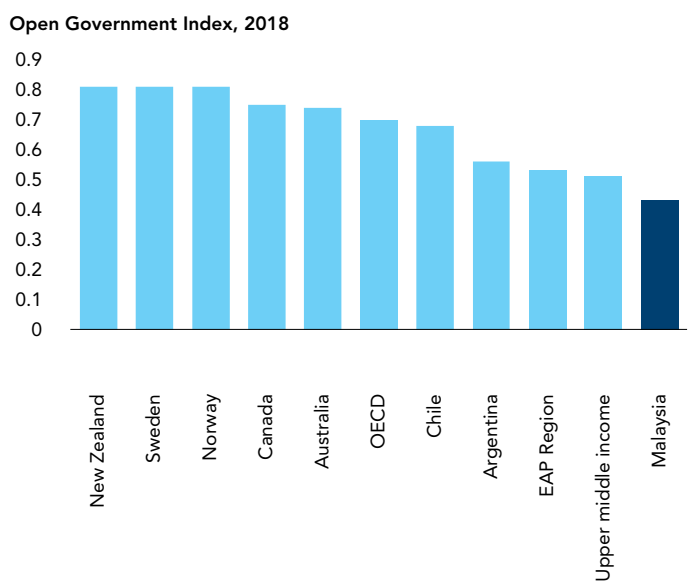

...but has risen as a share of public expenditure over recent years

Central Government Wage Bill as a Percentage of Public Expenditure Plotted Against Log of GDP per Capita, Malaysia: 2000-18 and Comparator Countries for Most Recent Year Available

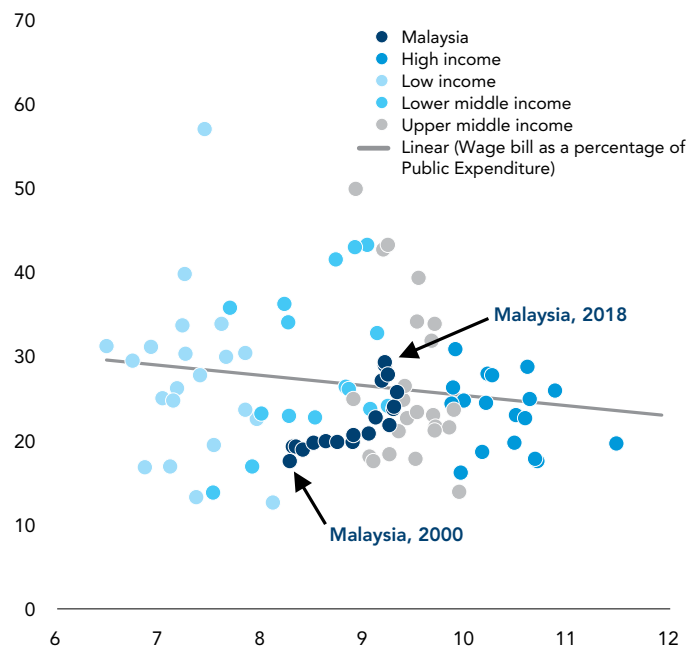

....and the adoption of digital technologies in the management of the public service

Percentage of Jobs that are Susceptible to Automation

100

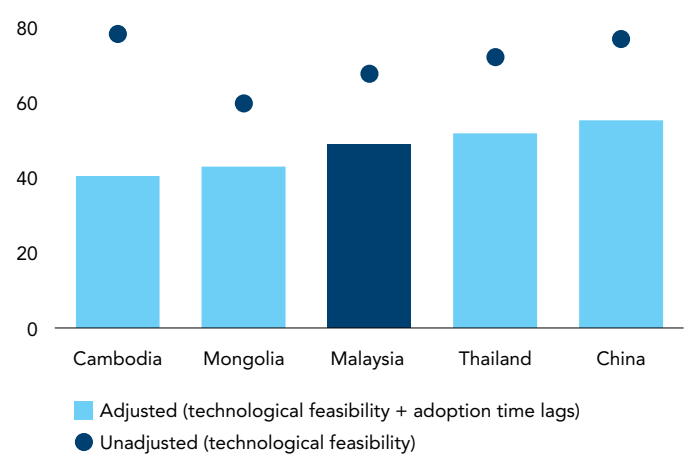




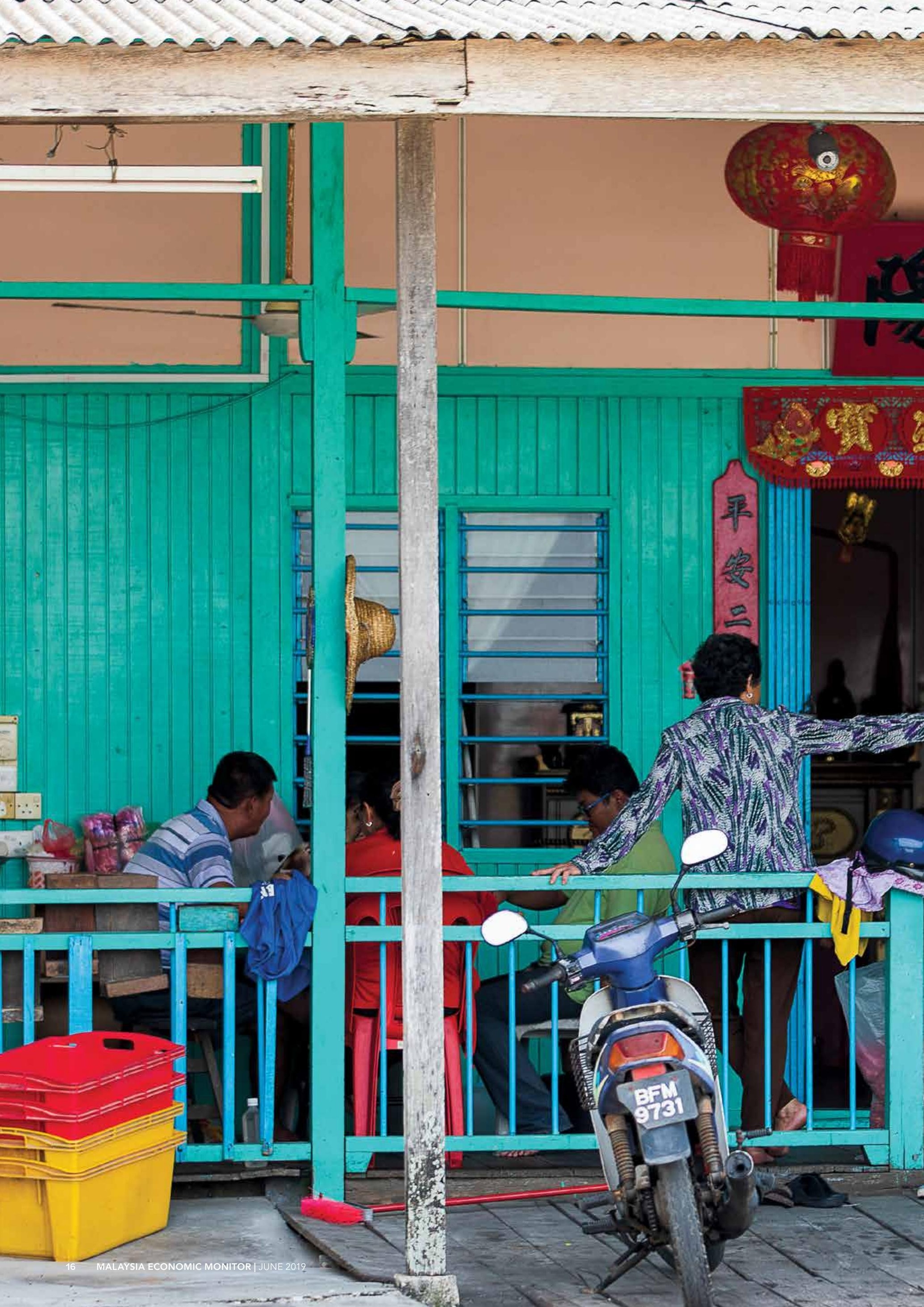




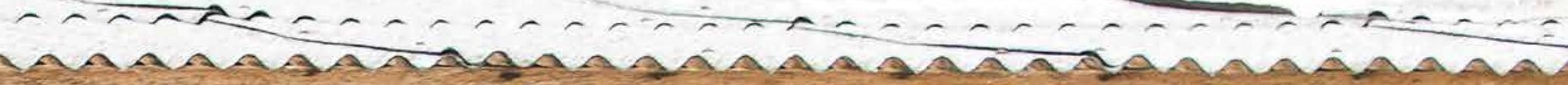

PART ONE

omic

Recent Economic

Developments

\section{and Outlook \\ gat}

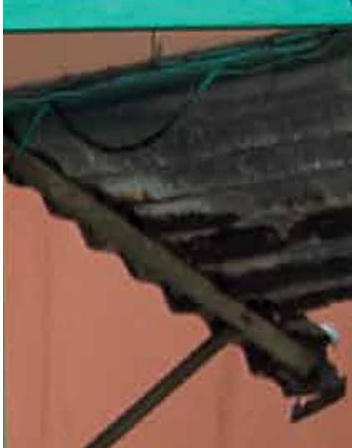

2
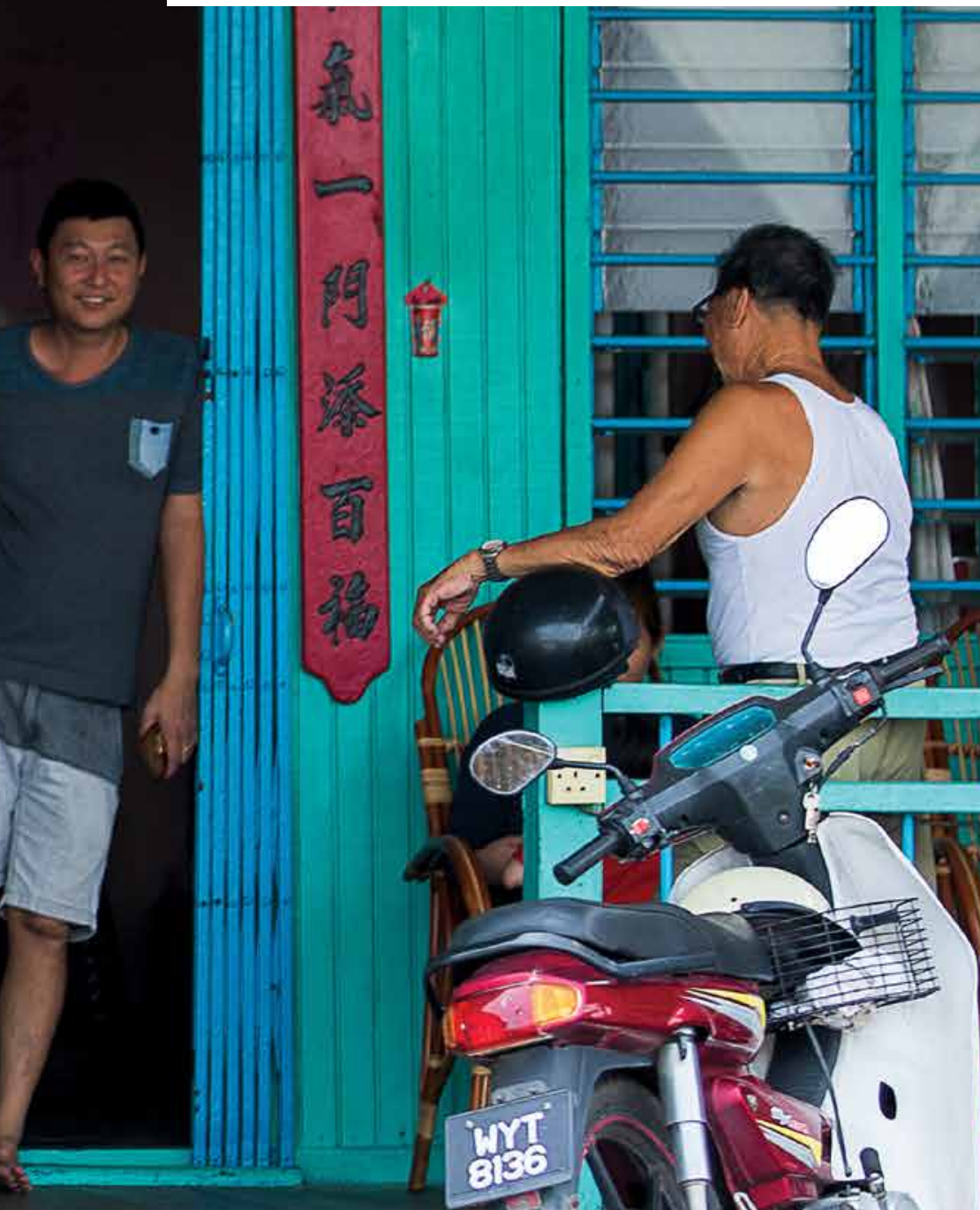

C

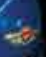

tate

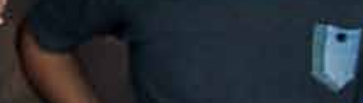

l

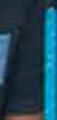
$-\quad-17-1$

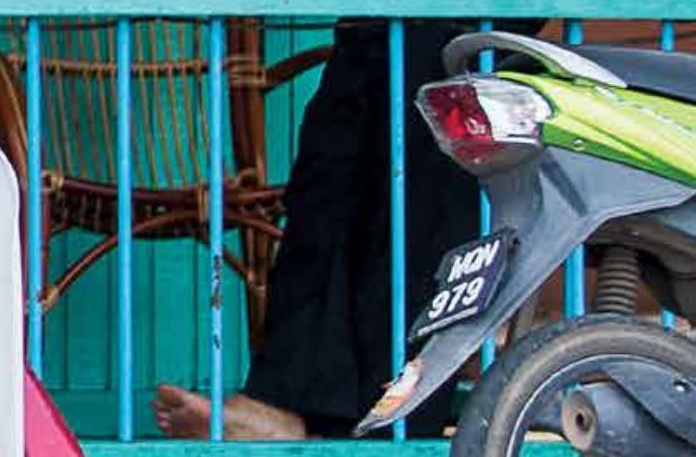

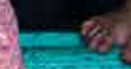

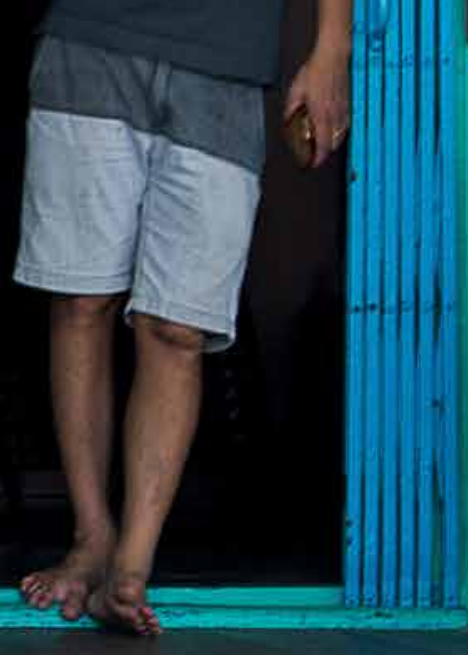

res. 


\section{Recent economic developments}

\section{Regional growth has moderated amid increased headwinds}

Global economic activity has continued to soften, with decelerating international trade and investment activity. The global growth rate is estimated to have eased to 2.6 percent $^{1}$ in Q1 2019 (Q4 2018: 2.7 percent) (see Figure 1). Activity in major advanced economies, especially in the Euro Area, and in several major emerging market and developing economies (EMDEs) has been weaker than previously anticipated. Global industrial production and trade expansion have lost considerable momentum since mid-2018, with weakening global investment activity and persistent policy uncertainty. In response to these developments, major central banks have adopted more accommodative monetary policy stances for the near term, contributing to the relatively stable global financing conditions since early 2019. Recent high-frequency indicators suggest that the weakness

\section{FIGURE 1}

Global growth has continued to moderate amid softening trade and investment activity

\section{GDP, $y / y$, Percentage}

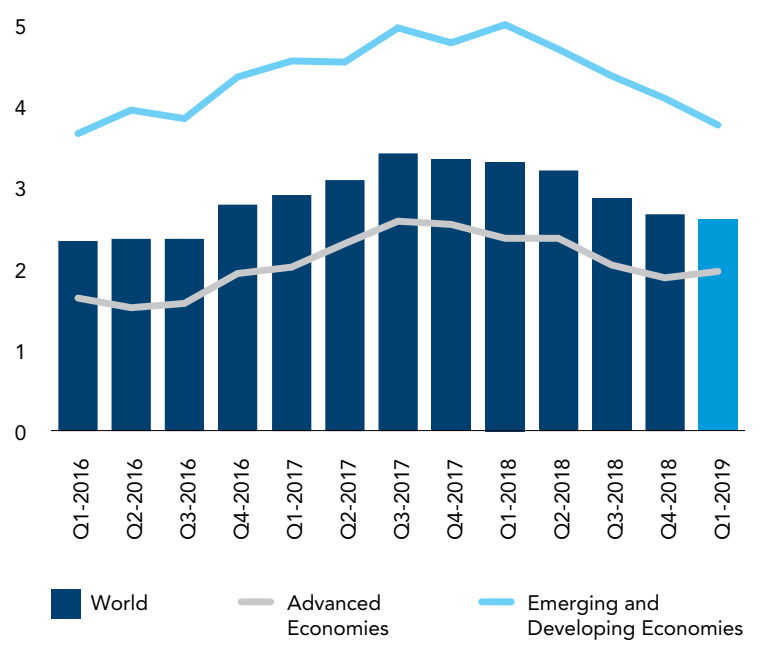

in global growth may be receding, but momentum remains weak.

Growth in the developing East Asia and Pacific (EAP) region has eased in the context of less favorable external conditions (see Figure 2). The regional economy grew at a marginally slower pace of 6.1 percent in Q4 2018 and Q1 2019 on account of weaker trade and manufacturing activity, as well as the ongoing moderation of China's economy. Growth in the rest of the region is also slowing, but less sharply, albeit with notable heterogeneity. Regional trade has softened notably amid weakening global investment and elevated trade policy uncertainty related to the ongoing US-China trade tensions. The recent moderation notwithstanding, the EAP region remains the main driver of global economic activity, contributing to about one-third of global growth.

\section{FIGURE 2}

Growth among regional economies has also eased slightly in a context of a less favorable global environment

GDP, $y / y$, Percentage

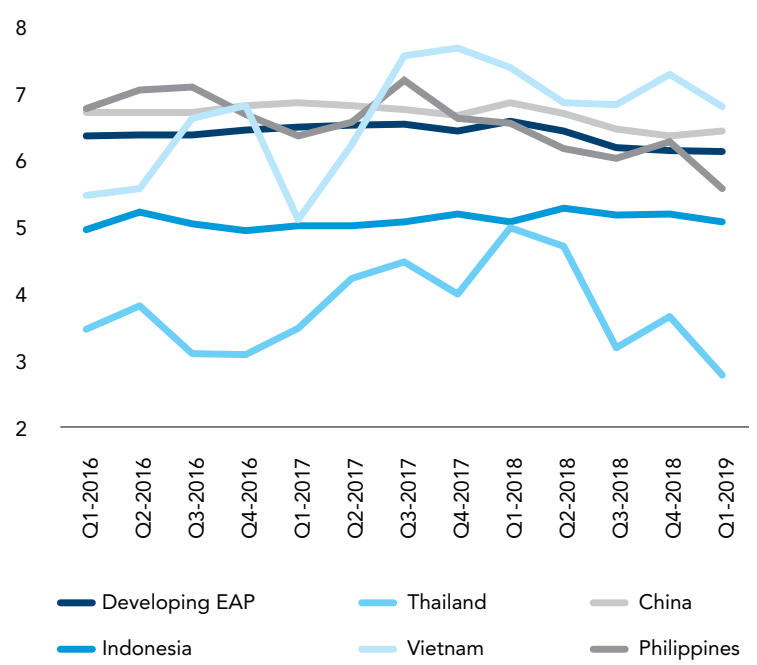

Source: World Bank Global Economic Prospects 


\section{Malaysia's economy has continued to grow at a more modest pace}

In Malaysia, quarterly GDP grew at a moderate rate of 4.5 percent in Q1 2019 (Q4 2018: 4.7 percent) (see Figure 3). Malaysia's economic expansion in Q1 was largely supported by sustained consumption expenditure in both the private and public sectors, with total consumption expenditure expanding at 7.4 percent during the quarter (Q4 2018: 7.4 percent) and contributing to 5.0 percentage points of output growth (see Figure 4). Net trade added a further 0.9 percentage points to growth despite weakening export expansion, with the subdued export growth being more than offset by the decline in import demand over the period. Overall economic activity, however, was constrained by weaker-than-expected investment growth and continued inventory drawdowns, which subtracted 0.9 and 0.5 percentage points respectively from growth.

Household consumption, the main driver of domestic demand growth, has remained solid. Private consumption continued to expand strongly at 7.6 percent in Q1 2019 (Q4 2018: 8.4 percent), accounting for 4.3 percentage points of the aggregate output growth during the period. Over the past two quarters, household spending has been underpinned

\section{FIGURE 3}

Malaysia's economic growth continued to moderate in Q1 2019...

GDP, y/y, Percentage

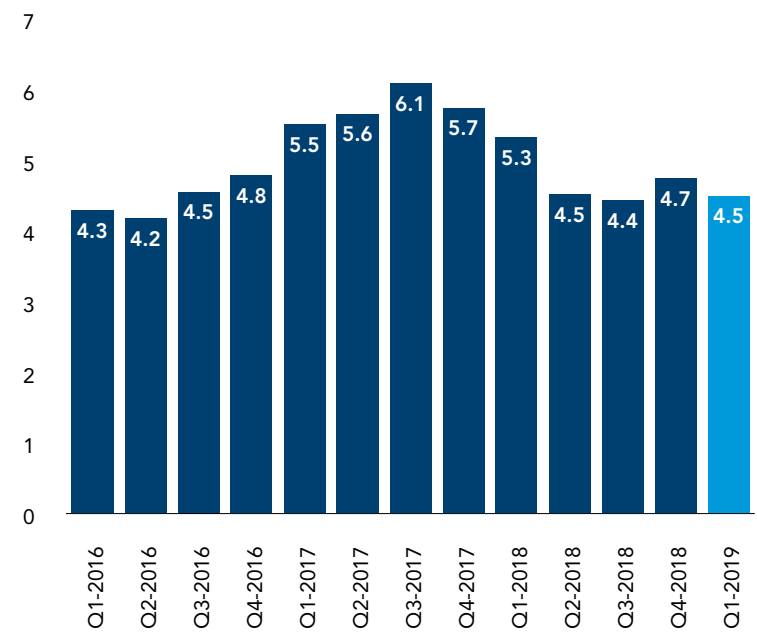

Source: DOSM by continued growth in real incomes amid stable employment and wage growth, and by a moderation in consumer price inflation. Meanwhile, public consumption accelerated to 6.3 percent (Q4 2018: 4.0 percent), mainly due to increased expenditure on supplies and services.

Gross fixed capital formation (GFCF) registered its first quarterly decline since Q2 2015, reflecting subdued business investment growth and a further contraction in public investment. Private investment growth slowed materially to 0.4 percent in Q1 2019 (Q4 2019: 5.8 percent), with increased uncertainty appearing to have weighed on business confidence. The recent weakness in investment spending was further dampened by the continued decline in public investment following the near completion of several multi-year infrastructure projects, and by the ongoing reviews of major public infrastructure projects. In terms of investment type, the quarterly slowdown in capital spending was evident across structure (-1.3 percent; Q4 2018: 1.3 percent), machinery and equipment (-7.4 percent; $4 \mathrm{Q}$ 2018: -1.3 percent) as well as other asset clusters (-2.2 percent; 4Q 2018: 4.5 percent).

FIGURE 4

...weighed down by weaker-than-expected investment growth and continued inventory drawdowns

Contribution to GDP, y/y, Percentage

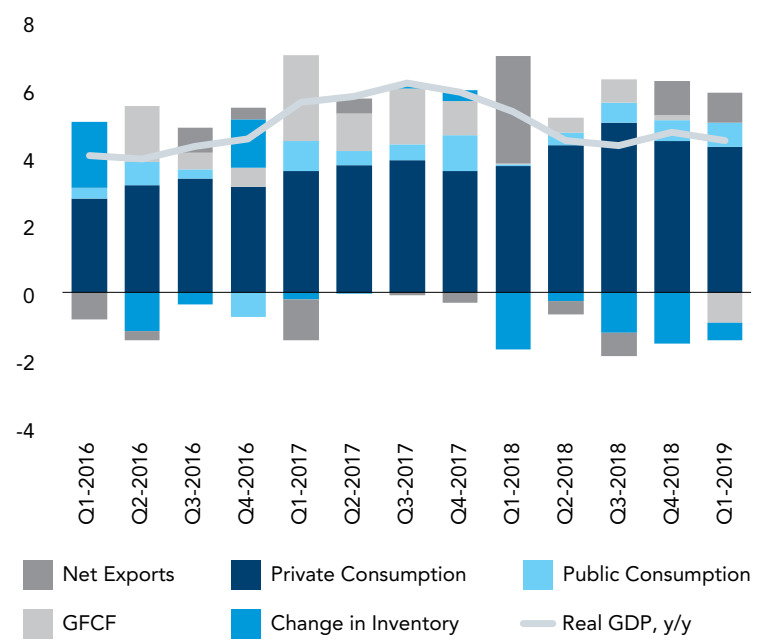

Source: World Bank staff calculations based on DOSM data 
On the supply side, growth moderated across most economic sectors except for agriculture. The growth rate for the services sector moderated to 6.4 percent during the quarter (4Q 2018: 6.9 percent), largely due to the normalization of the wholesale and retail subsector following the largely tax policy-induced expansion in 2018. Manufacturing activity has also moderated in recent quarters, with growth standing at 4.2 percent in Q1 2019 (4Q 2018: 4.7 percent). This mainly reflects the softening global demand for electrical and electronics (E\&E) exports, including semiconductors. In the construction sector, growth further decelerated to 0.3 percent during the quarter (40 2018: 2.6 percent), constrained by the slowdown in new large infrastructure projects and the persistent excess of newly built properties. The contraction of the mining sector deepened, with the rate standing at -2.1 percent in Q1 2019 (4Q 2018: -0.7 percent), mainly due to several unplanned closures of oil and gas facilities across Malaysia. Meanwhile, the agriculture sector rebounded, with the growth rate standing at 5.6 percent during the quarter (4Q 2018: -0.1 percent), due in part to the recovery of oil palm production, which was affected by adverse weather conditions in previous quarters.

Recent indicators suggest that Malaysia's economic expansion will continue at a relatively modest pace in the near term. The Industrial Production Index (IPI), which tends to be volatile, increased at a faster pace in April at 4.0 percent (March 2019: 3.1 percent). This largely reflects a slight pickup of output growth in the manufacturing sector and a recent turnaround in mining activity. Meanwhile, growth of wholesale and retail sales moderated further to 5.3 percent during the month (March 2019: 5.4 percent), due largely to slower growth in retail trade. The Malaysia composite leading index, a measure of the overall economic performance in the months ahead, indicates that the economy will continue to grow at a relatively modest momentum in the Q3 2019. The Malaysian Institute of Economic Research's Business Conditions and Consumer Sentiment Index in Q1 2019 similarly point towards a more moderate pace of economic expansion in the near term.

\section{TABLE 1}

\section{GDP growth decomposition}

GDP, $y / y$, Percentage

\begin{tabular}{cccccccccccccc} 
& 2016 & $\mathrm{Q} 1$ & $\mathrm{Q} 2$ & $\mathrm{Q} 3$ & $\mathrm{Q} 4$ & 2017 & $\mathrm{Q} 1$ & $\mathrm{Q} 2$ & $\mathrm{Q} 3$ & $\mathrm{Q} 4$ & 2018 & $\mathrm{Q} 1$ \\
& & 2017 & 2017 & 2017 & 2017 & & 2018 & 2018 & 2018 & 2018 & 2019 & 2019 \\
\hline GDP & 4.4 & 5.5 & 5.6 & 6.1 & 5.7 & 5.7 & 5.3 & 4.5 & 4.4 & 4.7 & 4.7 & 4.5
\end{tabular}

\begin{tabular}{llllllllllllll} 
Consumption & & & & & & & & & & & & & \\
$\quad$ Private Sector & 5.9 & 6.5 & 6.9 & 7.1 & 6.9 & 6.9 & 6.6 & 7.9 & 8.9 & 8.4 & 8.0 & 7.6 \\
\hline \multicolumn{1}{c}{ Public Sector } & 1.1 & 7.6 & 3.4 & 4.0 & 6.9 & 5.5 & 0.4 & 3.1 & 5.2 & 4.0 & 3.3 & 6.3 \\
\hline Gross Fixed Capital Formation & 2.6 & 9.5 & 3.9 & 6.6 & 4.4 & 6.1 & 0.4 & 1.6 & 2.8 & 0.6 & 1.4 & -3.5 \\
\hline Exports of Goods \& Services & 1.3 & 9.9 & 9.3 & 10.6 & 5.1 & 8.7 & 2.4 & 2.6 & 0.7 & 3.1 & 2.2 & 0.1 \\
\hline Imports of Goods \& Services & 1.4 & 13.0 & 9.6 & 12.2 & 6.2 & 10.2 & -2.3 & 3.6 & 2.0 & 1.8 & 1.3 & -1.4
\end{tabular}

\begin{tabular}{lcccccccccccc} 
Sectoral & & & & & & & & & & & & \\
Agriculture & -3.7 & 6.5 & 4.5 & 3.1 & 9.3 & 5.8 & 3.1 & -1.7 & -0.8 & -0.1 & 0.1 & 5.6 \\
\hline Mining & 2.2 & 1.0 & -0.5 & 2.3 & -0.9 & 0.4 & -0.6 & -3.4 & -5.7 & -0.7 & -2.6 & -2.1 \\
\hline Manufacturing & 4.4 & 5.9 & 6.0 & 7.0 & 5.3 & 6.0 & 5.3 & 4.9 & 5.0 & 4.7 & 5.0 & 4.2 \\
Construction & 7.5 & 6.8 & 8.3 & 6.2 & 5.9 & 6.7 & 4.9 & 4.8 & 4.7 & 2.6 & 4.2 & 0.3 \\
Services & 5.7 & 5.7 & 6.3 & 6.5 & 6.2 & 6.2 & 6.5 & 6.5 & 7.3 & 6.9 & 6.8 & 6.4
\end{tabular}

Source: World Bank staff calculations based on DOSM data 


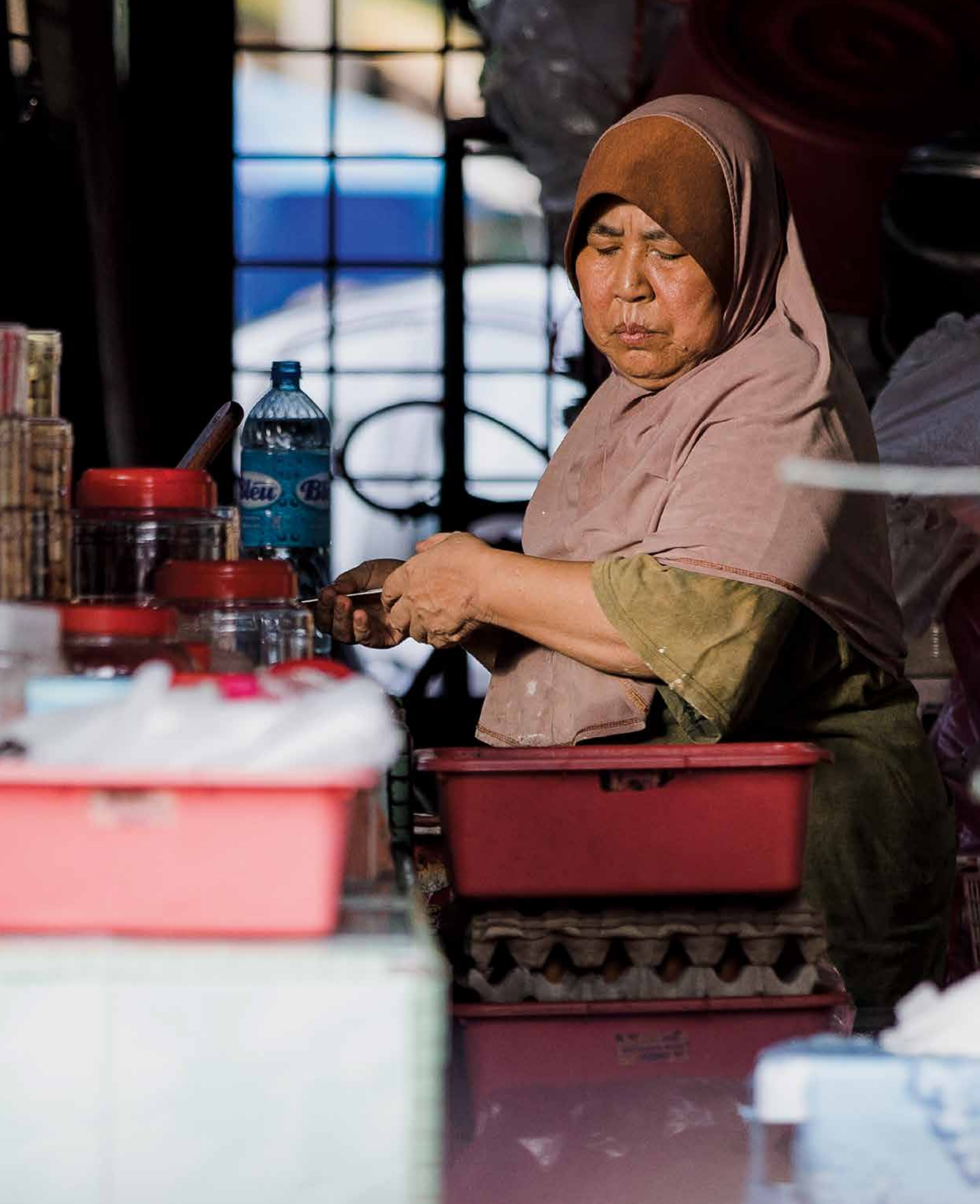




\section{Export growth has eased in recent months}

\begin{abstract}
Export growth has slowed amid softening external demand for manufactured exports. With intensifying US-China trade tensions, Malaysia has been able to gain market share for a number of tariff-affected products in both the US and China (see Box 1). However, in aggregate terms, weakening global demand is dominating Malaysia's overall export performance. In Q1 2019, gross exports declined for the first time since Q3 2016, with a growth rate of -0.7 percent (Q4 2018: 8.1 percent). The moderation was broadbased, with declines across most major manufactured and commodity exports (see Figure 5). While E\&E exports have continued to drive much of the recent growth momentum, the pace of expansion has eased considerably, in line with the slowdown in the global technology cycle. Non-E\&E manufactured exports also declined appreciably over the quarter, largely due to weakening foreign demand for chemical and metal products.
\end{abstract}

Gross imports contracted due to lower demand for intermediate and capital imports. Malaysia's gross imports fell by 2.5 percent in Q1 2019 (Q4 2018: 5.7 percent). Much of this decline was attributable to the subdued growth of intermediate goods (0.0 percent;

\section{FIGURE 5}

Export growth has slowed amid softening external demand for manufactured exports

Contribution to Export Growth, y/y, Percentage

25

20

15

10

5

0

$-5$

$-10$

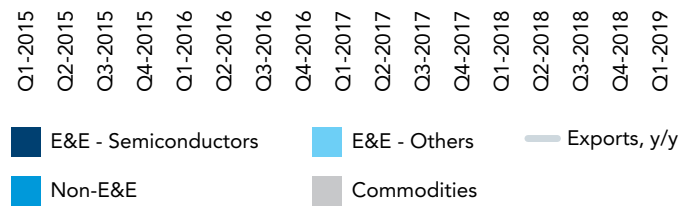

Q4 2018: 1.1 percent) following the softening demand for manufactured exports. Imports of consumption goods also expanded at a slower pace of 1.1 percent (Q4 2018: 4.7 percent), with much of this growth driven by imports of durable items. Meanwhile, capital imports contracted further by -9.8 percent (Q4 2018: -9.4 percent) during the quarter, consistent with the recent slowdown in investment activity.

The current account surplus widened appreciably to 4.5 percent of GDP in Q1 2019, (Q4 2018: 2.9 percent), primarily reflecting a larger trade balance and a narrower deficit on primary income (see Figure 6). During the quarter, the goods surplus increased further to RM33.8 billion (Q4 2018: RM32.7 billion), equivalent to 9.4 percent of GDP, with a decline in merchandise export growth being more than offset by a decline in imports. There was a smaller deficit in the services account at -RM1.8 billion in Q1 2018 (Q4 2018: -3.8 billion), with the decline partly due to increased net tourism receipts and reduced payments for foreign transportation services. Largely due to lower net payments related to portfolio investment, the deficit on primary income also narrowed in Q1 2019 to -RM10.1 billion (Q4 2018: -12.9 billion). Meanwhile,

\section{FIGURE 6}

The current account surplus widened appreciably due to a larger trade balance and a narrower income deficit

Current Account Balance, Percentage of GDP

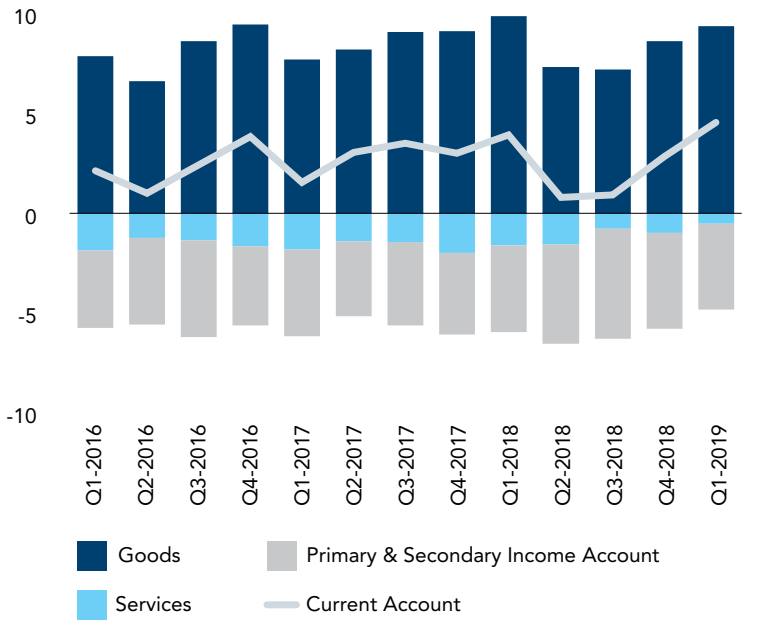

Source: World Bank staff calculations based on DOSM data 
the secondary income account deficit sustained at -RM5.5 billion (Q4 2018: -RM5.2 billion) with continued sizable outward remittances from foreign workers. In the financial account, foreign direct investment (FDI) inflows were higher in Q1 2019 at RM21.7 billion (Q4
2018: 12.9 billion), channeled mainly into the healthcare services and manufacturing sector. In 2018, approved FDI increased 48 percent to RM80.5 billion (2017: RM54.4 billion).

TABLE 2

Selected external sector indicators

\begin{tabular}{|c|c|c|c|c|c|c|c|c|c|}
\hline & $\begin{array}{c}\text { Q1 } \\
2017\end{array}$ & $\begin{array}{c}\text { Q2 } \\
2017\end{array}$ & $\begin{array}{c}\text { Q3 } \\
2017\end{array}$ & $\begin{array}{c}\text { Q4 } \\
2017\end{array}$ & $\begin{array}{c}\text { Q1 } \\
2018\end{array}$ & $\begin{array}{c}\mathrm{Q} 2 \\
2018\end{array}$ & $\begin{array}{c}\text { Q3 } \\
2018\end{array}$ & $\begin{array}{c}\text { Q4 } \\
2018\end{array}$ & $\begin{array}{c}\text { Q1 } \\
2019\end{array}$ \\
\hline Balance of Goods \& Services (\% of GDP) & 5.9 & 6.8 & 7.7 & 7.1 & 8.3 & 5.8 & 6.4 & 7.6 & 8.8 \\
\hline Current Account Balance (\% of GDP) & 1.5 & 3.0 & 3.5 & 3.0 & 3.9 & 0.8 & 0.9 & 2.9 & 4.5 \\
\hline Total Exports (\% of GDP) & 70.5 & 70.2 & 70.7 & 68.9 & 68.5 & 68.5 & 69.0 & 69.0 & 66.3 \\
\hline Total Imports (\% of GDP) & 64.6 & 63.4 & 63.0 & 61.8 & 60.2 & 62.8 & 62.6 & 61.4 & 57.4 \\
\hline Net Portfolio Investment (RM billion) & -32.4 & 17.5 & -9.9 & 9.4 & -1.5 & -37.9 & 0.8 & -5.8 & 2.1 \\
\hline Gross Official Reserves (RM billion) & 422.2 & 424.8 & 427.7 & 414.7 & 416.4 & 423.4 & 427.0 & 419.6 & 420.2 \\
\hline Gross Official Reserves (US\$ billion) & 95.4 & 98.9 & 101.2 & 102.4 & 107.8 & 104.7 & 103.0 & 101.4 & 103.0 \\
\hline
\end{tabular}

\section{Inflation turned temporarily negative due to several policy-related factors}

\begin{abstract}
Headline inflation turned negative in Q1 2019, reaching an average rate of -0.3 percent $(Q 4$ 2018: 0.3 percent), with the decline largely due to lower domestic fuel costs (see Figure 8). The lower fuel prices were due to the reintroduction of the managed float fuel pricing mechanism amid lower global oil prices during the quarter (see Figure 9). As such, the RON95 petrol prices were lower in January and February 2019 than in the same period last year, contributing to the negative $\mathrm{CPI}$ in these two months. The negative inflation also reflects the base effect of the removal of the goods and services tax (GST) from last year. The decline in prices was not broad-based, with only 20 percent of consumer items registering
\end{abstract}

price reductions. The $\mathrm{CPI}$ returned to positive territory in March and April 2019.

Underlying inflation has remained positive and stable. The core inflation rate, which excludes the impact of volatile items such as fresh food and priceadministered items, remained stable at 0.3 percent in Q1 2019 (Q4 2018: 0.4 percent). While overall inflation has remained stable and low, concerns regarding the cumulative increase in the cost of living pressures have continued to linger, particularly among lower-income households which tend to spend a greater proportion of their incomes on essential items such as food and housing. 


\section{Malaysia appears to be benefitting from trade diversion in some export products as a result of the US-China trade tensions}

With bilateral trade between the US and China declining since the implementation of tariffs, Malaysia's exports to the US and China of products targeted by tariffs have increased. This suggests that Malaysia is deriving some short-term benefits from the US-China tensions as a result of trade diversion. It also points to the underlying competitive strength of the Malaysian economy.

Malaysia's exports of tariff-affected products to the U.S. and China have increased in value by more than US\$1 billion since the tariffs were imposed. An analysis of trade data shows gains in the US market of US\$0.36 billion, equivalent to 1.7 percent of Malaysia's goods exports to the US for the same period, and gains in the Chinese market of US $\$ 0.91$ billion, equivalent to about 6 percent of Malaysia's goods exports to China. These statistics are derived from an examination of US and Chinese imports from Malaysia of products on the six US and Chinese lists of goods affected by tariffs, which the two countries have imposed on each other over this period. Specifically, the imports from Malaysia for such products in the period following the tariff implementation is compared to imports in the corresponding period a year ago. ${ }^{2}$

Most of the increase in Malaysia's tariff-affected exports to the U.S. and China has been driven by the increased exports of four products (see Figure 7). In particular, the increase in Malaysia's exports of electronic integrated circuits, including processors and controllers, and memories (on which tariffs were imposed in August 2018) appears to account for the majority of its increased exports to the US market. Malaysia's exports to the US of other products on US List 1 and US List 2 products have also increased, but to

\section{FIGURE 7}

Malaysia has seen modest gains in exports to both the US and China

Year-on-year change in US and Chinese imports from Malaysia of tariff-affected products after tariff implementation, US\$ billion

1.2

1.0

0.8

0.6

0.4

0.2

0.0

$-0.2$

China list 3 :

Liquefied

natural gas

China list 2: \begin{tabular}{c|c}
\hline U.S. list 2: Memories & $\begin{array}{c}\text { Copper alloy, } \\
\text { waste and } \\
\text { scrap }\end{array}$ \\
\hline U.S. list 2: &
\end{tabular}

Processors

and controllers

U.S. list 1 and list 2:

(other)

U.S. list 3

China list 1 and list 2 (other)

China list 3:

Change in U.S. imports from Malaysia

Change in China imports from Malaysia

Source: World Bank staff calculations based on US Census and China Customs statistics

Note: U.S. (China) list 1 refers to tariffs imposed in July 2018 and covering US $\$ 34$ billion in imports to the U.S. from China. US (China) list 2 refers to US\$34 billon in imports to the U.S. from China. US (China) list 2 refers to tariffs imposed in August 2018 and covering US\$16 billion in imports to the U.S. from China. US (China) list 3 refers to tariffs imposed in September 2018 and covering US $\$ 200$ billion in imports to the U.S. from China.

a much lesser extent. The exports of products on US List 3 have declined. By contrast, the gains in the Chinese market are primarily driven by exports of copper waste and scrap (China List 2) and of liquefied natural gas (China List 3). There has also been an increase in exports of products on China List 1 and other products (apart from copper waste and scrap) on China List 2. There has been a decline in exports of other products (apart from liquefied natural gas) on China List 3. 
FIGURE 8

Headline inflation turned negative in January and February...

Inflation, $\mathrm{y} / \mathrm{y}$, Percentage

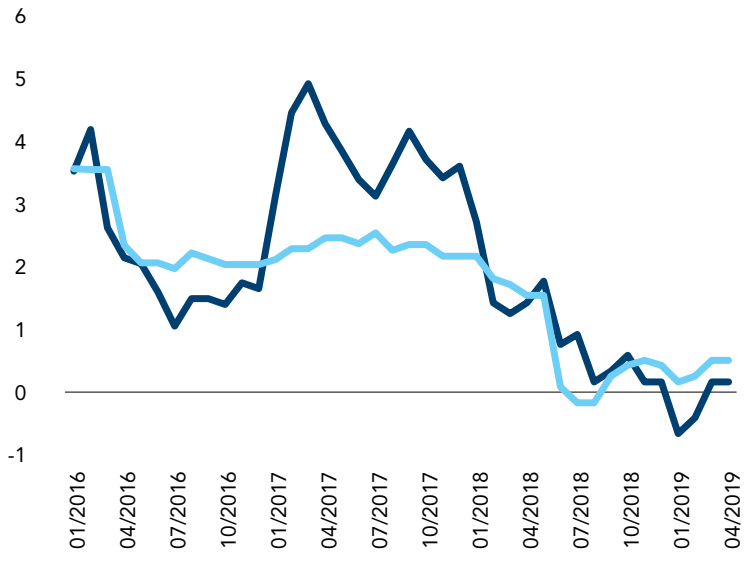

Source: DOSM

Conditions in the labor markets remained stable and supportive of economic growth. In Q1 2019, the labor force participation rate remained stable at 68.5 percent (Q4 2018: 68.5 percent), while the unemployment rate was unchanged at 3.3 percent (see Figure 10). However, the unemployment rate for those aged between 15 to 24 years continues to be high, at 10.4 percent in Q1 2019 (Q4 2018: 10.5 percent) (see Figure 11). By contrast, for every other age group, the

FIGURE 10

Labor market conditions have remained broadly stable...

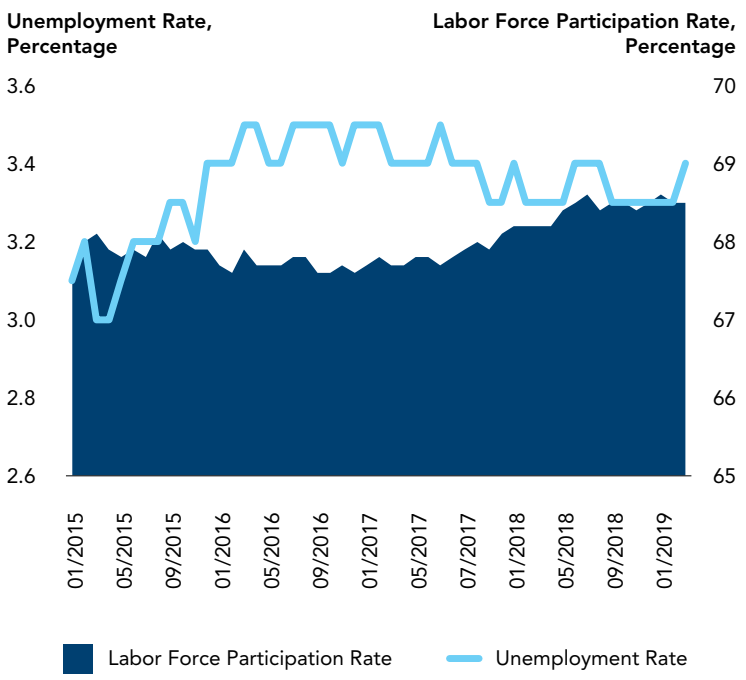

Source: DOSM

\section{FIGURE 9}

...due largely to lower transportation costs

Contribution to Inflation, $y / y$, Percentage

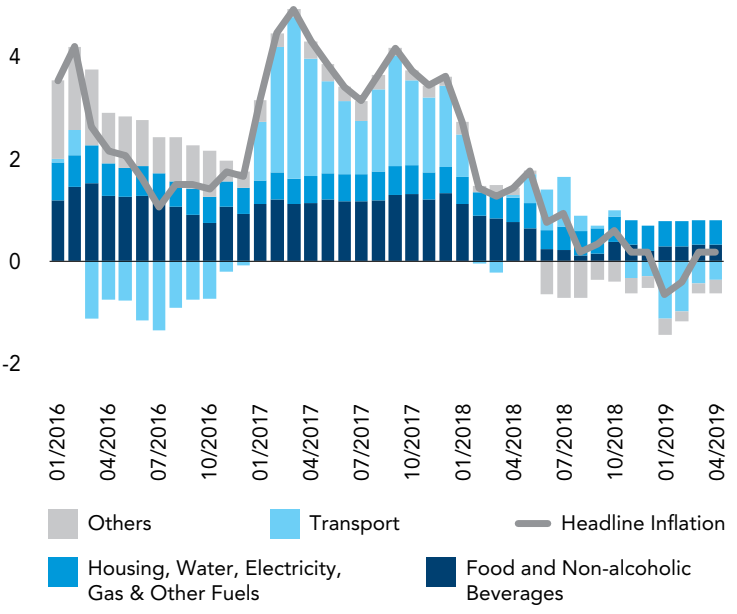

Source: World Bank staff calculations based on DOSM data

rate stood at 3 percent or lower. Meanwhile, the female labor force participation rate increased marginally, from 55.6 percent in Q4 2018 to 55.7 percent in Q1 2019. Over this quarter, wages in the manufacturing sector increased by 7.0 percent (Q4 2018: 9.8 percent), considerably higher than wage growth in the services sector, which increased by 3.8 percent (Q4 2018: 4.1 percent).

\section{FIGURE 11}

...however the unemployment rate among those aged 15-24 years remains high

Unemployment Rate, Percentage

14.0

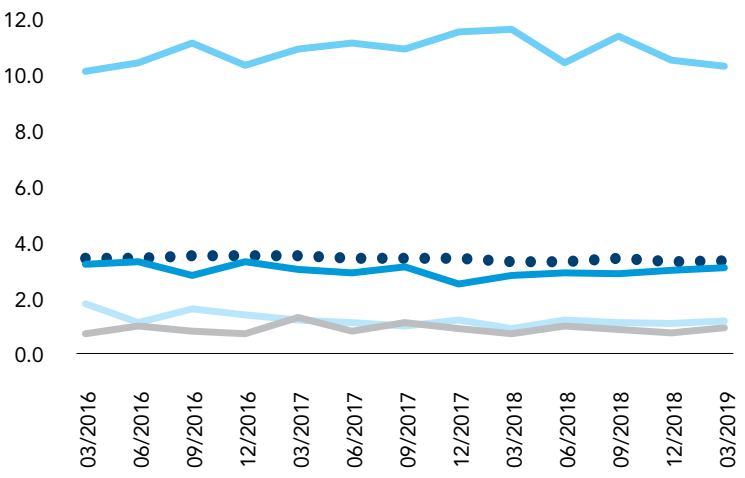

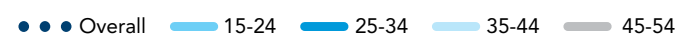

Source: DOSM 


\section{Conditions in the financial system have remained broadly stable}

\begin{abstract}
At the May 2019 monetary policy committee meeting, the Central Bank of Malaysia took the decision to lower the overnight policy rate (OPR) by 25 basis points to $\mathbf{3 . 0}$ percent. BNM continued to expect Malaysia's economy to expand at a rate within the range of 4.3 to 4.8 percent in 2019 , and reiterated the considerable downside risks to the global economic environment. Meanwhile, underlying inflation is expected to remain stable in the absence of strong demand pressures. While domestic monetary and financial conditions remain supportive of economic growth, there are some signs of tightening of financial conditions. Hence, the adjustment to the OPR is intended to preserve the current degree of monetary accommodativeness.
\end{abstract}

Financial soundness indicators continued to indicate that the banking system's capitalization remained strong. As of the end of 2018, financial institutions recorded sound levels of profitability, with the banking sector registering an average return on equity rate of 12.6 percent (June 2018: 13.3 percent). Sufficient liquidity in the banking system, largely

\section{FIGURE 12}

Net financing moderated on lower banking loans and issuances in the capital market

Contribution to Net Financing Growth, y/y, Percentage

10

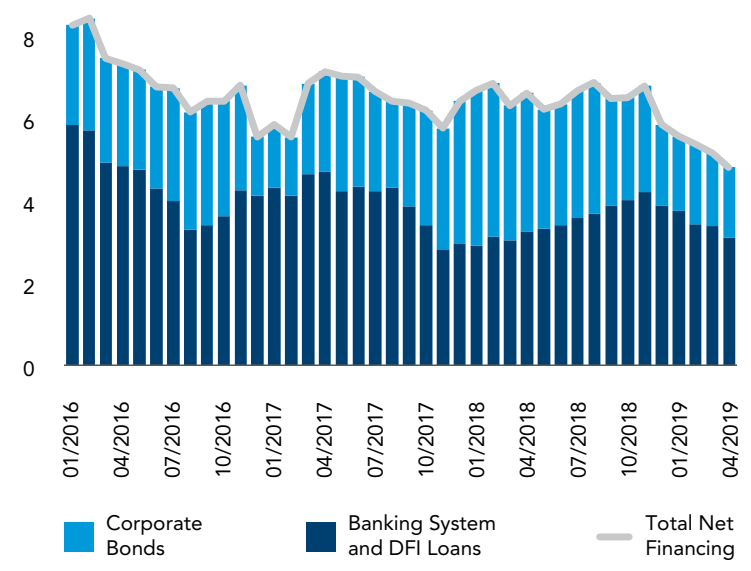

supported by stable funding sources such as deposits and long-term borrowings, remained supportive of financial intermediation, with banks' liquidity buffers able to withstand potential exigent needs. As of Q1 2019, financial institutions recorded an excess of capital buffers of RM154 billion, indicating that financial institutions are able to withstand severe economic and financial shocks. In addition, the impairment and delinquencies level remained low and stable, reflecting the banking system's sound asset quality.

Growth in net financing moderated slightly to 5.1 percent in Q1 2019 (Q4 2018: 5.8 percent) (see Figure 12). This moderation was driven by the lower growth of both outstanding loans and issuances of corporate bonds, which expanded by 4.5 percent and 7.1 percent respectively (Q4 2018: 5.1 percent and 8.0 percent). Issuances of corporate bonds were mainly channeled towards financing capital expenditure and operating expenses. In the banking system, the deceleration of growth in outstanding loans for businesses was due to lower loan growth in the real estate and construction sectors, following a slowdown

\section{FIGURE 13}

Household debt declined further to 83 percent of GDP

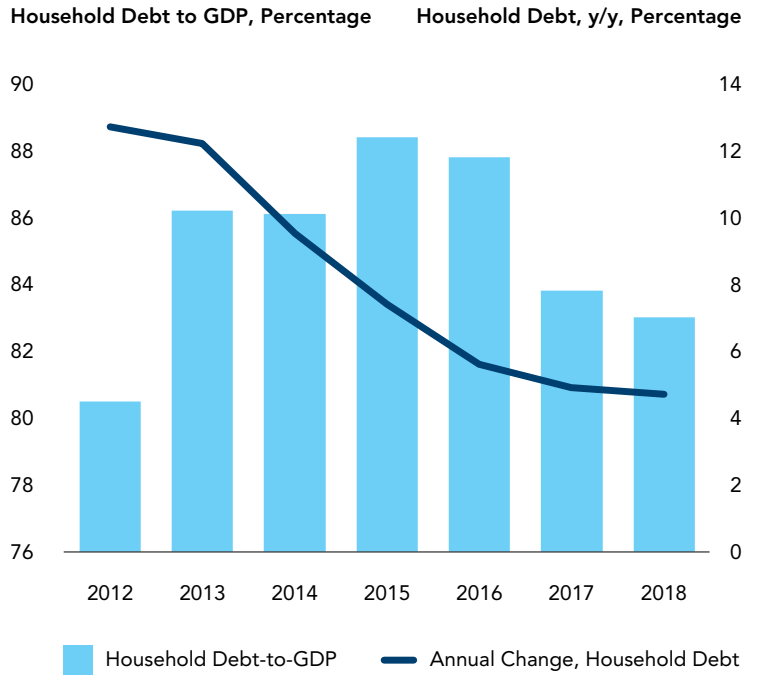

Source: BNM 
in the property segment and the near-completion of a number of large-scale projects. In the household segment, outstanding loan growth during the period was relatively stable at 5.0 percent (Q4 2018: 5.2 percent).

In 2018, household debt declined further to 83 percent of GDP (2017: 83.8 percent) (see Figure 13). Growth in household debt also moderated, from 4.9 percent in 2017 to 4.7 percent in 2018 , mainly due to the slower growth of residential property and motor vehicle loans. Although household debt remained elevated, about two-thirds of household loans are secured by property or securities, thus reducing the net exposure of financial institutions. Debt service ratios (the ratio of households' total monthly debt obligations to monthly disposable income) of newly-approved loans have remained below 60 percent for the bulk of household loans. The overall quality of lending by both banks and non-banks to households remained sound, with the aggregate impairment ratio improving to 1.2 percent (2017: 1.4 percent).

Domestic financial markets have been affected by heightened risk aversion, driven by both domestic and external factors. The FBM KLCl declined by 3.3 percent between March and May before recovering in recent weeks, mainly reflecting concerns regarding softening global growth and an escalation in the trade

\section{FIGURE 14}

Domestic financial markets have been affected by heightened risk aversion...

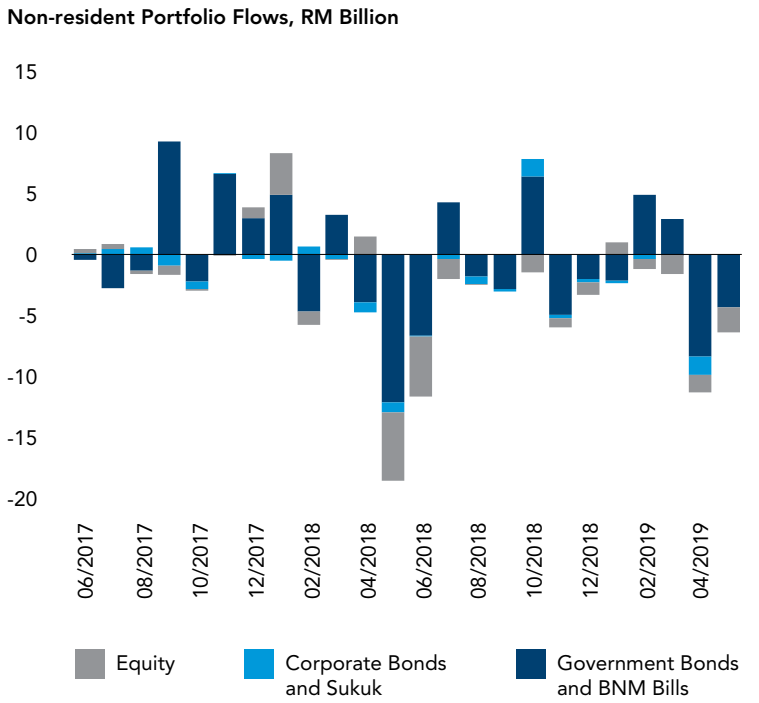

tensions between US and China. In the domestic bond market, Malaysian Government Securities (MGS) yields experienced temporary spikes in the second half of April following speculation that Malaysia would be excluded from the FTSE World Government Bond Index (WGBI), which contributed to a sizable unwinding of nonresident holdings of MGS amounting to RM8.3 billion in April (see Figure 14). While domestic institutions would likely provide sustained support to the government borrowing, the possible exclusion raises questions regarding the longer-term participation of passive foreign investors in Malaysia's MGS market (see Box 2). Interbank rates were broadly unchanged, indicating that the overall conditions in the financial markets remained stable.

The ringgit broadly weakened against the US dollar and most regional currencies, mainly reflecting outflows from the domestic bond market (see Figure 15). In the period between April 1 to June 20, the ringgit depreciated by 1.8 percent against the US dollar to stand at RM4.16. Over this period, the ringgit also weakened relative to the euro (-2.2 percent), Japanese yen (-4.6 percent) and most regional currencies. As of June 14 , the value of international reserves stood at US\$ 102.6 billion, sufficient for 7.2 months of retained imports cover and is at the ratio of 1.1 to short-term external debt.

\section{FIGURE 15}

\section{...contributing to the continued depreciation of the ringgit against the US dollar}

\section{MYR/Currency, Rebased to January 2017 $=100$} (Upward Trend Indicates MYR Depreciation)

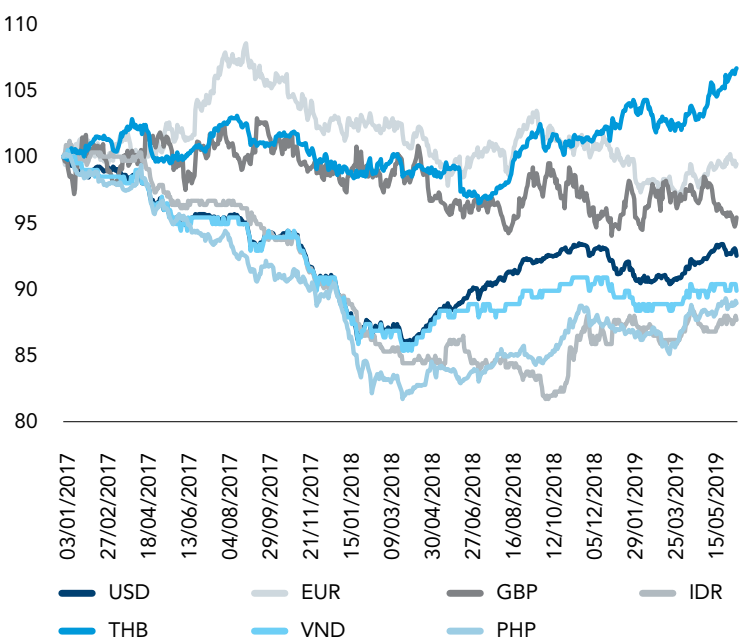

Source: World Bank staff calculations based on BNM data 


\section{BOX 2}

\section{The effects of benchmarks on international capital flows}

\begin{abstract}
On April 15, 2019, FTSE Russell announced that Malaysia had been placed under review for possible exclusion from the World Government Bond Index (WGBI). The selection of Malaysia for review was not unique but was rather part of a more general pattern of inclusion in and exclusion from international benchmark indexes, with this process having implications for the allocation of capital across borders.
\end{abstract}

As an increasing number of international mutual funds and other institutional investors have become more passive, the assets that follow benchmark indexes have increased. Passive funds tend to allocate inflows (capital injections) proportionally to the weight of each country in indexes such as the MSCl Emerging Market (EM) Index or the MSCI World Index. Therefore, changes in these indexes (due to changes in country weights or countries being added or removed) can trigger a similar rebalancing by the funds that track them, resulting in sizeable movements to international capital flows.

Reallocations due to changes in benchmark indexes can produce unexpected effects in international capital flows that are not necessarily explained by economic fundamentals. For instance, emerging countries tend to have larger weights in emerging market indexes than in developed market ones. Thus, they might face capital outflows when upgraded and inflows when downgraded. A case of this occurred in 2009, when MCSI announced that Israel would be upgraded from emerging to developed market status and moved from the MSCl EM Index to the World Index. As a result, Israel's weights went from 3.17 to 0 in the $\mathrm{MSCl}$ EM Index and from 0 to 0.37 in the $\mathrm{MSCl}$ World Index. As the value of assets allocated to the two indexes was similar, shifting Israel to the World Index implied a much lower total capital allocation to that country, resulting in equity outflows to a value of about
US\$2 billion. Because of this effect, large emerging countries, such as the Republic of Korea and Taiwan, China, have on occasion actually lobbied to not be upgraded to developed market status (Bloomberg, 2014).

The benchmark reclassifications may have implications for countries and asset classes other than those specifically targeted. The removal of a large country from a benchmark can have consequences in terms of capital flows to the rest of the countries in the same index, even if the fundamentals of these countries do not change. For instance, Qatar and the United Arab Emirates together accounted for around 40 percent of the $\mathrm{MSCl}$ Frontier Markets (FM) Index. Thus, in May 2014, when these countries were upgraded to the MSCl EM Index, funds tracking the MSCl FM Index had to significantly increase their loading in the other frontier countries. This resulted in significant inflows and stock market price increases in countries such as Nigeria, Kuwait, and Pakistan (see Figure 16). Similarly, $\mathrm{MSCl}$ announced in February 2019 that it would increase the weight of China's A shares in the MSCl EM Index ( $\mathrm{MSCl}, 2019)$. If China's overall weight increases, other countries in the index will lose weight. For example, the weights of Korea and Taiwan will fall from 15.0 to 12.7 percent and from 11.1 to 10.4 percent, respectively. As a result, there is speculation that China would increase its capital inflows at the expense of the rest of the countries in the index, which would experience capital outflows (Bloomberg, 2019).

The benchmark effect can affect the overall economy through its impact on exchange rates and debt markets. By leading to capital movements, reclassifications can cause exchange rate appreciation or depreciation, depending on whether the benchmark changes produce capital inflows or outflows, respectively. This effect occurred in Colombia, when 


\section{FIGURE 16 \\ Reclassification in frontier markets can have dramatic effects on capital flows}

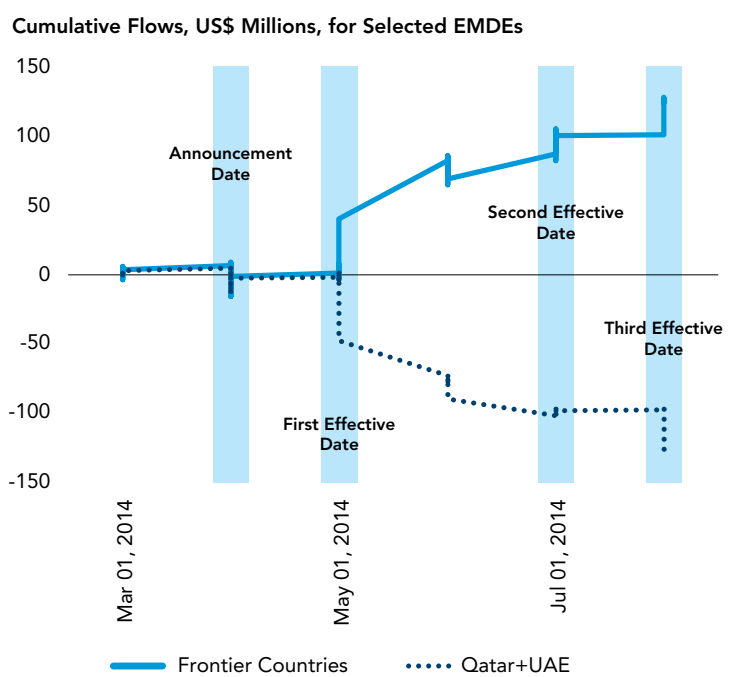

Source: World Bank staff calculations using data from Raddatz et al (2017)

five local currency bonds were included in J.P. Morgan's flagship local currency bond index in March 2014. As a result, Colombia experienced large sovereign debt capital inflows. These inflows led to an appreciation of the Colombian peso. At the same time, this event affected Colombian debt markets, leading to a higher share of foreigners holding local currency Colombian bonds and a 5 percent increase in the Colombian local currency bond index. Furthermore, as foreigners started buying sovereign bonds, some local banks sold part of their allocation in these bonds and used the proceeds to increase credit to firms (Williams, 2018).

Benchmarks can lead to the amplification and contagion of shocks. Countries that experience positive (or negative) domestic shocks will tend to see their weight increase (or decrease) in the benchmark indexes. Consequently, these countries would receive a relatively higher (or lower) share of subsequent injections of capital to investment funds. In other words, the use of benchmarks creates a positivefeedback that amplifies domestic shocks in a country. On the other hand, a country can be affected by shocks in other countries, even if its performance is stable. Positive shocks in other countries (and thus relatively higher returns abroad) would reduce the weight of the first country, resulting in capital outflows. In turn, contagion could be benign when negative shocks in other countries result in inflows to the first country.

Benchmark indexes can have important implications for the movement of capital across borders. In particular, changes in benchmarks can explain counterintuitive and unexpected movements in cross-country investments and assets prices. Most of the benchmark effect is observed at the time when the change is effectively implemented, rather than when it is first announced. The extent of the impact depends on the size of benchmark investors and the relative importance of countries in these benchmarks. At the same time, by altering the relative country weights, the change in benchmark can affect the extent to which countries are exposed to international markets and, thus, to future reclassifications. After the immediate reclassification effects, countries will be more or less exposed to international markets, depending on how important they are in benchmark indexes. As more international investors start to follow indexes more passively, the benchmark effect is expected to become more relevant. As a result, it will become increasingly important to understand the general equilibrium effects of the benchmark effect. 


\section{Federal government debt as a share of GDP has increased slightly}

\begin{abstract}
Federal government debt as a percentage of GDP increased to 51.2 percent in 2018 (2017: 50.1 percent), with risks remaining manageable. The higher level of debt was due to the upward adjustment in the fiscal deficit to 3.7 percent of GDP in 2018, to accommodate new policy directions and in response to short-term adjustments. 97.1 percent of the federal government borrowing was denominated in ringgit, limiting the exposure to valuation changes resulting from currency movements. Potential rollover risks are also limited, with more than 75 percent of outstanding issuances having a remaining maturity period of more than three years as at end-2018.
\end{abstract}

Total committed government guarantees that are serviced by the government to finance the ongoing infrastructure projects also increased in 2018, to 9.2 percent of GDP (2017: 7.4 percent). Other liabilities, including the net debt of 1 Malaysia Development Berhad (1MDB), dropped to 15 percent of GDP (2017: 21.8 percent), with this decline driven largely by cost rationalization exercises on the government's outstanding public-private partnership commitments. The overall value of the federal government debt and liabilities is estimated to stand at RM1.1 trillion, or 75.4 percent to GDP (2017: 79.3 percent). The government has indicated that its debt consolidation plan will resume in 2019, with a target debt-to-GDP ratio of around 47 percent by 2025. The government also announced the formation of the Debt Management Office (DMO), which will supervise the issuance and structure of debt and formulate strategies to reduce the government's debt and liability burden.

The government announced several new revenue measures in the first half of 2019. First, it announced the sugar tax on sweetened beverages, to be levied on the manufacturers, and is expected to take effect in July. Second, it announced the tourism departure levy, which is expected to come into effect in the second half of 2019. In addition, the government is in the midst of rationalizing tax incentives for investments. The government also announced the imposition of a digital services tax, implemented through an extension of the 6 percent SST to cover imported services provided by foreign digital service providers. However, this will only come into effect in January 2020. The government's Tax Reform Committee has indicated that it is in the final stage of finalizing its proposal to enhance tax revenue. The committee has been tasked with looking into measures to reduce tax leakages, to access the underground economy, to enhance tax administration, and to consider new sources of revenue. The government has also stated that it does not plan to introduce any new taxes in 2019 , other than those that have already been announced.

\section{The absence of adequate measures to boost revenue will constrain the amount of fiscal policy space}

On the expenditure side, the new fuel subsidy framework is expected to be rolled out in July 2019. A more targeted framework and the gradual removal of untargeted subsidies could contribute to reduced expenditure on subsidies. At the same time, moving from blanket subsidies at the pump to targeted cash payments to beneficiaries of the Bantuan Sara Hidup (BSH) would improve allocative efficiency. The government is committed to achieving its fiscal deficit target of 3.4 percent of GDP in 2019, in line with the current fiscal consolidation plan. 


\section{Economic outlook}

\section{Growth in East Asia is projected to slow over the near term}

In 2019, global conditions are expected to be less supportive of regional growth, reflecting weakerthan-expected international trade and investment activity at the start of the year. Over the year, the global growth rate is expected to decline to 2.6 percent (2018e: 3.0 percent), 0.3 percentage points below previous projections (see Figure 17). Growth in advanced economies is projected to decelerate over the near-term future, partly reflecting the waning fiscal stimulus in the United States. In the medium term, these economies are expected to converge gradually to their relatively modest potential growth rates, which remain constrained by aging populations and subdued productivity growth. Growth in EMDEs is projected to ease further to a four-year low of 4.0 percent this year (2018e: 4.3 percent), before gradually recovering in 2020-21, as the financial market stress and other adverse factors currently affecting a number of the large economies dissipate.

\section{FIGURE 17}

Global economic growth is projected to moderate over the near term

GDP, $y / y$, Percentage

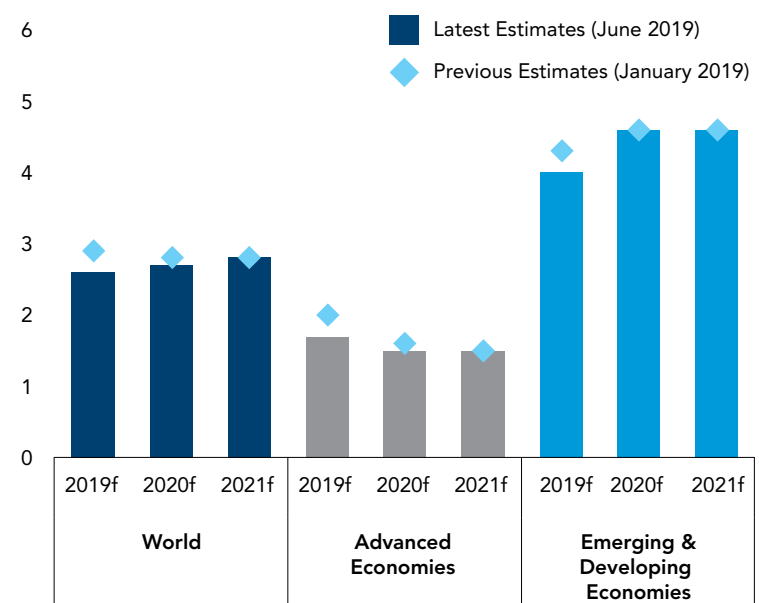

Source: World Bank staff projections
Growth in the developing EAP countries is projected to moderate over the near term, with increased external headwinds. Regional growth is expected to ease to 5.9 percent in 2019-20 (2018e: 6.3 percent), mainly reflecting the continuing slowdown in China amid domestic and external headwinds (see Figure 18). Regional growth excluding China is projected to slow to 5.1 percent in 2019 (2018e: 5.2 percent) before edging up to 5.2 percent in $2020-21$ as global trade stabilizes. Domestic demand will remain the primary driver of growth in most economies in the region on the back of stable private consumption, which is expected to partially offset the negative effects of the less supportive external environment.

\section{FIGURE 18}

Growth in developing EAP is expected to slow, with increased external headwinds

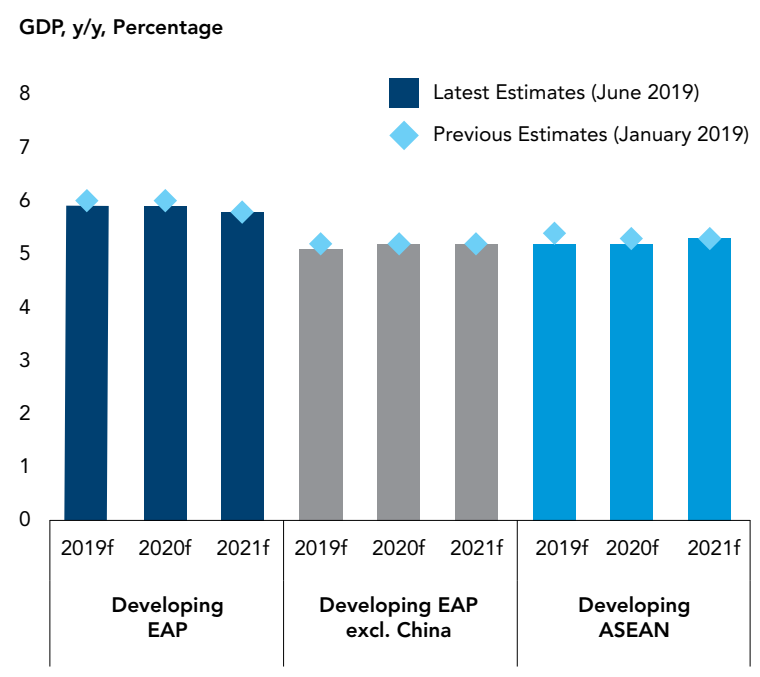

Source: World Bank staff projections 


\section{Malaysia's economy is expected to expand at a relatively modest pace}

With the increased headwinds, Malaysia's GDP growth is forecast to moderate in 2019. Malaysia's GDP growth rate is expected to decelerate to 4.6 percent in 2019 (2018: 4.7 percent), 0.1 percentage point lower than in the previous forecast. This decline largely reflects the weaker-than-expected investment and export activity in Q1 2019. While private consumption is sustained by stable labor market conditions and continues to support domestic demand, its growth is projected to moderate to 6.6 percent this year (2018: 8.0 percent), following the robust expansion in household expenditure in 2018 especially during the zero-rated GST period. In the public sector, the planned rationalization of government operating expenditure will weigh on the contribution from government consumption, with growth projected to decelerate to 1.8 percent during the year (2018: 3.3 percent).

Gross fixed capital formation is projected to remain subdued into the near-term future, weighed down by slower public and private capital spending growth. The near-term outlook for private investment activity is expected to be slightly weaker than previously envisaged, expanding at the rate of 2.9 percent in 2019 (2018: 4.3 percent). This revision mainly reflects the softer-than-expected business investment data observed in Q1 2019, with faltering external demand and softening business sentiment. Meanwhile, public sector investment is expected to contract further, by -7.0 percent, over the year (2018: -5.0 percent), with several multi-year public infrastructure projects nearing completion and with the government adopting a more cautious approach towards new infrastructure investment. While the government has announced the revival of two key infrastructure projects, the ECRL and Bandar Malaysia, both of which could help boost public investment, the full details and overall plans have not yet been disclosed. As such, the positive spillovers to economic activity may be limited in the near term.

The weakness in the external sector is likely to persist into the near team, with softening global demand weighing on export growth. Malaysia's export growth is currently projected to moderate to 0.7 percent in 2019 (2018: 2.2 percent) in the context of softening global growth and faltering trade momentum, aggravated by prolonged domestic supply constraints in the commodity sectors. Export expansion is projected to remain modest over coming years, in the context of the less supportive global environment. Similarly, import growth is projected to decelerate to the estimated rate of 0.4 percent over the

TABLE 3

GDP growth and contribution to growth

\begin{tabular}{|c|c|c|c|c|c|c|c|c|c|}
\hline \multicolumn{5}{|c|}{ GDP Growth, $y / y$, Percentage } & \multicolumn{5}{|c|}{ Contribution to GDP Growth, Percentage Point } \\
\hline & 2018 & $2019 f$ & $2020 f$ & $2021 f$ & & 2018 & $2019 f$ & $2020 f$ & $2021 f$ \\
\hline GDP & 4.7 & 4.6 & 4.6 & 4.6 & & & & & \\
\hline $\begin{array}{l}\text { Domestic Demand } \\
\text { (including stocks) }\end{array}$ & 4.3 & 4.6 & 4.8 & 4.9 & $\begin{array}{l}\text { Domestic Demand } \\
\text { (including stocks) }\end{array}$ & 4.0 & 4.3 & 4.5 & 4.5 \\
\hline Final Consumption & 7.1 & 5.7 & 5.5 & 5.4 & Final Consumption & 4.8 & 4.0 & 3.8 & 3.8 \\
\hline Private Sector & 8.0 & 6.6 & 6.3 & 6.2 & Private Sector & 4.4 & 3.7 & 3.6 & 3.6 \\
\hline Public Sector & 3.3 & 1.8 & 1.7 & 1.7 & Public Sector & 0.4 & 0.2 & 0.2 & 0.2 \\
\hline \multirow[t]{2}{*}{$\begin{array}{l}\text { Gross Fixed Capital } \\
\text { Formation }\end{array}$} & 1.4 & 0.0 & 1.1 & 1.9 & $\begin{array}{l}\text { Gross Fixed Capital } \\
\text { Formation }\end{array}$ & 0.3 & 0.0 & 0.2 & 0.4 \\
\hline & & & & & Change in Stocks & -1.2 & 0.3 & 0.4 & 0.3 \\
\hline External Demand & & & & & External Demand & & & & \\
\hline $\begin{array}{l}\text { Exports of Goods \& } \\
\text { Services }\end{array}$ & 2.2 & 0.7 & 0.6 & 0.6 & $\begin{array}{l}\text { Exports of Goods \& } \\
\text { Services }\end{array}$ & 1.5 & 0.5 & 0.4 & 0.4 \\
\hline $\begin{array}{l}\text { Imports of Goods \& } \\
\text { Services }\end{array}$ & 1.3 & 0.4 & 0.5 & 0.5 & $\begin{array}{l}\text { Imports of Goods \& } \\
\text { Services }\end{array}$ & 0.8 & 0.2 & 0.3 & 0.3 \\
\hline
\end{tabular}

Source: World Bank staff calculations and projections 
year (2018: 1.3 percent). This largely reflects the lower growth of intermediate and capital exports, consistent with lower-levels of export demand and a slowdown in overall investment activity.

News-based measures of economic sentiment point towards a lower forecast of GDP growth compared to those of professional forecasters. Complementary news-based measures of economic sentiment ${ }^{3}$ indicate a softer perception of the economic conditions in Malaysia during $\mathrm{H} 1$ 2019, with the sentiment-adjusted growth forecast in 2019 tracking below the consensus forecast throughout the period (see Figure 19). Below-trend optimism was especially notable across the economic, corporate and industrial, and trade categories through March, coinciding with the deterioration of sentiment around global growth prospects. The overall sentiment has improved slightly since then, supported in part by BNM's decision to lower the OPR in May (see Figure 20).

Headline inflation is expected to increase modestly in 2019, with the effects of transitory policyrelated factors dissipating. Consumer price inflation is projected to average at about 1 percent for 2019 as a whole (2018: 1.0 percent), mainly due to the diminishing effects of the changes to consumption

\section{FIGURE 19}

The sentiment-based forecast of GDP growth has been tracking below the consensus forecast...

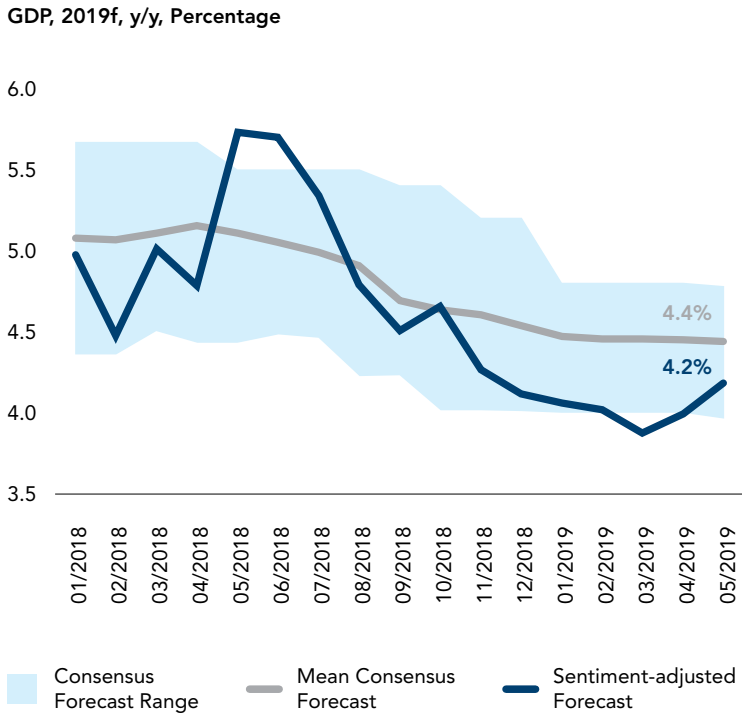

Source: World Bank staff projections tax policy towards the second half of the year. The projected modest increase in inflation in H2 2019 is also predicated on the assumption that the float pricing mechanism for RON95 and diesel will be reintroduced in mid-2019. This will result in fuel subsides becoming more targeted, leading to an upward adjustment in domestic retail fuel costs in line with the recent trends in global oil prices. Underlying inflation is expected to be broadly contained over the near term in the absence of immediate domestic cost pressures.

Looking further ahead, Malaysia remains on track to achieve high-income economy status by 2024 . Malaysia's gross national income (GNI) per capita stood at US $\$ 10,460$ in 2018 , US $\$ 1,915$ below the threshold level of US\$12,375 that the World Bank currently sets to define high-income country status, based on estimates using the Atlas method. The latest World Bank staff projections indicate that Malaysia could exceed the defined threshold at some point between 2021 and 2024. As Malaysia's economy converges with the highincome economies, it is important to be attentive to the broader aspects of development and societal wellbeing, such as health, education and the distribution of wealth, that are not adequately captured by advances in per capita income terms (see Box 3).

\section{FIGURE 20}

\section{...reflecting largely below-trend optimism in the economic and corporate clusters}

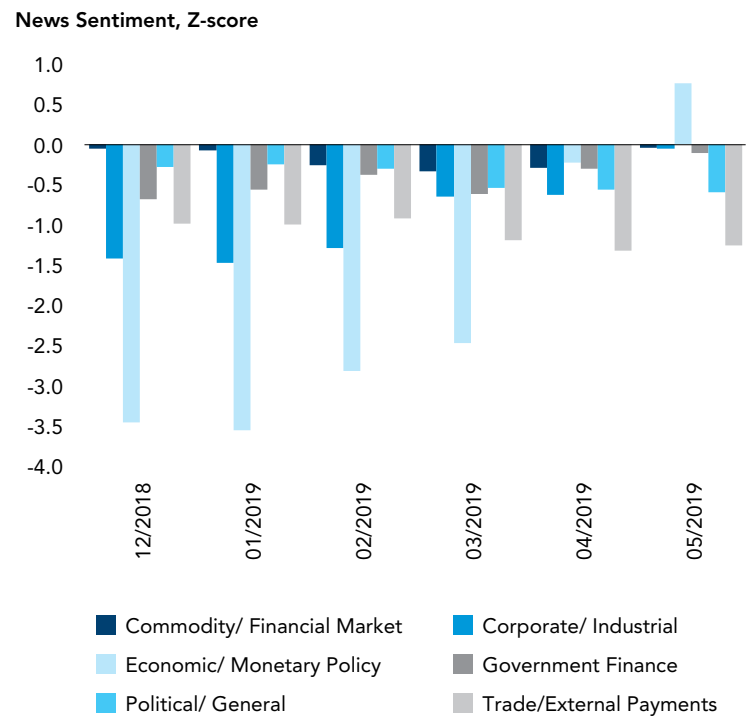

Source: World Bank staff calculations

${ }^{3}$ The news-based sentiment index is derived by the staff of the World Bank through an analysis of the proportion of positive words ("gain", "improve", "agreement", etc.) relative to the proportion of negative words ("concern" "fear" "decline", etc.) present in a vast collection of news articles on Malaysia's economy. Information derived from media reports has two main advantages compared to official statistics. First, measurements of economic conditions can be calculated in real-time, at a daily frequency. Second, this information enables the measurement of economic forces that might not be easily captured by traditional data sources, providing complementary insight into factors such as the collective sentiment regarding economic prospects. A recent study based on historical data in 25 countries between 1991 and 2017 suggests that including news-based measures of sentiment reduces the forecast errors of GDP growth by 12 percent on average relative to the consensus forecast. 


\section{Malaysia's growth dividend from increasing education quality and health indicators to the levels of high-income countries}

Recent analysis has shown that accelerating human capital development will be critical for enabling Malaysia's successful transition to a highincome and developed nation. According to the World Bank's Human Capital Index, Malaysia currently ranks 55th out of 157 countries. While Malaysia performs well in terms of some components of the index, it does less well in others. A particular area where Malaysia will need to improve its performance is with regard to learning outcomes (World Bank 2018a).

The World Bank's Long-Term Growth Model (LTGM) can be used to simulate a boost to long-term growth in Malaysia by increasing the quality of education and health in response to this challenge. The LTGM

\section{FIGURE 21}

Simulations for Malaysia's rate of human capital growth

Human Capital, y/y, Selected Simulations

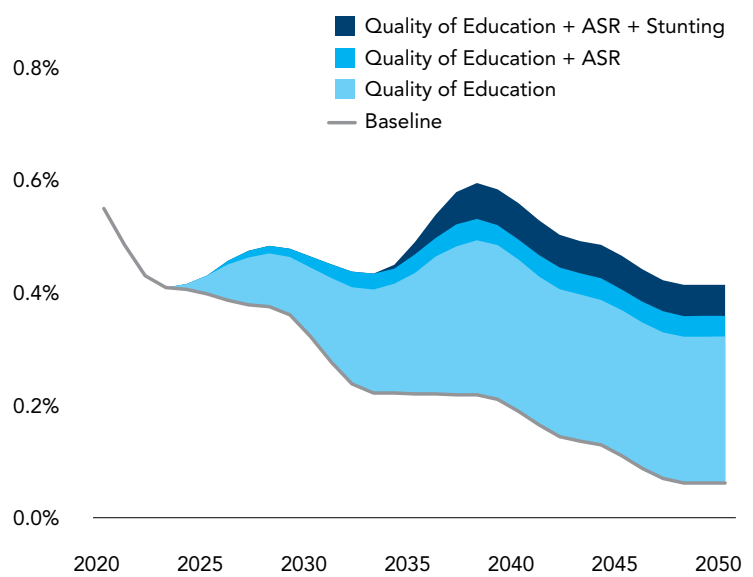

is based on the celebrated Solow-Swan growth model, adapted to developing/emerging economies. An extension, based on the World Bank Human Capital Index, allows for an analysis of the long-run growth effects of improved learning quality and health outcomes. Education quality here is measured using normalized test scores and is embodied in each child when they are in school. The health of the population is approximated in two ways. First, the Adult Survival Rate (ASR) is the fraction of current 15-year olds who would survive to age 60 , assuming that the current agespecific mortality rates apply throughout their lifetime. Second, the stunting rate is measured as the fraction of 5-year-old children who have a height that is more than two standard deviations below the median. The

\section{FIGURE 22}

Simulations for Malaysia's long-term rate of GDP growth

GDP, $y / y$, Selected Simulations

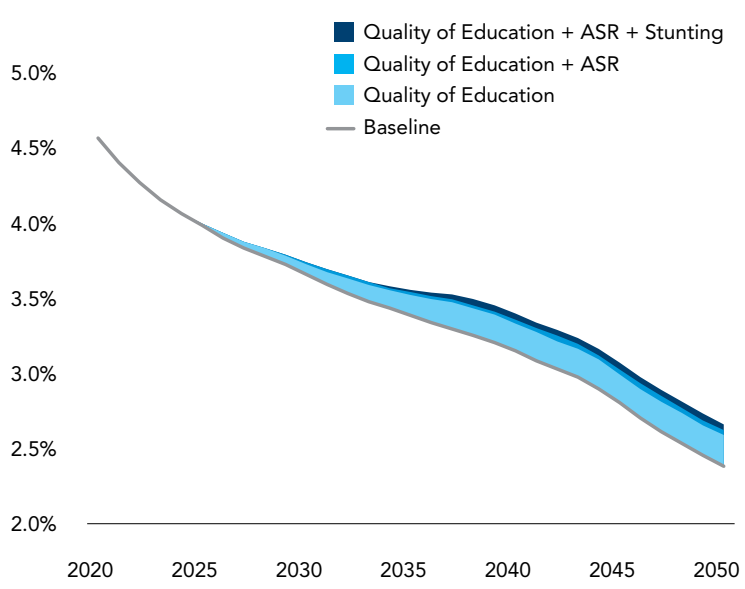




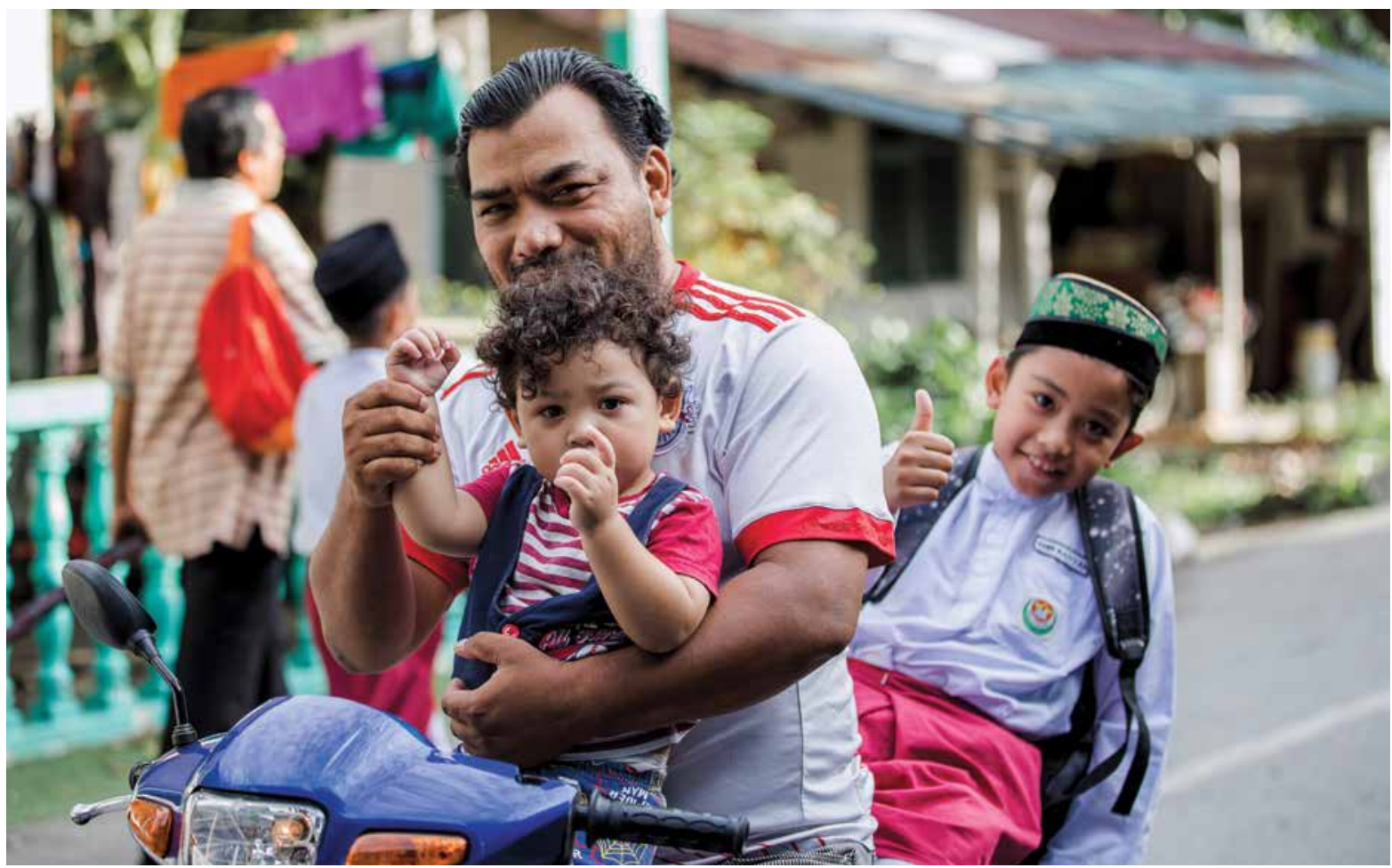

simulations assume that other growth drivers, besides human capital (e.g. investment, productivity), continue at their historical trend rates.

In the business-as-usual baseline, the headline annual GDP growth rate is initially at around $\mathbf{4 . 6}$ percent, but slows over the next 30 years to a trend rate of $\mathbf{2 . 4}$ percent (see Figure 22). In this baseline, education quality is assumed to be constant (at 75 percent, its 2018 value). However, human capital growth slows over time from an initial rate of 0.6 percent to around 0.2 percent by 2035 and 0.06 percent by 2050, as the gains from previous expansions to schooling start to fade (see Figure 21, health measures are also constant in the baseline). Slowing long-term headline growth also reflects slower population growth (falling from 1.3 percent today to 0.4 percent by 2050); an aging population; and a declining return on private investment (given relatively high investment rates). Slowing growth is common as countries make the transition to high income status but can also motivate new pro-growth reforms.
Increasing education quality and the two health indicators to the 50th percentile of high-income countries boosts growth by 0.25 percentage points in the period from 2035 to 2050 (see Figure 22).

The results are mostly driven by education quality. Malaysia's current education quality (75 percent) is good compared with other upper middle-income countries. However, it is below the 25th percentile of high-income countries, and well below regional aspirational peers such as South Korea (90 percent) and Singapore (93 percent). Boosting schooling quality today to the high-income 50th percentile (83 percent) increases human capital growth by 0.25 percentage points (see Figure 21), and GDP growth by around 0.2 percentage points (see Figure 22) - but only after 2035, when today's children start to join the workforce (the smaller effects over 2025-35 are because today's older children only receive partial treatment). Combined, the two health indicators add almost 0.1 percentage points to human capital growth over 2035-50 and 0.06 percentage points to GDP growth. By 2050, the level of GDP is almost 5 percent higher.

Notes: Common assumptions: (i) the investment share of GDP is assumed to stay at its 2018 value of 24.5 percent of GDP (6.5ppts public and 18ppts private); (ii) Total Factor Productivity (TFP) growth is assumed to remain at 0.9 percent (close to the 15 -year average using Penn World Tables 9 data); (iii) the labor share is 0.5 (similar to PWT9 data); and (iv) capital-to-output ratio is at its steady state value of 2.25. The assumed return to an extra year of schooling is 12 percent. The depreciation rate is 5.8 percent (from PWT9). 



\section{Risks to Malaysia's growth outlook continue to tilt towards the downside}

The possibility of escalating trade tensions, sharper-than-expected slowdowns in major economies and a maturing global technology cycle could weigh on Malaysia's growth in the near term. Given Malaysia's high degree of trade openness and global value chain integration, the growing protectionist tendencies and unresolved trade tensions pose a significant risk to domestic growth in the near term. Prolonged unresolved trade tensions could translate to heightened uncertainty, leading to a decline in global business sentiment, subsequently offsetting any potential short-term gains for Malaysia resulting from trade and investment diversion from China. A maturing global technology cycle could also contribute to the growing uncertainty and further dampen growth. Early indications of the slowdown have already been observed in the moderation of E\&E manufacturing due to weaker global demand in Q1 2019, which contributed to lower manufacturing exports.

Growing uncertainty regarding the external environment could also lead to more subdued business sentiment and to a moderation in overall investment. Several indicators of business sentiment ${ }^{4}$ suggest that businesses are notably less optimistic about the near-term outlook in the context of slowing global growth and prolonged policy uncertainty. In addition, there are signs of firms slowing down on hiring, capacity building and expansion activities, which could subsequently affect the momentum of economic growth.

The relatively high level of public debt will continue to exert constraints on fiscal policy space. The government has undertaken a number of initiatives to increase revenue collections and to diversify the revenue base, including the establishment of the Tax Reform Committee and the introduction of a number of new taxes. The overall impact of these measures, however, is expected to be small in the near term. The higher level of public debt, with the absence of adequate revenue measures, will continue to constrain the flexibility of fiscal adjustment against future macroeconomic shocks. In addition, there are relatively sizable committed government guarantees and other commitments, such as those arising from publicprivate partnerships, which would place additional pressure on the fiscal policy space over the longer term. In the private sector, the relatively high level of household debt in the context of persistent property market excesses remains a source of risk to macrofinancial stability, as well as acting as a constraint on household spending.

\section{Near-term policies should focus on boosting resilience and protecting the vulnerable}

In the immediate term, the government should aim to build fiscal buffers, to facilitate private investment, and to ensure adequate social protection for lowerincome households. With growing uncertainty and with risks to the economy tilting to the downside, it is important to ensure adequate room for policy space and maneuverability. More targeted social protection systems could help to alleviate cost pressures and to provide financial support to lower-income households.
Given the current constraints on fiscal policy space, it is crucial for the government to undertake bold reforms and measures to increase revenues. Malaysia's near-term fiscal consolidation has been primarily driven by vigorous expenditure rationalization. Going forward, reforms should also focus on mobilizing revenues to expand fiscal space. Beyond timely existing initiatives (including the establishment of the Tax Reform Committee and the realignment of tax incentives),

${ }^{4}$ The Malaysian Institute of Economic Research (MIER) business conditions survey, RAM Business Confidence Index. 
more could be done to diversify sources of fiscal revenue. For instance, the personal income tax revenue could be broadened through the implementation of a more progressive tax structure. At present, Malaysia's personal income tax revenue is estimated at 2 percent of GDP (see Figure 23), lower than many upper-middle income and high-income countries. Malaysia's top marginal income tax rate currently stands at 25-28 percent. This is relatively low compared to many regional countries and most high-income countries. Second, the current coverage of the SST could be expanded. Similar to personal income tax, Malaysia's tax revenue on goods and services in proportion to GDP is lower than that of most upper-middle and high-income countries (see Figure 24). Consideration could also be given to broadening the scope of capital gains taxes, and to strengthening the effectiveness of tax administration through the increased adoption of digital technology to more effectively enforce compliance.

The widening of the government's revenue base could also be accompanied by measures to expand and improve the existing social protection system to achieve overall progressivity. The government's planned move to a more targeted fuel subsidy framework could lead to potential savings that could subsequently contribute to the expansion of core social welfare programs, with evidence from a number of countries showing that progressive taxes and social transfers, such as targeted cash transfers, can be very effective in reducing income inequality. Currently,

\section{FIGURE 23}

Malaysia trails many upper-middle- and highincome countries in the collections of personal income tax revenue...

Personal Income Tax Revenue, Percentage of GDP, Average 2012-2017

30

25

20

15

10

0

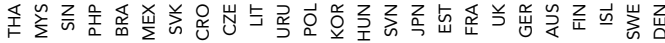

Malaysia has a range of social safety net programs that are administered by various ministries, including core welfare programs implemented by the Department of Social Welfare and the BSH program.

\section{The depth of Malaysia's social safety net system remains relatively underdeveloped}

\begin{abstract}
Malaysia performs relatively well in terms of breadth of coverage based on the number of potential beneficiaries of the various social safety net programs. However, compared to other countries in the region, the depth of Malaysia's social safety net system remains underdeveloped, as measured by the average expenditures per beneficiary relative to GDP per capita. Core welfare programs are particularly underfunded. In addition, stylized simulations of the impact of the BSH program suggest that the amount of benefits per beneficiary household is fairly small relative to household incomes, resulting in only a modest impact on overall inequality. Improvements to the existing social protection system could be achieved by increasing the total outlay for benefits; better
\end{abstract}

\section{FIGURE 24}

....and revenue from taxes on goods and services

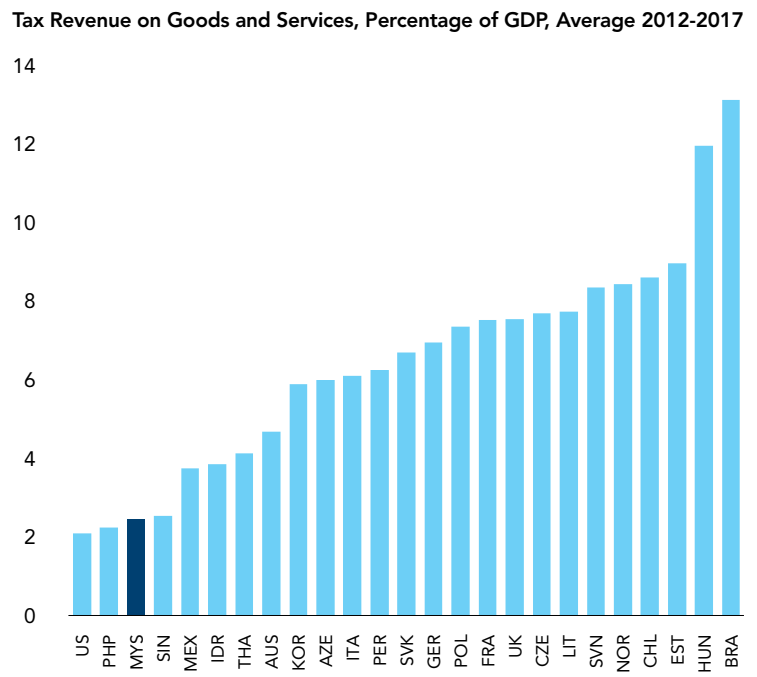

Source: World Bank staff calculations based on IMF data 


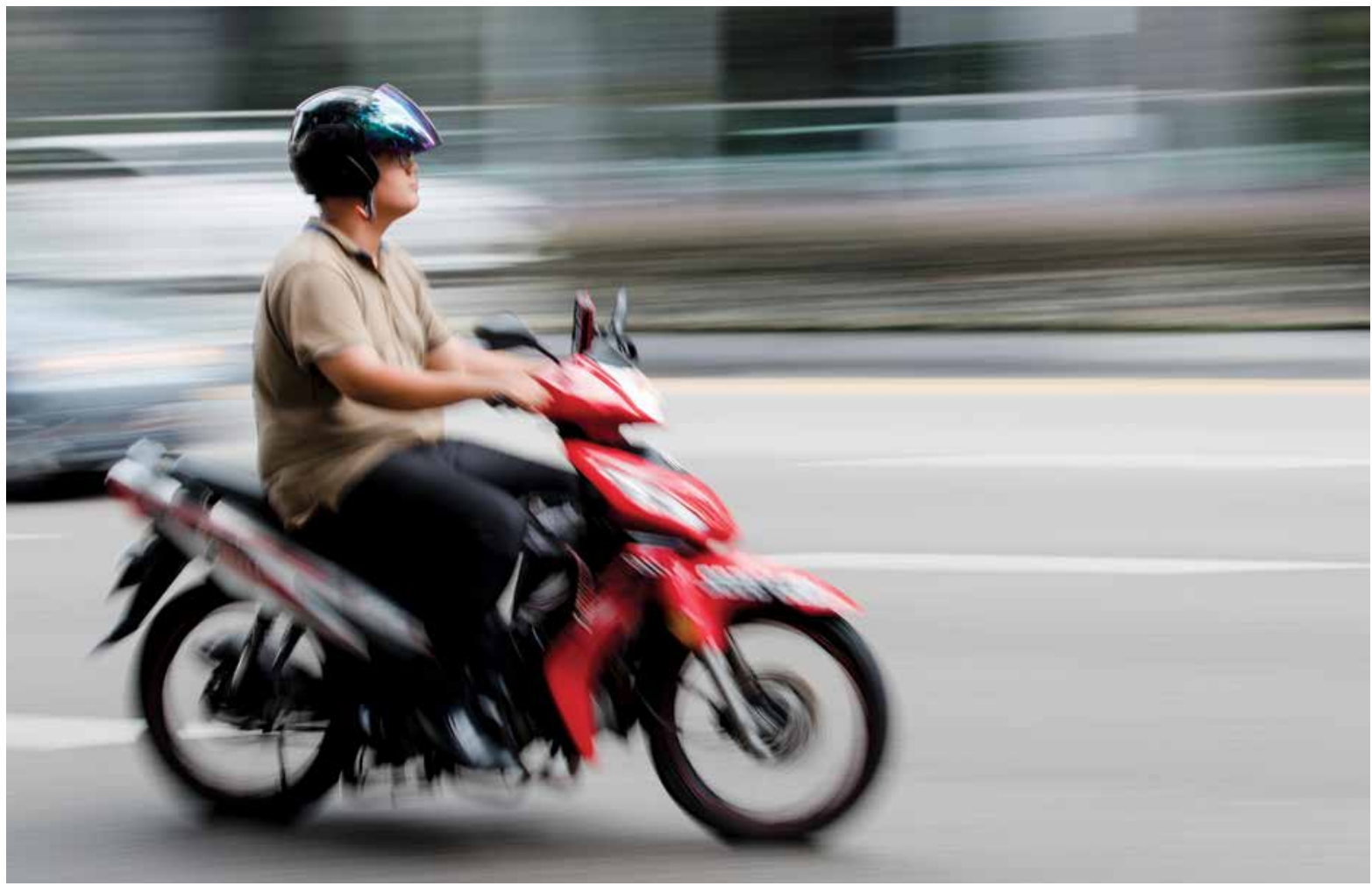

targeting that more directly factors in household size when determining eligibility and benefit amounts; and linking program eligibility to measures that promote human capital formation, such as school enrolment and attendance (see Box 4).

Over the medium term, as Malaysia transitions into a high-income economy, policy should focus on measures to boost human capital and to accelerate productivity growth. The achievement of shared prosperity and inclusive growth depends on increasing labor productivity, which in turn depends on stronger human capital development. Malaysia's score on the Human Capital Index $(\mathrm{HCl})$ is 0.62 , which is roughly comparable to other upper-middle income countries but considerably lower than that of its aspirational comparators. Improving human capital outcomes would include enhancing learning outcomes, reducing child undernutrition, and strengthening social protection systems to enable households to both invest in and protect human capital. Closing the gaps between men's and women's economic opportunities could also boost long-term growth. Accelerating productivity growth would also entail a commitment to boost investor confidence and to address market distortions resulting from unhealthy competition. The dominant role of GLCs has at times stifled competition, leading to higher costs and resulting in many productive firms operating below their optimal levels (see Box 5).
Concurrently, ongoing efforts by the government to reform governance to enhance transparency and to improve the efficiency of the public service should continue. Under the MTR of the 11th Malaysia Plan, governance reforms cover a number of areas, including elevating integrity and accountability, enforcing prudent public finance, and enhancing public service delivery. Given that spending on public service salaries and pension would continue to constitute the largest share of overall public expenditure, the emphasis should shift towards enhancing public sector efficiency and reinventing public services. This would require fundamental reforms to public service employment and the associated remuneration and reward system, including reviewing hiring policies and strengthening the link between compensation and employee performance.

More broadly, ensuring that Malaysia has an effective and efficient public service will be necessary for the achievement of shared prosperity. Building capacity and capability in the public service is core to the achievement of Malaysia's successful transition to a high-income and developed nation and to the fulfilment of society's increasing demands for better quality services. The types of public service that Malaysia needs for this transition, and the way that it is recruited, managed and incentivized are explored in more detail in Part 2 of this edition of the MEM. 


\section{Is income inequality in Malaysia rising or falling? Or both?}

\begin{abstract}
Inequality is one of the more contentious topics in economic policy and in social and political discourse. It is also one of the most easily misunderstood. To begin, there are fundamental disagreements between those who argue that inequality is unfair and undemocratic and those who believe that some inequality is desirable if it is the result of rewarding entrepreneurs and innovators who take risks and successfully contribute to the country's advancement. In addition, there are many domains of inequality to consider, with many distinctions between them, most notably the distinction between inequality of opportunities versus inequality of outcomes, such as income, wealth, health, and happiness. Within these domains, there are numerous ways of measuring inequality, with different measures sometimes pointing in different directions within a single given context. Here we focus on two perspectivesrelative and absolute-of income inequality.
\end{abstract}

Income inequality in Malaysia has either been falling rapidly or rising rapidly, depending on how it is measured. The most commonly used inequality measures (such as the Gini index or income shares)

\section{FIGURE 25}

Malaysia has seen an increasing income share of the B40, corresponding with a declining relative Gini index...

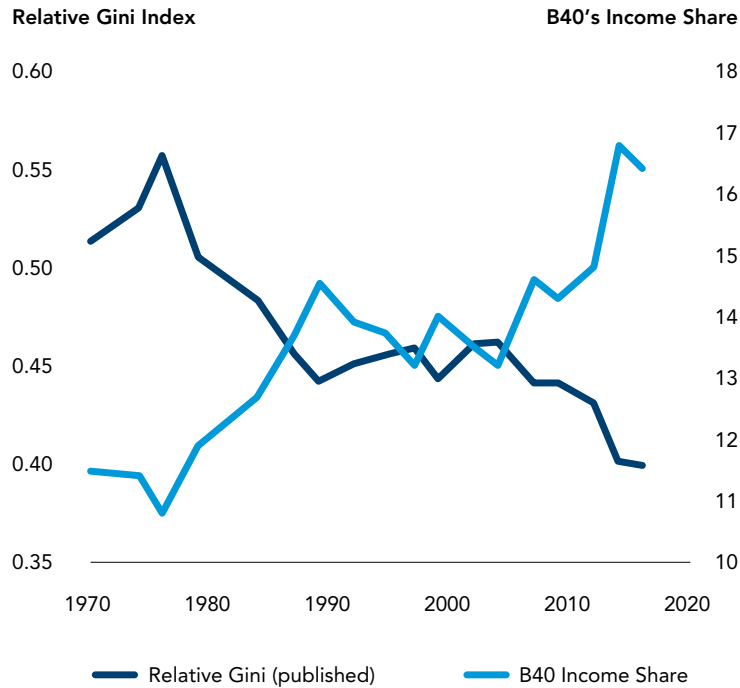

Source: World Bank staff calculations using DOSM data use a relative concept of inequality. That is, income is measured as a proportion of the average income or aggregate household income, respectively. According to these relative measures, it may be seen in Figure 25 that the relative Gini index declined from 0.51 in 1970 to 0.44 in 1989, where it remained until 2009, before again declining to 0.40 in 2014, where it remained in 2016. Over the same period, the total share of household income accruing to the bottom 40 (B40) increased from 11.5 to 16.4 percent, with a marginal decline in the period from 2014 to $2016 .{ }^{5}$

While relative income inequality has been declining, absolute income inequality has been increasing. Recent publications by KRI (2018), World Bank (2018a) and Ravallion (2019) have highlighted growing absolute gaps in income levels. The absolute Gini index, computed in the same manner as the relative Gini index but without normalizing by mean income, increases by a factor of more than four between 1970 and 2016 (see Figure 26). ${ }^{6}$ Thus, at the same time that lower income groups were gaining a larger proportion of total household income, the absolute gap in ringgit

\section{FIGURE 26}

...but while the relative Gini index has declined, the absolute Gini index has increased

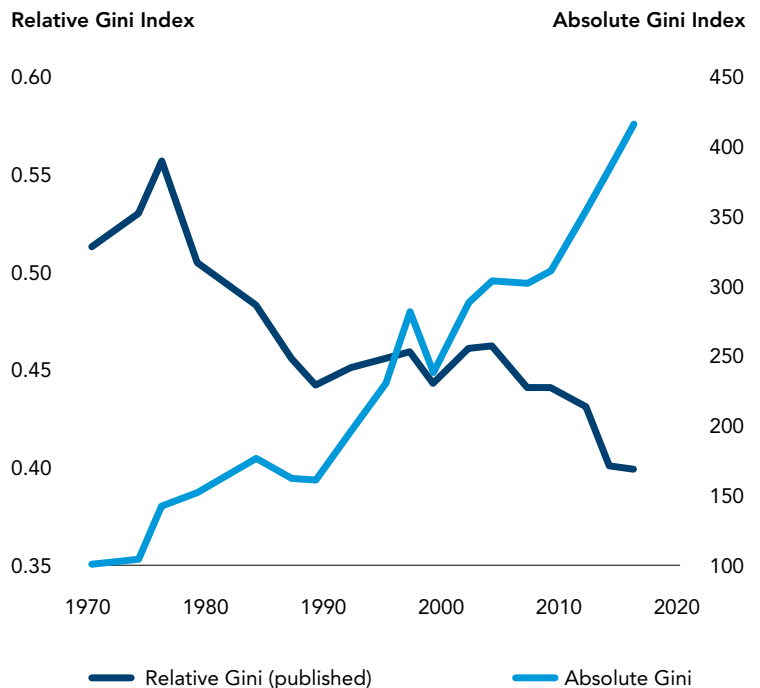

Source: World Bank staff calculations using DOSM data

Note: Absolute Gini index calculated in monthly income per household in constant 2010 Malaysian ringgit

${ }^{5}$ The most recent Household Income and Expenditure Survey (HIES) data is from 2016. The 2019 HIES is currently in the field, with results expected in mid-2020. ${ }^{6}$ Unlike the standard relative Gini index, the absolute Gini index is not bounded by zero and one. Its scale depends on units in which income is denominated, which is why it is essential to adjust for inflation. 
FIGURE 27

\section{Relative inequality is weakly correlated with household income growth...}

Annual Growth Rate of Relative Gini Against Annual Growth Rate of Mean Income, All Countries, Malaysia Highlighted in Blue

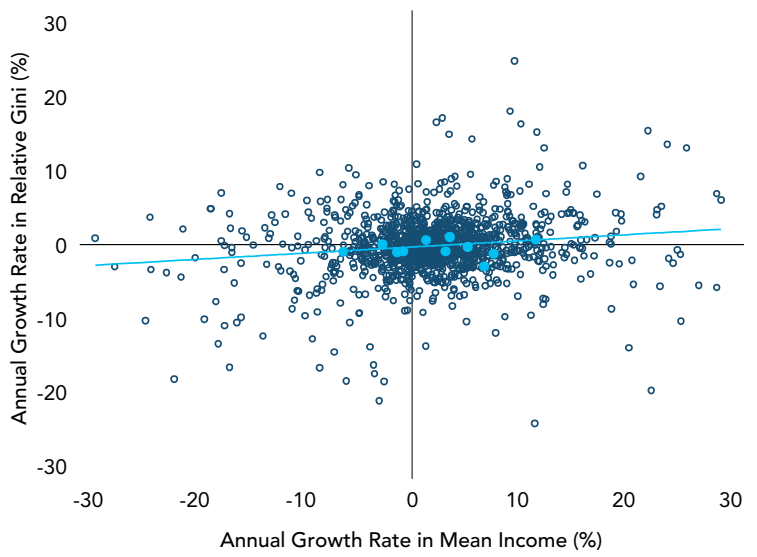

Source: World Bank staff calculations using PovcalNet data

terms was increasing because average incomes were increasing for all income classes and in larger absolute increments for higher-income households. For example, over this period, in inflation-adjusted terms, the average monthly income of a B40 household increased from RM 325 to RM 2,473, while the national average increased from RM 1,130 to RM 6,043. Thus, while B40 incomes improved from 29 to 41 percent relative to the national mean, the absolute difference between the B40's average income and the national average increased from RM 805 to RM 3570.

What can and should be done to reduce absolute income inequality? Many economists, but certainly not all, tend to emphasize relative inequality measures, especially in the context of a growing economy. If poorer people are gaining a larger share of a growing economic pie, what's not to like? A common rejoinder (see KRI 2018) is that most people don't observe their income shares, they observe themselves getting a salary increment of RM 100 while their richer neighbor receives an increment of RM 400, thus concluding that inequality is getting worse. Indeed, this likely shapes the perceptions of many Malaysians who feel that they are not benefiting from economic growth and are falling behind, despite what relative inequality measures say. It also reveals the potential pitfalls of over-reliance on a single statistic. Some reflection on the patterns of relative and absolute income inequality relative to income growth may help illuminate the debate.

Empirically, absolute income inequality changes almost in step with income growth, whereas relative inequality is only weakly correlated with growth. Figure 27 and Figure 28 summarize changes in inequality for 1,400 growth spells calculated from the World Bank's publicly-available PovcalNet database,
FIGURE 28

...whereas absolute income inequality and income growth are highly correlated

Annual Growth Rate of Absolute Gini Against Annual Growth Rate of Mean Income, All Countries, Malaysia Highlighted in Blue

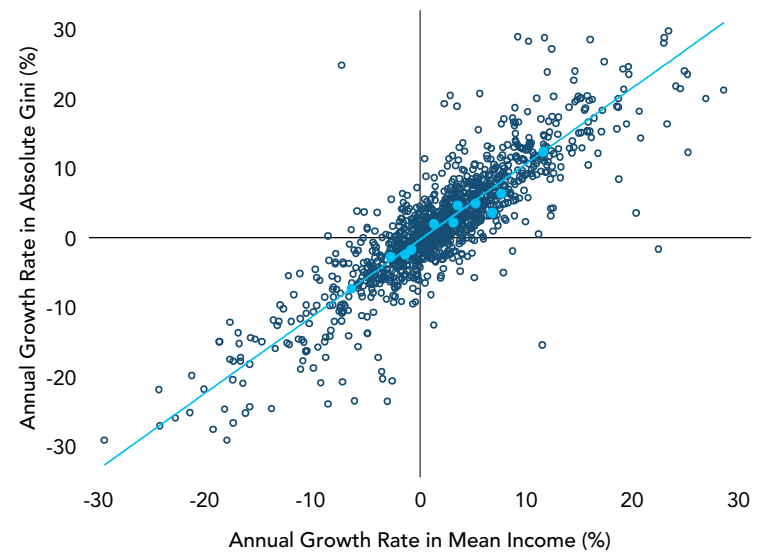

Source: World Bank staff calculations using PovcalNet data

which compiles data from more than 1,600 harmonized household surveys from more than 160 countries. ${ }^{7}$ The left panel shows no discernible relationship between income growth and relative inequality (slope 0.08, adj-R2 0.025), meaning that relative inequality has increased or decreased at about the same rate, regardless of the rate of income growth (Malaysia observations in red dots). In contrast, in the right panel, the absolute Gini increases almost in direct proportion with income growth (slope 1.09, adj-R2 0.80), tending to decline only when the economy is contracting. This matches Malaysia's experience, with Figure 26 showing that the only two periods in which the absolute Gini declined coincided with the mid-1980s commodities price shock and the Asian financial crisis.

Should reducing absolute income inequality be a policy objective, and if so, what are the tradeoffs? The absolute income Gini is the product of the relative Gini and average household income, implying that reducing absolute income in a growing economy requires a reduction in relative inequality that is large in comparison to the growth in mean income. The lower-right quadrant of Figure 28 shows that this a fairly rare occurrence. To achieve such a win-win outcome Malaysia would need proportionately faster income growth among lower-income households to resume the decline in relative income inequality that appears to have stalled in the period from 2014 to 2016. Malaysia's relative income inequality is high compared to countries at a similar income level. Resuming the downward trend in relative income inequality is a worthy objective in its own right, and will also contribute to reducing absolute income inequality, or at least slowing its increase. This will depend on growth and social policies to ensure that all Malaysians share in the country's prosperity. 


\section{Malaysia's need for speed: How regulatory action is unleashing ultrafast internet}

Over the past decade, Malaysia's internet market has been characterized by relatively slow growth compared to most of its regional peers. This lag has been especially noticeable in terms of the adoption of fiber internet services, which are a sine qua non for the sustained development of any digital economy. Malaysia has not only lagged in comparison with more advanced economies, but also relative to middleincome comparators (see Figure 29).

Recent World Bank analytical work to identify policies to promote Malaysia's digital economy found that this lag was at least partly due to limited competitive pressure in the market, marked by the dominance of incumbent Telekom Malaysia (TM). As of December 2017, TM held a 90 percent market share. For context, this made Malaysia the most concentrated

\section{FIGURE 29}

Until recently Malaysia has lagged in the uptake of fiber internet subscriptions...

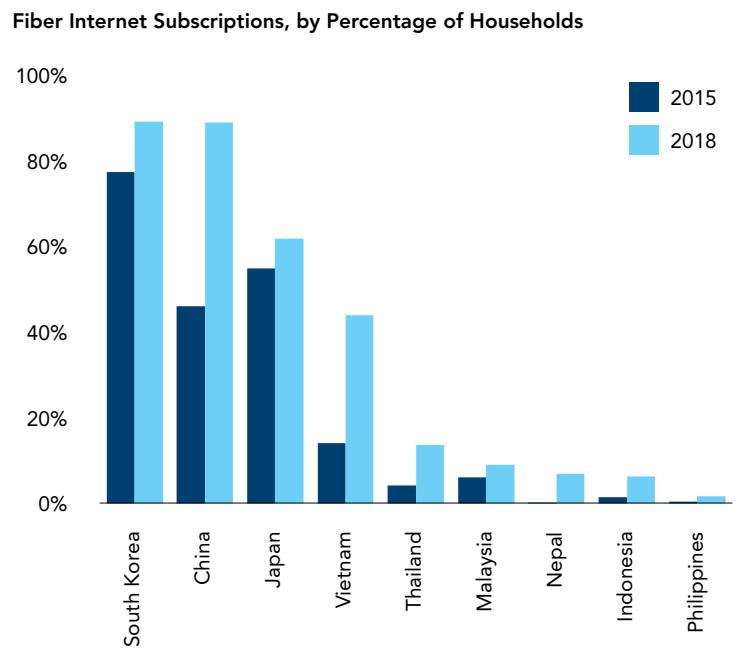

fixed broadband market in the Asia-Pacific region for any country with a population larger than one million people. Limited competition combined with difficulties in network deployment constrained alternative internet service providers (ISPs) from rolling out their networks or offering services on competitive terms (World Bank 2018b).

However, regulatory reforms undertaken in Malaysia's telecommunications sector in 2018 have had a significant positive impact. Most visibly, a series of regulatory actions have caused the prices of fixed broadband services to drop and triggered a shift in consumer demand towards faster internet connections. In 2018, the Government introduced an important measure known as the Mandatory Standard on Access Pricing (MSAP), which was implemented by

\section{FIGURE 30}

...but broadband prices have fallen dramatically over the past year...

\section{Average Prices of Fixed Broadband Plans}

January 2018

December 2018

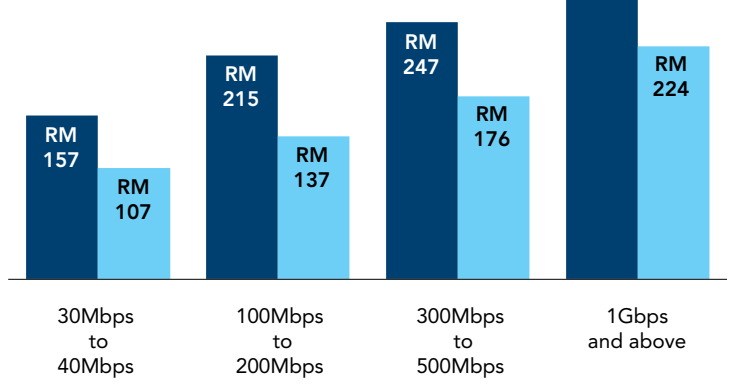


TABLE 4

....and speeds increased during 2018, especially for fixed connections

Tested speeds in Mbps

Tested speeds in Mbps

Fixed internet

Mobile internet

\begin{tabular}{lcccc} 
& Dec-17 & Mar-19 & Dec-17 & Mar-19 \\
\hline Fastest five (average) & 135.9 & 155.2 & 54.8 & 62.8 \\
\hline Malaysia & 22.2 & $67.2(3 \mathbf{x})$ & 16.0 & $20.5(1.3 \mathbf{x})$ \\
\hline Global comparison (F5/MY) & 6.1 & 2.3 & 3.4 & 3.1
\end{tabular}

Source: World Bank staff calculations using data from Ookla Speed Test

the telecommunications regulator. MSAP regulates the prices and terms for alternative ISPs to access wholesale broadband capacity provided by TM. Similar measures have had positive impacts on broadband markets in Europe, for example. Likewise, this was expected to allow Malaysia's alternative ISPs to offer lower priced, higher quality services to their subscribers using the widespread and high-quality facilities of the TM network.

\section{Malaysia's average fixed broadband speeds have accelerated by three times in the space of a year}

The quality of fixed broadband connections, including cable and fiber internet services, rapidly responded to these regulatory changes. Within three months, multiple service providers, including $\mathrm{TM}$, announced new broadband subscription plans that included faster speeds at lower prices. The impact was especially evident for what is globally becoming the norm for basic broadband services (30 Mbps services), with average prices for those plans falling by 30 percent over 2018. Notably, the average price of plans for speeds in excess of $1 \mathrm{Gbps}$ (the emerging speed target for advanced economies) fell by over 40 percent. Price drops were seen across all plan types (see Figure 30 ).

As faster speed broadband plans have become more affordable, Malaysian subscribers have switched to these plans. Data from the telecommunications regulator MCMC shows that the number of fixed broadband subscriptions with download speeds of more than 100 Mbps grew by a factor of eight to 1.2 million subscribers in 2018. These increased speeds are reflected in the online tests conducted by subscribers.

Malaysia is now starting to close the gap with leading countries with respect to internet speed. In December 2017, the average speed of fixed broadband services in the five countries in the world with the fastest connections was more than six times faster than the average speed in Malaysia. By March 2019, this had narrowed to just over two times. Put another way, Malaysia's average fixed broadband speeds have accelerated by more than 300 percent in just over a year (see Table). The already-competitive mobile broadband market has seen a smaller improvement, reflecting the fact that it was already performing relatively well. However, it is now facing increased pressure to grow, with consumers demanding faster connections to feed their digital ambitions.

Recent events show the impact of policy reform on market outcomes. The implementation of regulations that boost competition have been shown to have positive effects on subscription and affordability in many contexts. Malaysia's experience shows the potential gain, demonstrating the demand for highquality, affordable internet services and indicating that the digital transformation is yet to be fully realized. It also indicates that this is a first, even if critical, step in a longer journey to provide all Malaysians with access to ultrafast, affordable broadband services, that will position them and their businesses and the economy for growth in an increasingly digital world. 


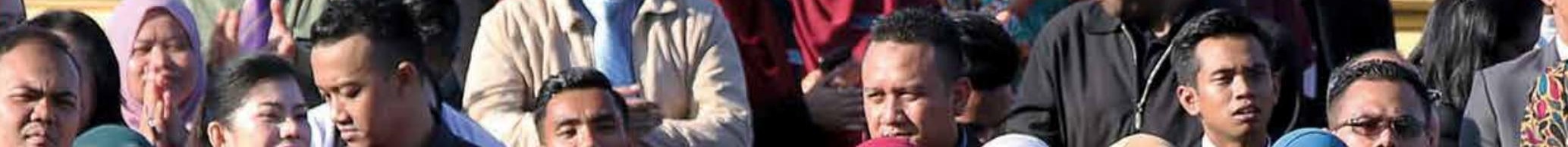

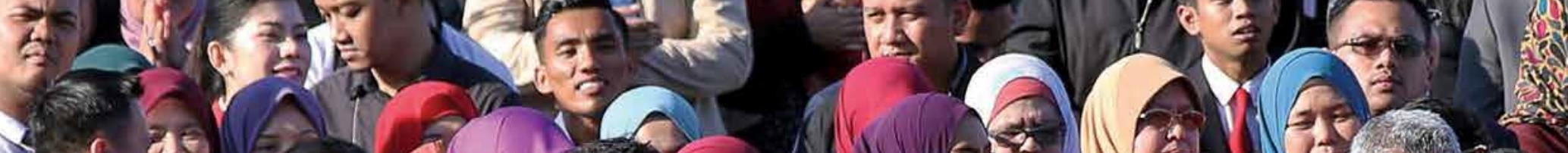
(2) (4)

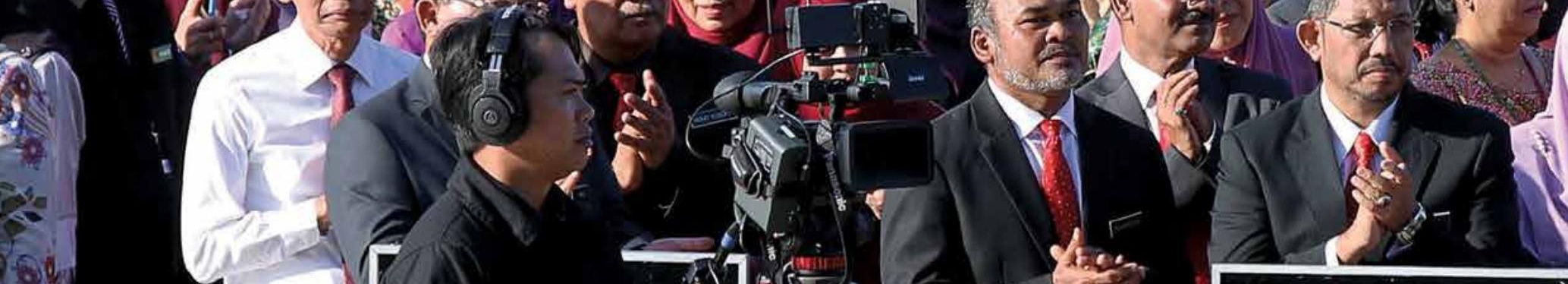
a) Tus 2 thive 
(a) (2) (2)

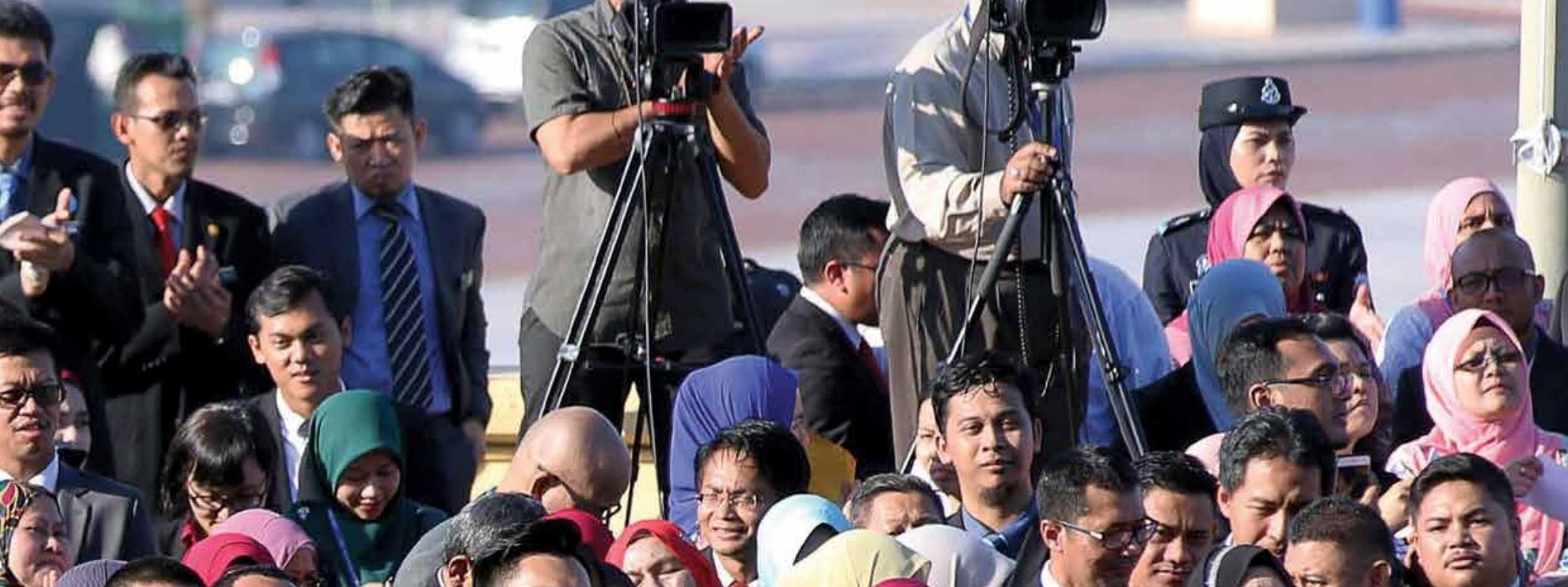

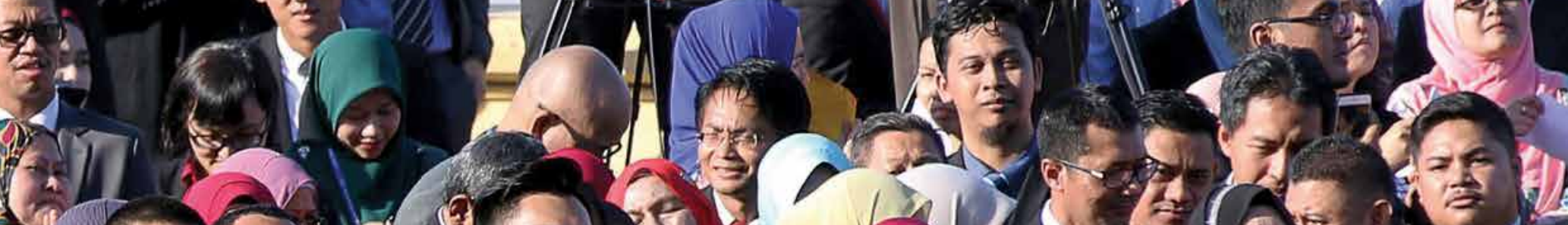

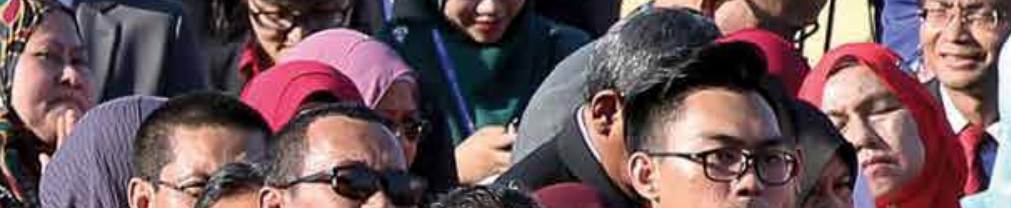

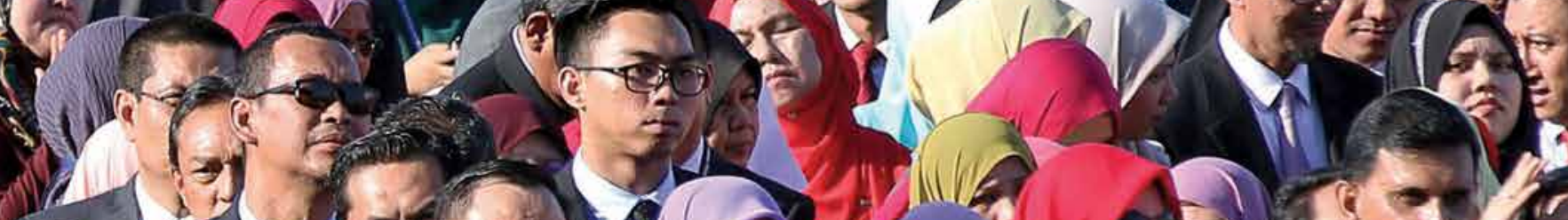

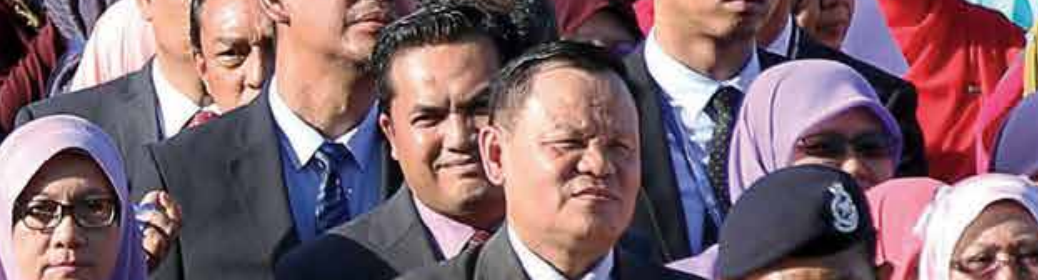
1 $47)^{3}$

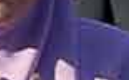
(1) (1) 178
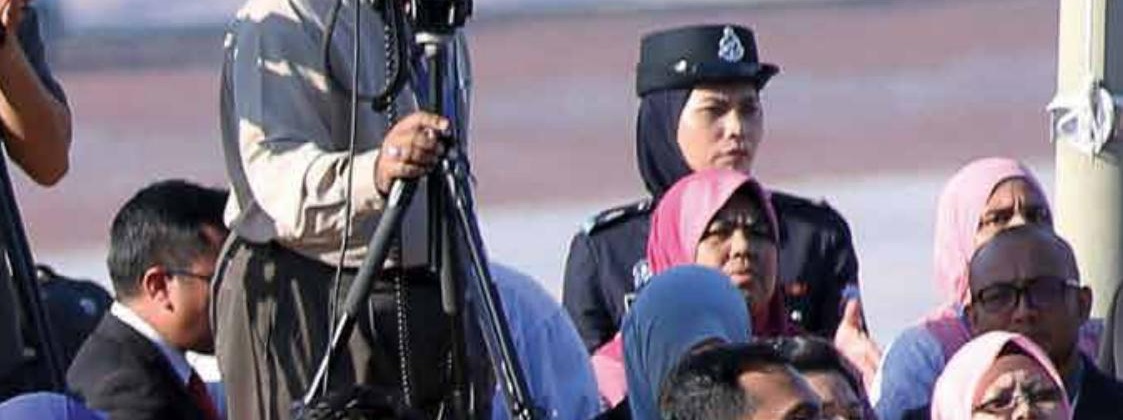


\section{Re-energizing the public service}

\section{The public service plays a vital role in Malaysia's transition to a high-income and developed economy}

There is a well-established connection between institutional quality and economic growth. Strong public institutions underpin successful economic growth and development, with recent research demonstrating the relationship between the existence of a strong, merit-based public service and higher rates of growth. While the developing EAP countries have benefited from relatively good economic governance, the challenges to enhancing state effectiveness are more significant now than they were at earlier stages of development.

Enhancing state effectiveness can be defined in terms of improving the capacity of government to clearly define objectives and priorities, and to attain them. The argument is as follows: the developing EAP countries seek to transition to higherincome status, they will face both pre-existing and new governance challenges, with increasingly rigorous demands on state institutions. Additionally, as policy makers try to facilitate the emergence of increasingly affluent, middle-class societies, they will face increased societal expectations regarding the range and quality of services delivered by the state. Therefore, enhancing state effectiveness is an integral part of making a successful transition to a higher state of economic development. Achieving this will require a renewed focus on not merely having the right form of institutions, but on ensuring the effectiveness of the functions of these institutions and how they are implemented. Malaysia's Public Service is at the heart of the institutional architecture that is necessary to facilitate the country's transition to a developed economy.

Thirty years ago, Malaysia's Vision 2020 (Wawasan 2020) expressed the aspiration of achieving the transition to an industrialized and developed country by 2020. Undeniably, Malaysia has made good economic progress and has introduced several reforms to realize this goal over these past decades. However, the pace of reforms and development has not been consistent as the country struggles to meet its goals within the 2020 timeframe. The explanations for this are many and varied but can at least be partly attributable to gaps that undermine the ability of the government to implement key policies needed to meet its development priorities. One such gap is the capacity of the public service, which is key to furthering the country's development agenda. This has come under criticism in the recent years and there are questions around whether the public service has the right people, skills and tools to perform its role effectively. Reforming the public service, including overall public sector governance, cannot be done independently from broader economic and social reforms. ${ }^{8}$ With the Vision 2020 approaching its end date, the government has decided to extend the timeframe for the achievement of the stated aspiration by a few more years. Given the importance of strong institutions for enhancing growth and ensuring shared prosperity, it is perhaps timely for this edition of the MEM to focus on the capacity of the public service in Malaysia.

This special topic looks at the state of Malaysia's overall public sector governance and, more specifically, the role and significance of the public service in that context, including through benchmarking with regional and global comparators. While it is well understood that governance encompasses a broad range of issues, including institutions, anti-corruption,? transparency, accountability, civic participation, the rule of law, amongst others, this MEM focuses on the people who are at the heart of public sector governance. Thus, it

${ }^{8}$ A flagship report on Malaysia's high-income transition is under preparation by the World Bank Global Knowledge and Research Hub in Malaysia.

${ }^{9}$ A report on Anti-Corruption that examines successful cases of tackling corruption around the world is under preparation by the World Bank Global Knowledge and Research Hub in Malaysia. 
focuses on public servants and the system by which they are managed. Along with the importance of effective human resources management (HRM) in the public service, the MEM stresses the importance of fostering transparency. The special topic examines not just recruitment, promotions and other HRM practices, it also explores the means by which an enabling, trust- enhancing environment of transparency and openness could be developed within the public sector. It further sheds light on the impact of digital technologies on human resources and the need for recalibrating skills in the public sector and to ensure that public servants are able to effectively support Malaysia's transition to a high-income and developed country.

\section{Malaysia's public service performs at par or ahead of the region, but shows a stagnant or declining trend and falls short of high-income comparators}

\begin{abstract}
Malaysia's transition from a low to upper middleincome country can be partly attributed to the strength of many of its institutions and their ability to effectively design and implement national development strategies. This includes the implementation of key policies focused on eradicating poverty and boosting growth through economic diversification and industrial expansion. Developing countries within and outside the region have been keen to learn from Malaysia's experience, particularly from the role that its public institutions played in facilitating the transformation of its economy from a largely natural resource-based, lower-income country to a modern and industrialized upper middle-income country. However, barring a few indicators like the World Bank's Doing
\end{abstract}

\section{FIGURE 31}

Malaysia performs well with low regulatory costs of doing business...

Doing Business Ranking, Selected Countries in EAP

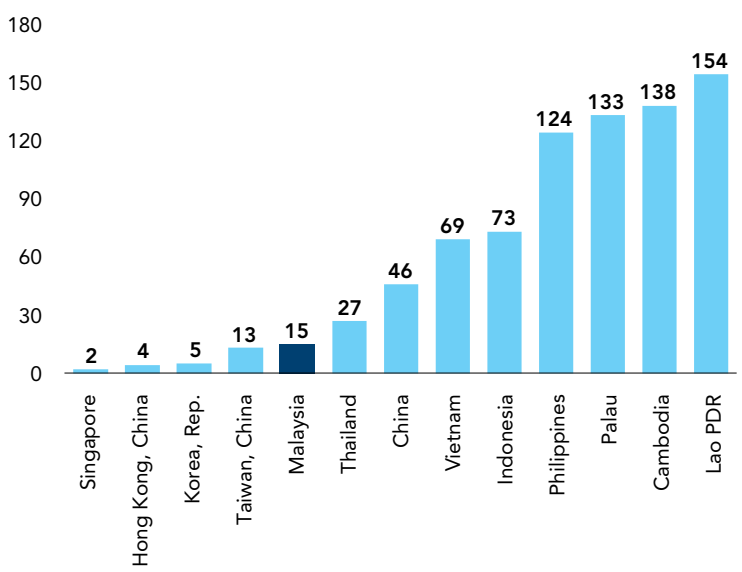

Source: World Bank Doing Business Index
Business Index (see Figure 31), where it is one of the top performers in the region, it's performance on other key indicators like the Government Efficiency indicator (see Figure 32) has remained largely stagnant or even declined.

Malaysia's performance is far less impressive when compared with that of OECD and other high-income countries (see Box 6). Although it seems natural to compare Malaysia's public service with that of other countries in the region, these may not be the most appropriate comparators in a period when Malaysia is transitioning to high-income and developed nation status. For example, while Malaysia is ahead of its regional peers on the government

\section{FIGURE 32}

...but performance has been largely stagnant on scores of government effectiveness

Government Effectiveness Ranking, 2018

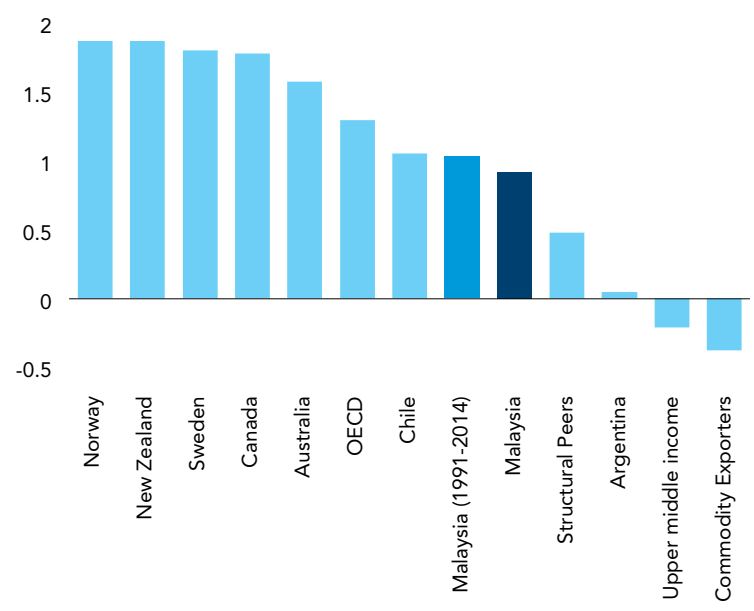

Source: World Bank Find My Friends using Worldwide Governance Indicators and Global Competitiveness Index 
effectiveness indicator, ${ }^{10}$ its progress has stagnated in recent years and lags behind the OECD average and other high-income countries on this measure. The index for voice and accountability is well below what would be expected given Malaysia's level of per capita income and some indicators like political stability and government effectiveness have worsened over time. This suggests that Malaysia has not been making progress in key areas of governance and public sector performance which leads to the question whether the public service has the right people, capacities, resources, values and motivation to meet the country's emerging needs.

Malaysia also lags behind both high-income and other upper-middle income countries in terms of openness, not just in the area of public service employment, but also on overall governance. Malaysia's relatively weak performance on the Open Government Index (OGI) $)^{11}$ is consistent with observations around the challenges faced by the research community in accessing government data (see Figure 33). While information on government and public sector plans, initiatives and programs is generally available and accessible online, there is as yet no right-to-information law or formal requirement to publish many of these documents. While there is some degree of civic participation, it is not always clear how feedback is collected and integrated into the policy design process. Transparency regarding this process is important to foster an environment of openness and inclusiveness across the public sector.

\section{FIGURE 33}

Malaysia performs poorly in measures of open government...

Open Government Index, 2018

0.9

0.8

0.7

0.6

0.5

0.4

0.3

0.2

0.1

0
While efforts to modernize the public sector began in the 1990s it is unclear if the benefits have been fully maximized. During this period, Malaysia rolled out its Multimedia Super Corridor initiative to facilitate the country's transformation into a modern state by 2020. It was among the first few countries in the region to make a big push for the adoption of ICT to improve operational and service delivery efficiency in government through its Electronic Government (EG) initiative. The EG initiative helped accelerate the adoption of ICT in the public service, facilitating the provision of electronic services and the development of human resource management information and online payment systems. However, a number of issues pertaining to the interoperability of systems and streamlining back-end processes remain unaddressed. Thus, Malaysia lags behind aspirational comparators, including Singapore and South Korea, in indices related to the implementation of e-government (see Figure 34). The government acknowledges that while the number of government online services has grown, its ability to provide end-to-end online services (such as transactions with cashless payments) remains below target. The challenge is compounded by the rapid pace of urbanization, which results in higher expectations, and greater demands from citizens for better urban services (World Bank 2015a). To make the quantum leap from one of the better-performing public services in Southeast Asia to being on par with the public services of OECD countries, Malaysia will have to adopt a holistic approach to assimilate technology in the public service and make optimal use of digitalization.

\section{FIGURE 34 \\ ... but relatively better in the adoption of e-government}

E-Government Index, 2018

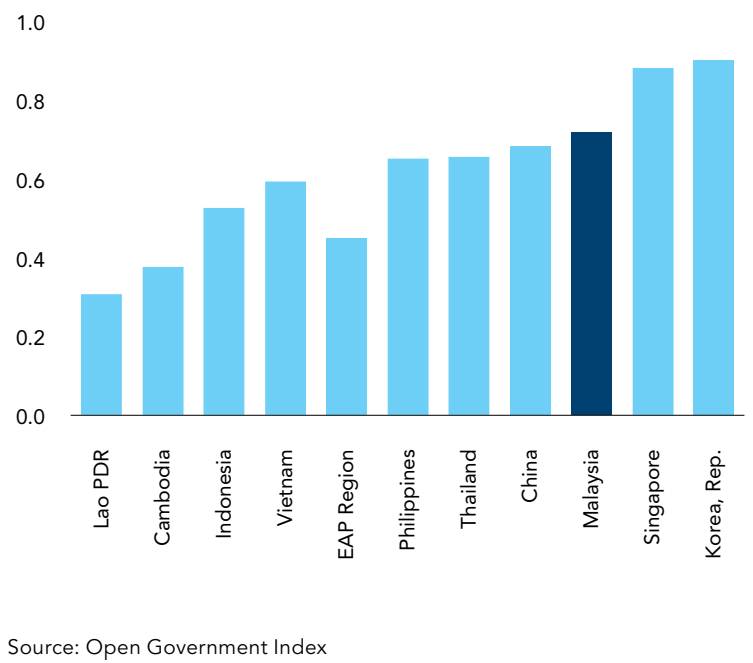

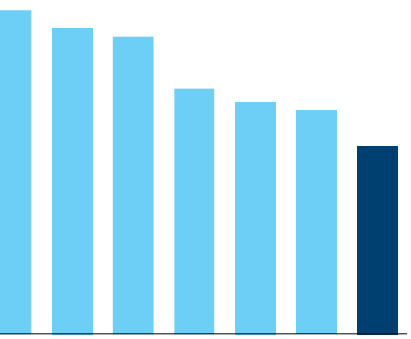

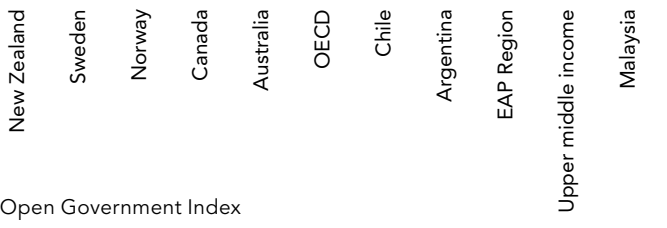

${ }^{10}$ The index captures perceptions of the quality of public services, the quality of the civil service and the degree of its independence from political pressures, the quality of policy formulation and implementation, and the credibility of the government's commitment to such policies.

11 The OGI covers four dimensions of government openness: publicized laws and government data, right to information, civic participation, and complaint mechanisms. 


\section{Dimensions of Malaysia's governance in comparative perspective}

The Worldwide Governance Indicators provide a basis to compare selective aspects of public sector effectiveness across countries. These indicators enable cross-country comparisons across a range of dimensions, including voice and accountability; political stability and the absence of violence; government effectiveness; regulatory quality; the rule of law; and the control of corruption. Performance in terms of these indicators is scored from -2.5 (weak) to +2.5 (strong).
In general, while Malaysia is at par or better than its regional comparators, its performance is stagnating and the gap between its performance and that of aspirational peers remains large and is widening. Most of Malaysia's regional comparators fall into the middle-income category. As Malaysia aspires to transition to a high-income and developed nation, where the degree of shared prosperity is a measure of developed success, it is appropriate that it should aspire to achieve levels of public sector effectiveness comparable to those of the OECD economies.

\section{FIGURE 35}

Malaysia's public service is at par with the region, but shows a stagnant or declining trend; and a huge and widening gap with high-income comparators

Worldwide Governance Indicators, Selected Dimensions, Comparative Performance for Malaysia, Developing EAP Region and OECD Countries, 2013-2017

Voice and Accountability

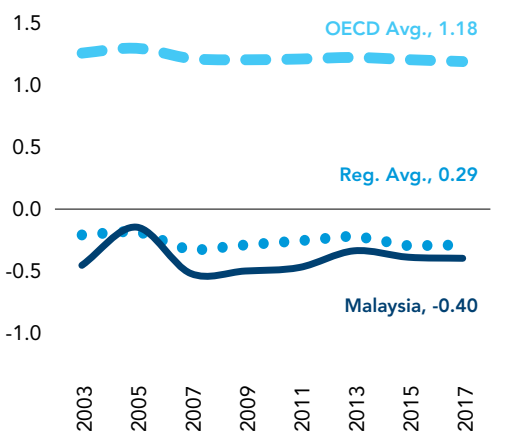

Regulatory Quality

1.5

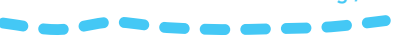

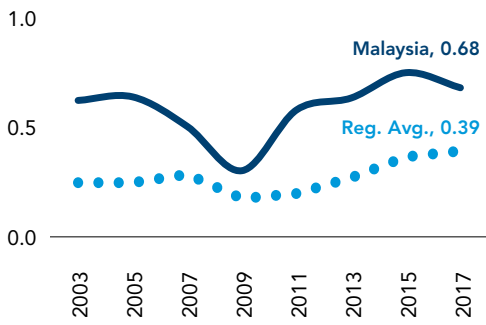

Political Stability and Absence of Violence

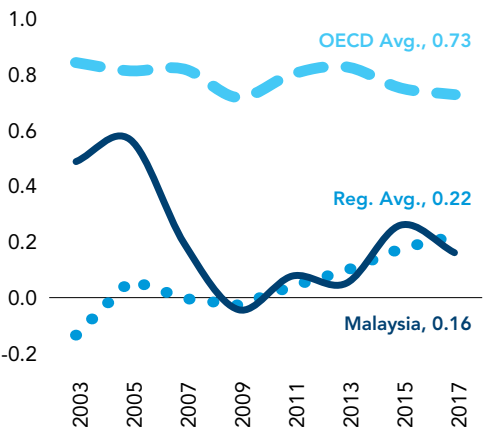

Rule of Law

1.5

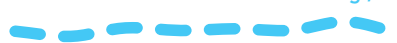

1.0

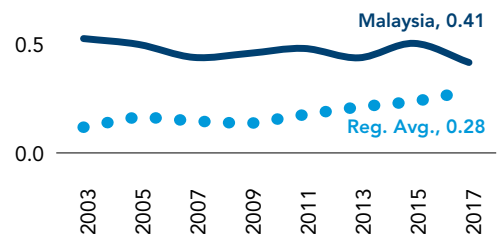

Government Effectiveness

2.0

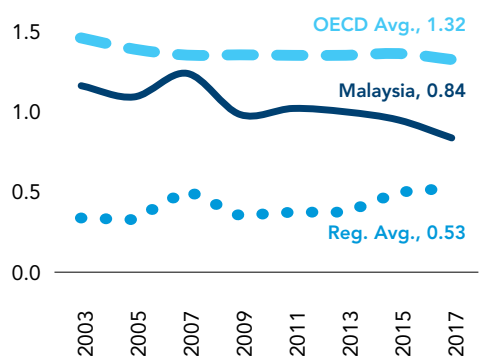

Control of Corruption

1.5 OECD Avg., 1.28

1.0

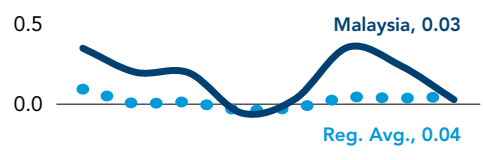

$-0.5$

రిิ 


\section{The public service faces challenges in fulfilling the emerging expectations of the people}

Like other East Asian countries with a growing middle-class, Malaysia faces rising expectations and increased demands from citizens for betterquality public service delivery and a more responsive public service. The instrumental role of Malaysia's public service in facilitating the country's socio-economic development since independence is widely acknowledged. People's expectations regarding the public service and delivery of public services remain high, with the current the Prime Minister often articulating his desire to restore the public service to its "glory days" in his speeches. Various efforts have been made to improve the quality of public service delivery, monitor its performance, and implement corrective measures. However, despite these efforts, there is a perception that the public service has not been able to fully internalize these reforms and there are gaps in implementation affecting service delivery outcomes. The public service is again under the spotlight, due to the government's current emphasis on good governance, transparency and integrity. In particular, the capacity of the public service to meet the emerging expectations and challenges as Malaysia transitions to a high-income country is being questioned.

In the recent MTR of the 11th Malaysia Plan, the issue of governance was elevated to the forefront. The 11th Malaysia Plan (RMKe-11), the most recent of Malaysia's national development plans, is intended to facilitate the achievement of the aspirations outlined in Vision 2020. While plans and strategies with defined targets have been well-articulated, it is the effective implementation of the same that has fallen short of expectations. In the MTR, the government acknowledged key constraints to improving public services and outlined a wider set of reforms aimed at rebuilding the public service, its people and institutions. A step in this direction was the increased focus on anti-corruption measures to restore integrity and accountability in the government (see Box 7). The National Anti-Corruption plan and the creation of an overarching agency to monitor progress towards its implementation are a good start to tackle corruption.
However, the actual challenge, based on experience from other countries, lies in maintaining the courage to implement and sustain these reforms in the face of resistance. While experience shows that this has often been difficult, it is not impossible with strong leadership, commitment and determination.

\section{A culture of greater openness involves risk, but would go a long way towards building trust in government}

Past assessments by the World Bank have indicated the existence of gaps in Malaysia's public service, and particularly its HRM, that impede the delivery of high-quality services. Governments can only be effective if their public servants are motivated and able to effectively implement policies, programs and deliver services (Bureaucracy Lab, World Bank). To achieve this, the role of HRM should not be limited only to personnel management, but it should effectively support public institutions to achieve their objectives. The assessments have revealed a disconnect between HRM systems and stakeholder expectations regarding the type of public service and administrative capacities needed to support Malaysia's transition. Malaysia's overly-centralized HRM system, with a career public service system that does not fully leverage the skills and professional talents of the public servants, complex remuneration practices, and a lack of market alignment between pay and recruitment are some of the areas of concern. 


\section{Re-centering governance, integrity and anti-corruption in Malaysia}

\begin{abstract}
Malaysia's May 2018 general elections ushered a new coalition government into federal office for the first time since peninsular Malaya's independence from Great Britain in 1957. Onethird of the incoming Pakatan Harapan government's election manifesto was centered around issues related to governance, with a strong emphasis on enhancing integrity across public institutions; curbing corruption; reforming the Parliament and the judiciary; and improving the electoral system. The new government has established a framework for reform; introduced changes to the process of formulating policies; and developed a system to monitor progress with an aim to institutionalize good governance and integrity at all levels of government.
\end{abstract}

The government has established the National Centre for Governance, Integrity and AntiCorruption (GIACC), which reports directly to the Prime Minister. It has also established the Cabinet Special Committee on Anti-Corruption (JKKMAR), chaired by the Prime Minister himself. GIACC has been given the mandate to coordinate and monitor all initiatives related to governance, integrity, and anticorruption. The National Anti-Corruption Plan (NACP) (2019-2023), launched in January 2019, envisions Malaysia as a corruption-free country, to be achieved through improving the accountability and credibility of the judiciary and prosecution and law enforcement agencies; increasing efficiency and responsiveness in public service delivery; and ensuring integrity in business.

Since the formation of GIACC on June 1, 2018, it has implemented close to 80 initiatives. Key measures include the establishment of parliamentary select committees, comprising of parliamentarians from both sides of the house; a policy on the declaration of assets by administrative and parliamentary members; and a directive banning political appointments to head of mission posts. Several other initiatives related to strengthening governance and integrity and eradicating corruption are in progress, many of which require a two thirds majority of the Parliament to amend the Federal Constitution, including initiatives to limit prime ministers' terms to a maximum of two and to ensure the separation of powers and responsibilities between the executive, the legislature and the judiciary.

Key reform initiatives that are in the final draft stages include:

- Reviewing the entire electoral process, including the area of political financing, by the Election Commission.

- Establishing an Independent Police Complaints and Misconduct Commission.

- Limiting the involvement of administrative members (politicians) in the appointment of secretary generals and director generals, to empower the public service.

- Enacting the Malaysian Ombudsman Act to replace the Public Complaints Bureau.

- Forbidding political appointees to government linked companies (GLCs).

- Formulating Procurement Act (under preparation) to ensure transparency and best value for tax payers' money.

- Improving the transparency and integrity of budgets by: i) conducting a mid-year budget review; ii) formulating tighter criteria and imposing greater scrutiny for off-budget allocation; and iii) ensuring the recording and monitoring of public expenses in accordance with the established financial procedures.

Another 115 initiatives, as outlined under the NACP (2019-2023), are currently in progress. 


\section{Malaysia's public sector size and wage bill has been an issue of concern}

\begin{abstract}
With Malaysia's population of approximately 32 million, its public service employs about 1.7 million people, accounting for $\mathbf{1 1 . 4}$ per cent of total wage employment. This means that there are approximately 5.3 public servants to every 100 Malaysian citizens. There are seven branches of public services, with these being the General Federal Public Service (consisting of schemes such as the administrative and diplomatic service or PTD); the public services at the State level; the Joint Services (common to the Federation and one or more of the state governments) $i^{12}$ the education service; the judicial and legal service; the armed forces; and the police force. In Malaysia, the term 'civil service' is generally used to refer to the civilian or non-disciplined components of the wider public service, thus excluding the armed forces and the police force. Close to onethird of the total number of civil servants are employed in the education service alone, while another 14 per cent are employed in the health sector. The General Federal Public Service employs 39 per cent of the total number of public servants.
\end{abstract}

Comparing the size of the public service across countries in terms of numbers and wage bill can be challenging due to non-standardized definitions and categorizations of government employment around the world. In addition to issues related to the availability of reliable government employment statistics in many countries, the difficulty is compounded by the fact that public employees can be categorized in various ways according to their occupation, employment status and who pays their salaries. For example, local government employees paid from the central budget might be categorized as local government staff in some countries, while in others they may be categorized as central government staff. Similarly, various monetary and non-monetary benefits may be accorded to public servants at different levels, adding to the complexity of comparing public sector wage bills across countries. Other than wage bill and employment, the overlaps and duplication, budget optimization, implementation efficiencies and effectiveness can also contribute to complicating the size issue in the public sector.

Despite these challenges, a number of indices and measures may provide useful insights into employment levels and wage bill sustainability.
These can be used to assess the affordability and sustainability of the wage bill and to determine whether it is consistent with the operation of a motivated and professional public service. The relative size of government employment and the public sector wage bill can be broadly assessed through some of the following indicators:

- Public sector wage bill as a percentage of GDP: Developing countries tend to have smaller governments relative to GDP and consequently a lower ratio.

- Number of government employees as a percentage of the total population: Governments acting as an employer of last resort have often taken on large numbers of public servants in the lowest grades on meager wages.

- Number of government employees as a percentage of total employment: This metric is similar to the preceding one, but it corrects for developing countries that have a relatively high proportion of children in the population, leading to a relatively low public servant to population ratio.

- Public sector wage bill as a percentage of total public sector spending: In order to deliver quality public services, governments will need to spend money on goods and services as well as on wages and salaries.

- Recruitment growth rate: When government recruitment grows faster than GDP, revenue or population growth, it is clear that either financial stability (growing deficits) or future performance (through reduced wages or reduced non-wage expenditure) may be jeopardized.

Cross country comparisons show that while Malaysia's public sector wage bill is tracking below regional averages, it has increased in proportion to total public spending during recent years (see Figure $\mathbf{3 6}$ and Figure $\mathbf{3 7}$ ). Malaysia's wage bill as a share of GDP has tracked just below comparative averages, at 5.6 percent of GDP in 2018. However, as a share of total public expenditure, spending on personal emoluments has increased steadily over the last twenty years, from a low of 17.6 percent in 2002, to a peak of 29.3 percent in 2017 , driven primarily by expenditure

${ }^{12}$ See Article 133 of the Constitution. 
FIGURE 36

Malaysia's government wage bill has been tracking below the average of comparators...

Central Government Wage Bill as a Percentage of GDP Plotted Against Log of GDP per Capita, Malaysia: 2000-18 and Comparator Countries for Most Recent Year Available

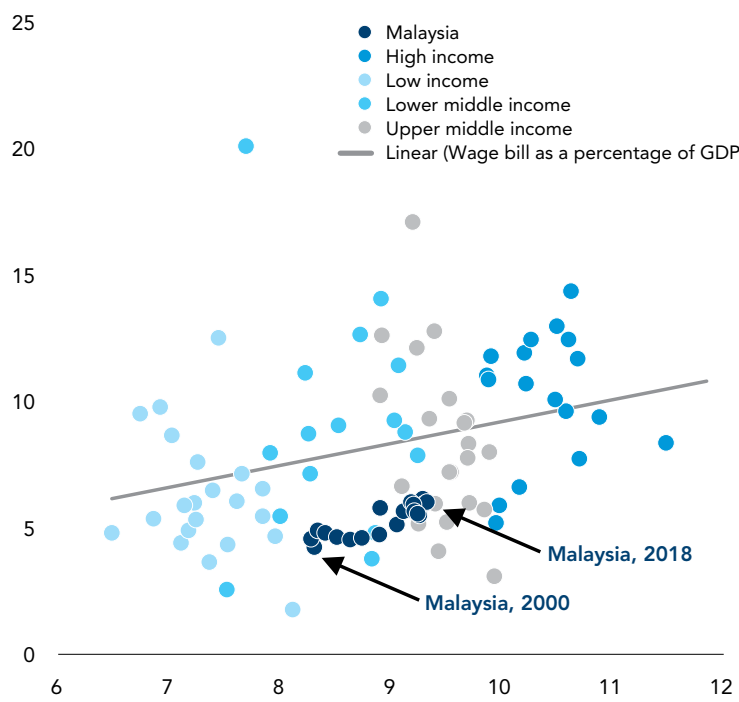

Source: World Bank staff calculations based on Worldwide Bureaucracy Indicators and MOF Malaysia data

consolidation across non-wage categories. The World Bank's 2011 Public Expenditure Review (PER) found that Malaysia was already at the upper end of wage bill affordability compared to some of the higher-income countries it aspires to emulate. The emolument-torevenue ratio indicated that Malaysia was spending a larger share of its revenues (about 27 percent in 2009) on its wage bill than a number of countries, including Canada (13.7 percent); Norway (12.5 percent); Australia (10.6 percent); and South Korea (9.6 percent). This percentage has steadily increased to 34.3 percent for Malaysia in 2018.

The significant increase in the wage bill since 2010 can be attributed to a large increase in the number of public servants; an increase in the number of posts; the conversion of contract staff into regular employees; and increases to salaries and allowances. Over this period, there was a rapid increase in the number of public servants, from about 1.2 million in 2010 to about 1.7 million in 2019. The World Bank PER analysis shows that the number of public service posts increased by 25 percent in the period from 2006 to 2010. The largest annual increase occurred in 2008 (in excess of 8 percent), with the growth rate slowing considerably to 1.7 percent by

\section{FIGURE 37}

...but has risen as a share of public expenditure over recent years

Central Government Wage Bill as a Percentage of Public Expenditure Plotted Against Log of GDP per Capita, Malaysia: 2000-18 and Comparator Countries for Most Recent Year Available

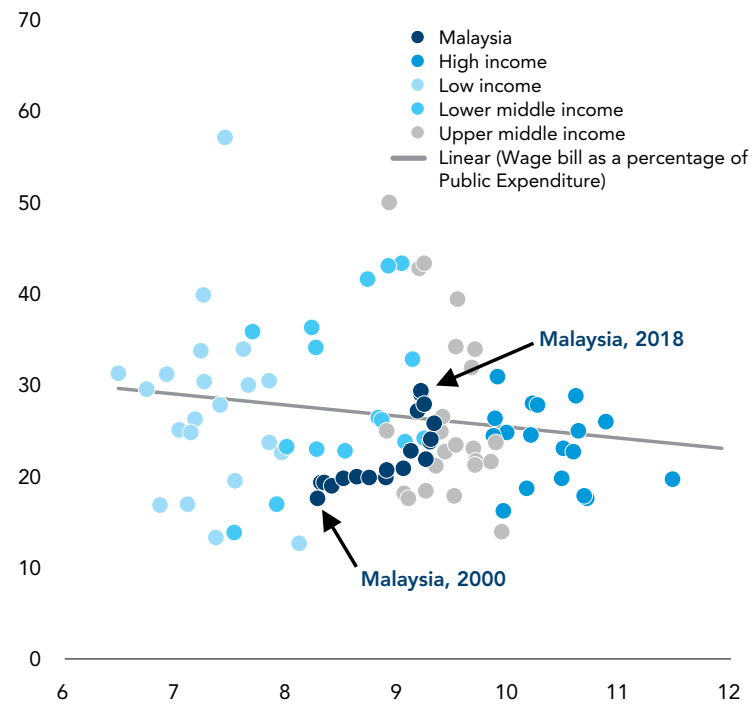

Source: World Bank staff calculations based on Worldwide Bureaucracy Indicators and MOF Malaysia data

2010. The growth in establishment positions over this period could be attributed to an increase in posts at all government levels, but particularly in federal agencies, where the number of posts increased by around 27 percent compared to 11 percent for state and locallevel posts. Other reasons for the increase in the wage bill include the increased conversion of contract and casual staff to full-time federal employees in the period from 2013 to 2017. The wage bill further increased as a result of increments in salary in 2012, 2013 and 2016, coupled with enhancement of allowances over the past few years.

The World Bank's analysis of public sector wages across 130 countries revealed a huge variation in public sector wage premium compared to private sector salaried employees depending on level of employment and choice of comparator. The size of the premium across countries varied significantly by worker characteristics (e.g. education, occupation, skills and gender) and was sensitive to the choice of the private sector comparator. ${ }^{13}$ In more than half the countries and occupations in the sample, public and private formal sector earnings did not differ significantly, except in occupations where there was a large amount of heterogeneity. Overall, and consistent

${ }^{13}$ The analysis draws on data from the World Bank's Worldwide Bureaucracy Indicators, a country-level data set containing public sector labor market indicators produced by the World Bank. 


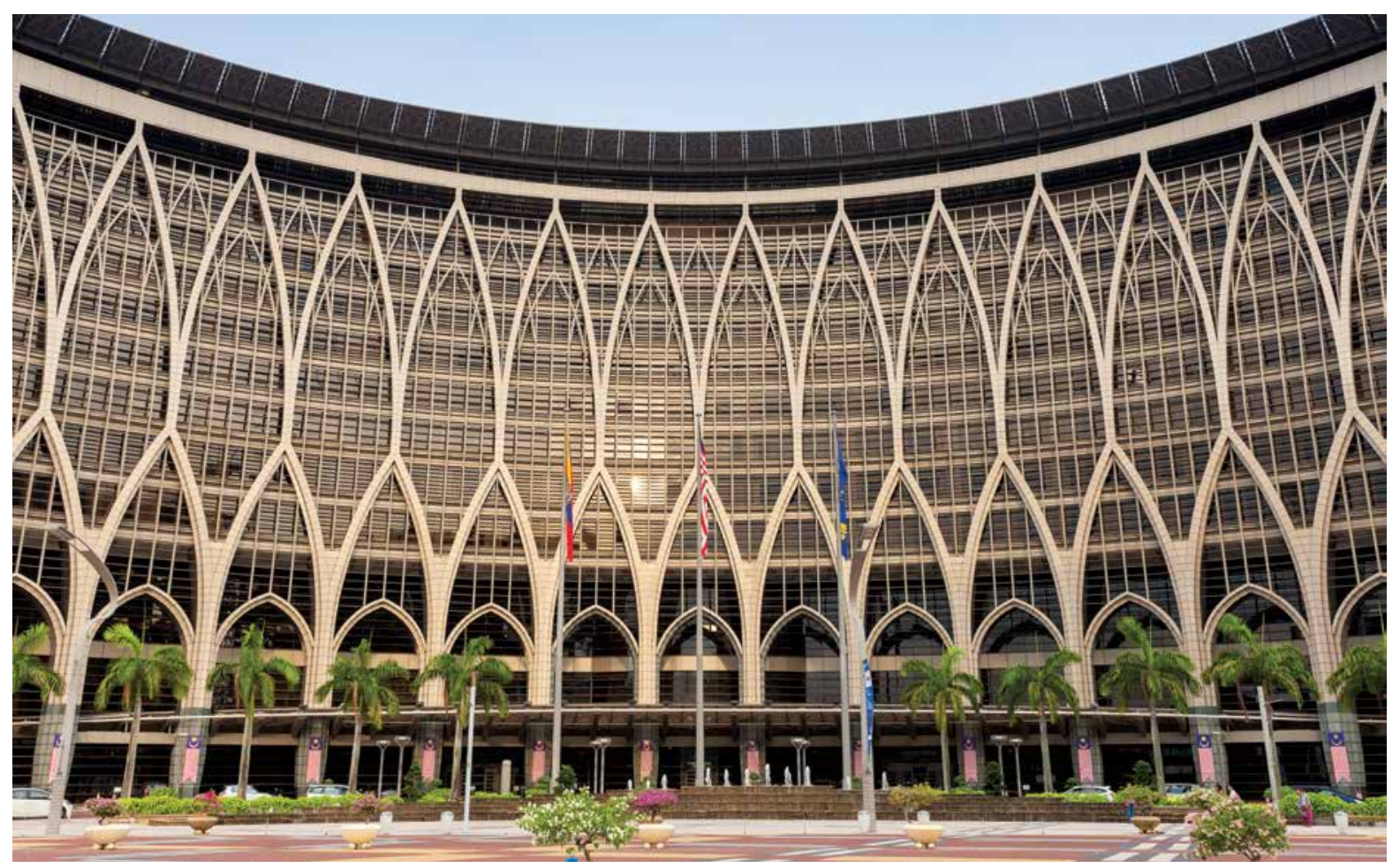

with the previous literature, the public sector premium was found to be larger in developing countries than in high-income countries. The public sector is more likely to pay premiums for clerks and workers in elementary occupations, but less for senior officials, professionals, and technicians. While recent data for Malaysia is not available, analysis carried out for the World Bank's PER presented a consistent set of findings to show that the public sector wage system was compressed, suggesting that jobs at the higher echelon provide less income growth than equivalent jobs in the private sector for the same skills. However, the compression ratio can change significantly when allowances and other benefits offered in the public sector are included in the comparison.

While wage and employment statistics are indicators that can serve as a useful starting point for a deeper and more nuanced analysis, policy recommendations cannot be based on these statistics alone. Evidence from international studies shows that decisions related to public sector pay and employment reforms and their timing can be situational and highly country context specific. A comprehensive employment and wage reform agenda would involve a detailed process, including wide-ranging consultations with stakeholders. Measures that artificially reduce the scope of the public service (for instance, excluding the armed forces) do not change anything except the definition of the public service. While the size of employment and the public sector wage bill provides information regarding the resources allocated to maintain the bureaucracy, these statistics do not shed light on the administrative capacity or the quality of service delivery. Nor do they indicate whether the size of the public service is appropriate, as public employment is a matter of national policy preference. Nevertheless, as a country moves towards achieving high-income status, it is likely to require increasingly specialized and more sophisticated skills that entails the organization of workflows and structures that support the transition (see Box 8). This needs to be complimented by a country's ability and efforts to enhance revenues that would ensure the sustainability of the wage bill in the long run.

While public sector management covers a wide range of issues and areas, all of which require attention, this report focuses on the government's efforts to improve the public service. It takes a closer look at the most important elements of public sector governance, these being: (i) the management of the public service itself; (ii) the government's role in encouraging an open, and transparent environment in the public sector through the establishment of the appropriate institutional, policies and legal framework; and (iii) the impact of new and emerging trends, including technological innovations and digitalization on employment in the public service. 


\section{An example of how the public service can experience both staff shortages and excesses at the same time}

\begin{abstract}
Malaysia's statistical system can be used as an example of the reforms and restructuring required to meet emerging challenges. In 2016, the Economic Planning Unit commissioned the World Bank to carry out a strategic review of Malaysia's statistical system. This involved a forward-looking analysis of the legal, institutional, organizational, and technical reforms needed for the system to support the information needs of a modern, developed and high-income country. The review provides several insights that are applicable more generally to modernizing the public sector.
\end{abstract}

To benefit from technological change, the composition of government personnel will need to change. Leveraging digital technologies requires a highly-skilled work force that is capable of designing, managing and interpreting the flows from advanced information systems. At present more than 85 percent of positions at the Department of Statistics Malaysia (DOSM) are relatively low-skilled clerical and support positions, with less than 15 percent consisting of professional and managerial positions. DOSM aims to gradually reverse those proportions, in a manner similar to Statistics Netherlands when it transformed its operating model. Statistics Netherlands reduced its number of managers in the process, as the more technologically skilled workers require less management oversight.

Budget realities imply that a more sophisticated public service tends to be relatively smaller, with a greater proportion of positions requiring high-level skills. Few governments can afford to significantly expand their number of highly skilled employees without making cuts elsewhere, including in the total number of employees. If one assumes a fixed budget, increasing the number of highly skilled staff typically entails the elimination of many more lower-skilled positions simply because higher skill levels come at a higher price. This is enabled by the labor-saving aspects of digital technologies. In the case of Statistics Netherlands, after its modernization exercise, it employed 40 percent fewer people with a 50 percent increase in output, a lower total budget, a more diverse array of products and services, and a substantial decrease in firms' data reporting burden. As the public sector is generally slower to shed workers than the private sector, this process may take time. However, it can be accelerated by retraining, redeployment, and incentives for early separation from the public service.

Modernizing the government service typically entails the adoption of new organizational structures. The optimal means to organize the work flow for a smaller, more skilled work force using advanced technologies will differ considerably from the means to optimize a larger, less skilled work force. In the case of national statistical offices, in many advanced countries, this has meant shifting from "vertical stovepipe" systems organized around particular statistical products (such as surveys and national accounts) to "horizontal" models that are organized around statistical processes that cut across different products (such as data collection, analysis and dissemination). Public sector entities have diverse missions and operational processes, making it difficult to generalize how these organizational changes should be planned and implemented. However, it is a virtual certainty that changes to the size, skills, and tools of the agency will require new ways of organizing work. 


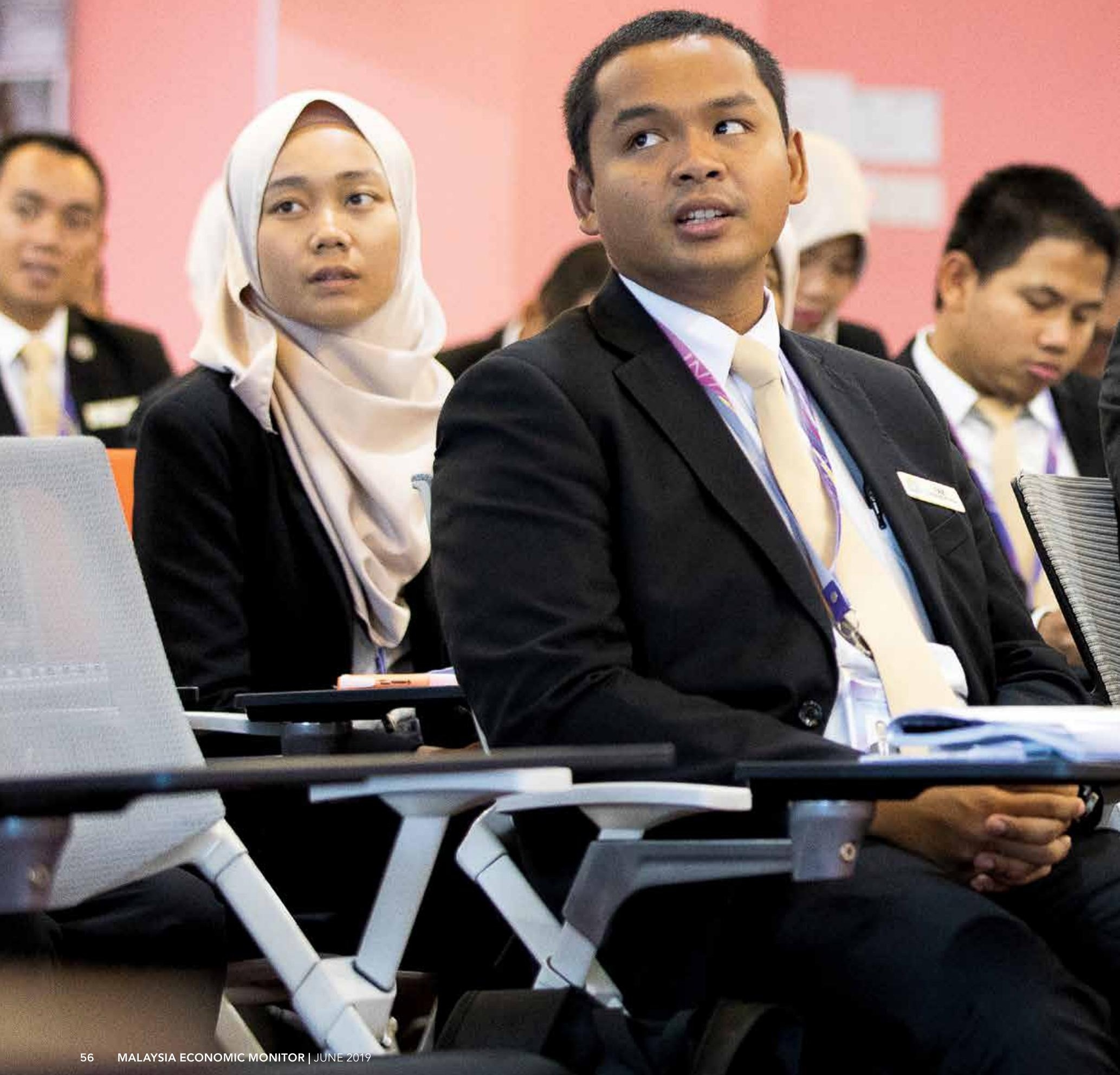




\section{So, how can Malaysia re-energize the public service to achieve shared prosperity?}

Building the capacity of the public service workforce is key to the successful implementation of public policies and to the achievement of national priorities. Given the strong relationship between HRM and organizational performance, it is important to have an effective HRM strategy that is able to attract, manage and retain the best talent. Such a strategy should include a transparent performance management system to determine rewards and promotions. Managing this is becoming increasingly challenging, with the public sector continuing to compete for top talent while having to deal with disruptions affecting public employment, including those related to the ever-evolving state of ICT innovation. At the same time, elements of Malaysia's public service already perform to a high standard and present useful lessons for broader reform. ${ }^{14}$ Further discussion of these challenges and an examination of the means by which Malaysia can foster an open, transparent, fair and neutral public service and of the measures it could implement to catch up with the high-income countries it aspires to emulate is covered below.

\section{Merit-based recruitment, decentralization, and the use of competency frameworks to induct the best talent}

There is ample evidence to support the proposition that bureaucracies characterized by meritocratic recruitment ${ }^{15}$ and predictable, rewarding career paths are associated with higher economic growth rates. Put simply, governments that recruit and promote based on merit have better growth performance than those that do not. This is relevant to Malaysia's aspiration to achieve high-income and developed nation status, as its public service plays a key role in facilitating national development. Good human resource policies are the most powerful tools to attract and retain the best talent required to ensure that the public service has the capacities and capabilities it needs to fulfil this role effectively. In developed Commonwealth countries, such as Australia, Canada, New Zealand, Singapore and the United Kingdom, there is a long-established tradition of merit-based recruitment and selection methods, with public servants at all levels recruited and promoted based on clearly-formulated, transparent and well-established practices.

Malaysia's public service is perceived to have an over-centralized system, characterized by a lengthy recruitment process and other suboptimal practices. A recent study of public sector HRM in nine Southeast Asian countries suggests that Malaysia's public service is the most centralized in the region. In Malaysia, most recruitment is handled centrally by the Public Service Commission (PSC), with inputs from the Public Service Department (PSD). The overcentralization of the system limits the strategic role that central agencies should play to detect, strategize and respond to emerging issues and challenges that may affect the capabilities of the public service. Over-centralization also limits the discretion and the flexibility of line ministries and agencies to make timely

\footnotetext{
${ }^{14} \mathrm{BNM}$ is one of the public institutions in Malaysia whose HRM processes is independent from the government. The central bank's human capital management framework strives to attract, retain and develop high quality talent. This encompasses several comprehensive initiatives including the awarding of scholarships to outstanding students and to current staff to pursue post-graduate studies at selected top universities around the world, as well as putting in a robust and clear succession plan. BNM also continuously improves its performance evaluation framework, with performance-based pay and evaluation frameworks, and plans to implement a 360-degree feedback system in 2019 which will allow for a more holistic approach to performance. The institution also invests significantly in staff training and development, with a total training budget at about 4-6 percent of gross salaries. Diversity is also at the forefront with women making up 43 percent of senior management, 55 percent of managers and 57 percent of first level executives. About 60 percent of the workforce are from Gen $Y$ and $Z$ (below the age of 40). BNM has been featured in various employment surveys as one of best places to work in Malaysia.

${ }^{15}$ The key feature of a meritocratic civil service is that it restricts politicians' power over their administrative agents. Meritocracy is understood as broadly comprising a number of forms. In the narrow, Weberian sense, it refers to a career-based public service, with entry through competitive exams, and government by principles of political neutrality.
} 
decisions related to their own human resource needs. Although the PSC has transitioned to using online methods in recent years, it can still take well over a year for an applicant to complete the recruitment process. Delays in recruitment have the potential to affect implementation, with vacancies not being filled on time.

The rigidity of Malaysia's recruitment system makes it challenging to recruit the best and brightest applicants. Recruitment is based on "schemes of service" that are very well established, but that are predominantly career-based rather than position-based. Once a person is recruited into a scheme of service, he or she is recruited into a career, but not necessarily a position. While over the years Malaysia has massively reduced the number of schemes of service, it is time to take a fresh look at the classification of the main categories of post. Schemes of service are found mainly in other middle and low-income Commonwealth countries, including Kenya, Mauritius and Nigeria. High-income countries such as Australia, Canada, New
Zealand and the UK instead base their HRM practices on a competency-based framework. With the current system, there are growing concerns that the bestqualified Malaysians do not generally apply for entry into the public service due to better, more rewarding opportunities elsewhere. The government has faced challenges related to the requirement that recipients of government scholarships serve in the public service, as is mandated by the terms of their scholarships. This is due not only to the poor enforcement of contracts, but to the lack of appeal that careers in the public service holds and to the unattractive jobs and roles that are offered to the recipients.

Increasingly, advanced countries utilize competency frameworks to recruit candidates with the appropriate level of skills, knowledge and capabilities into the public service and to ensure adherence to high moral and ethical standards for their appointment and promotion. These countries have been developing these frameworks over at least

\section{TABLE 5}

Examples of 'leading and communicating' competencies from the UK civil service

Competency framework for Level 6 (Director General and Director)

\section{Effective Behavior People who are effective are likely to.. \\ Actively develop and protect the reputation of the Department and the Civil Service - create a sense of pride and passion for public service}

Ineffective Behavior People who are less effective are likely to...
Overlook opportunities to champion achievements, difference and external experience in the Department and the Civil Service
Shape, promote and exemplify desired Departmental and the Civil Service values and culture
Act in ways which are at odds with desired culture and values - damages the Civil Service leadership reputation internally and externally
Be highly visible and credible at the most senior levels across and outside the Civil Service, communicating purpose and direction with clarity and enthusiasm

Engage positively in debate, surface tensions and resolve ambiguities across the Civil Service

Demonstrate insight into the link between the moral and business case for equality and diversity and achieving organizational priorities

Negotiate with and influence external partners, stakeholders and customers successfully at the highest levels
Lack confidence or impact at high levels, struggle with media spotlight, miss opportunities to communicate messages or give a confused or uninspiring narrative about what's important

Operate independently, rarely asking for input from senior colleagues and communicating infrequently

Disregard the link between the moral and business case for diverse and sustainable outcomes

Lack insight into the different motivations and agendas of the variety of stakeholders 
two decades, with increasing sophistication, and the frameworks that they utilize for different levels of employment are in the public domain. An example of a competency framework for effective behaviors expected from a senior public servant in the UK civil service in relation to the 'leading and communicating' competency is presented below (see Table 5).

Unlike Malaysia, in a number of high-income countries, both entry-level and senior promotion appointments are subject to open competition. In Malaysia, like in many other low- and middleincome countries, open competition applies only for entry-level appointments in the public service. Entry-level processes and promotion appointment processes are handled separately by the PSC and the PSD respectively. In Singapore, it is the PSC that is responsible for making appointments and granting promotions to senior management ranks. In New Zealand, even CEO (equivalent to Secretary-General) positions are filled by the State Services Commission (equivalent to PSC) after being advertised widely, including outside the country. Shortlisted candidates are required to present themselves at an assessment center for evaluation as an integral part of the selection process, and not merely for confirmation of their appointments, as in Malaysia. The interview panel members include the Commissioner, the Deputy State Services Commissioner, a panelist proposed by the responsible minister, and other people the Commissioner selects for their expertise relating to the business of the department and sector concerned. Such a process instils a sense of ownership within the hiring department, with full and due consideration given to the specific requirements of the position. The UK civil service appointment panels similarly recruit on the principle of open competition (see Box 9). The principle was given the force of law with the promulgation of the UK's Constitutional Reform and Governance Act 2010.

\section{Basic rules for recruitment and promotion in the UK civil service}

\begin{abstract}
"The need to avoid nepotism and favoritism means that you need to take great care when appointing someone from outside the civil service, or when promoting someone from within it. The basic rules for these appointments are as follows.

- All such appointments must be made on the basis of fair and open competition.

- All prospective applicants must be given equal and reasonable access to adequate information about the job and its requirements, and about the selection process.
\end{abstract}

- All applicants must be considered equally on merit at each stage of the selection process.

- Selection must be based on relevant criteria applied consistently to all the candidates.

- Selection techniques must be reliable and guard against bias.

You cannot therefore appoint someone to a job without an advertisement and competition, even if you believe them to be ideally or uniquely suitable." 


\section{Ensuring fair and neutral employment in the public service}

\begin{abstract}
Malaysia fares poorly on citizens' perceptions regarding equal treatment in public sector employment, ranking below the regional and OECD average in terms of the impartiality of public administration. Fair and neutral employment terms facilitate the emergence of a more diverse, resilient, and innovative workforce that is responsive to market demands and the needs of the country. In its election manifesto, the current government promised to establish an Equal Opportunity Commission to address discriminatory work practices in both the public and private sector. This is timely, with Malaysia ranking in the lowest place out of a group of selected comparators in the Institutional Profiles Database's perception survey regarding equality of access to public sector employment (see Figure 38). It also ranks way below the OECD average in the Quality of Government's (QoG) perception survey regarding the impartiality of public
\end{abstract}

\author{
Fair and neutral \\ employment facilitates \\ the emergence of a more \\ diverse, resilient and \\ innovative workforce
}

administration (see Figure 39). However, Malaysia has made progress in terms of inducting women into the public sector, with women filling close to 50 percent of the positions in Malaysia's public sector overall, with a higher share at the federal level (see Figure 40 and Figure 41). At the same time, there are ongoing challenges regarding the achievement of equal representation of men and women in leadership positions.

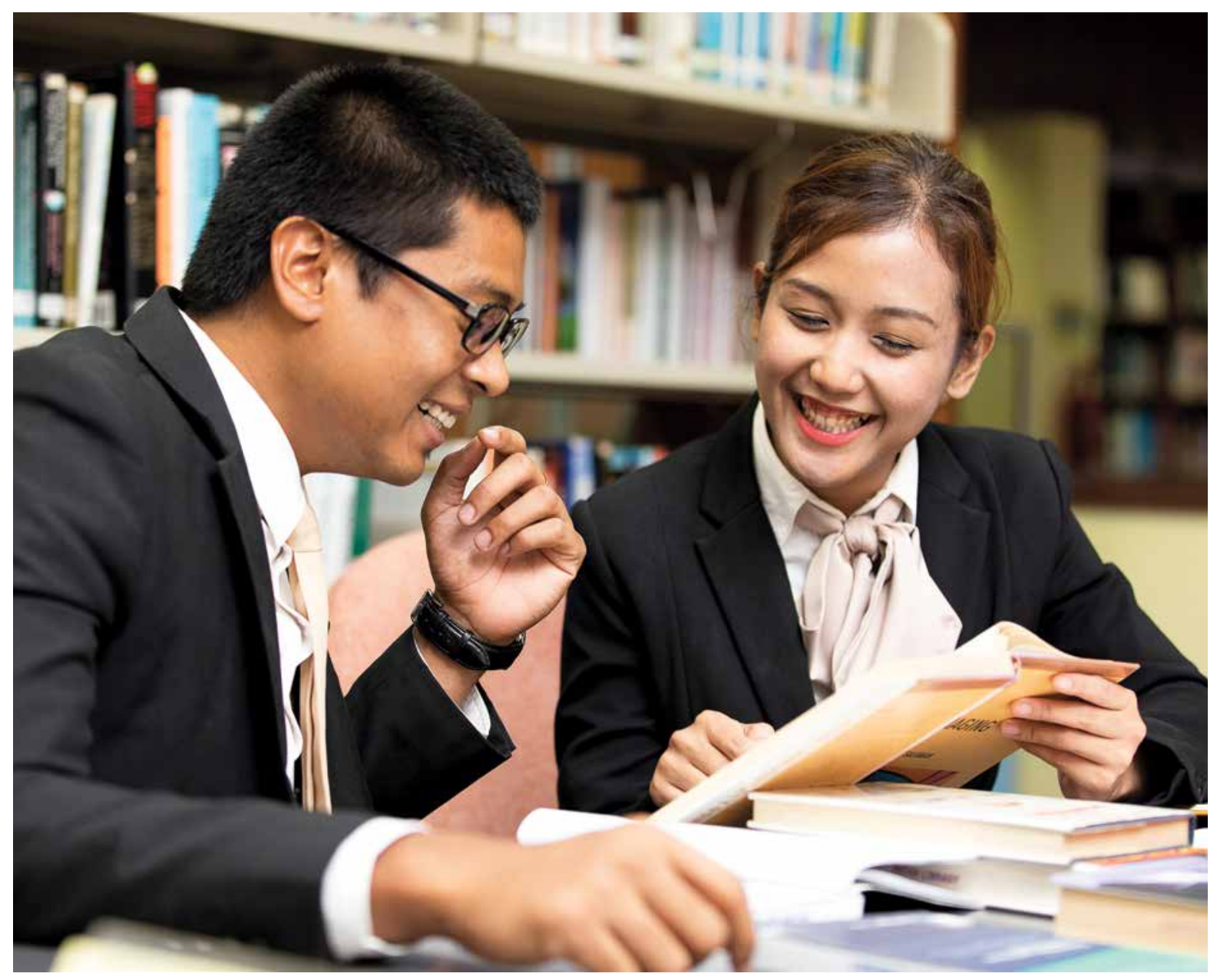


FIGURE 38

Citizen perceptions as to equal treatment in public sector employment are low...

Citizen Perceptions on Equal Treatment with Regard to Access to Public Employment, 2016

$$
5
$$

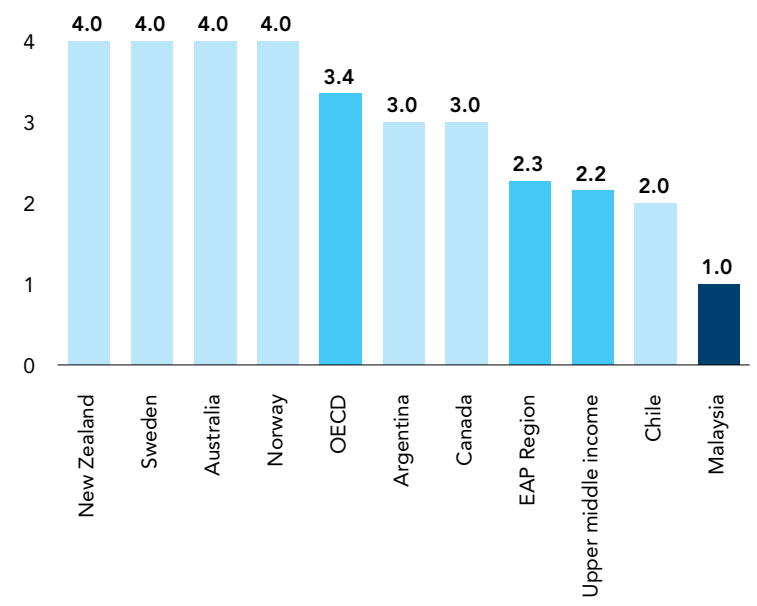

Source: Institutional profiles database

\section{FIGURE 40}

Women fill half of the positions in Malaysia's public sector overall, but the share is much lower outside the federal public service...

Gender Participation in the Malaysian Public Service, 2016

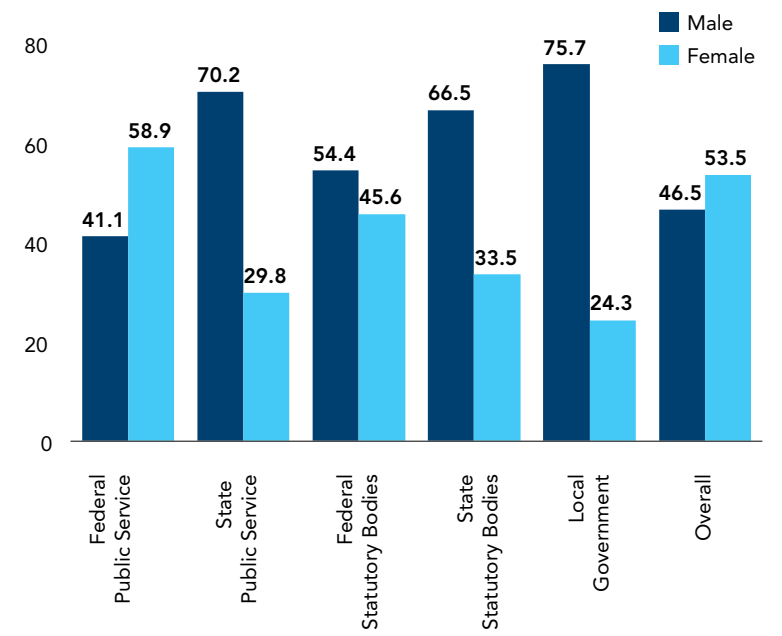

FIGURE 39

...with the share of citizens viewing the public sector as being impartial is also low
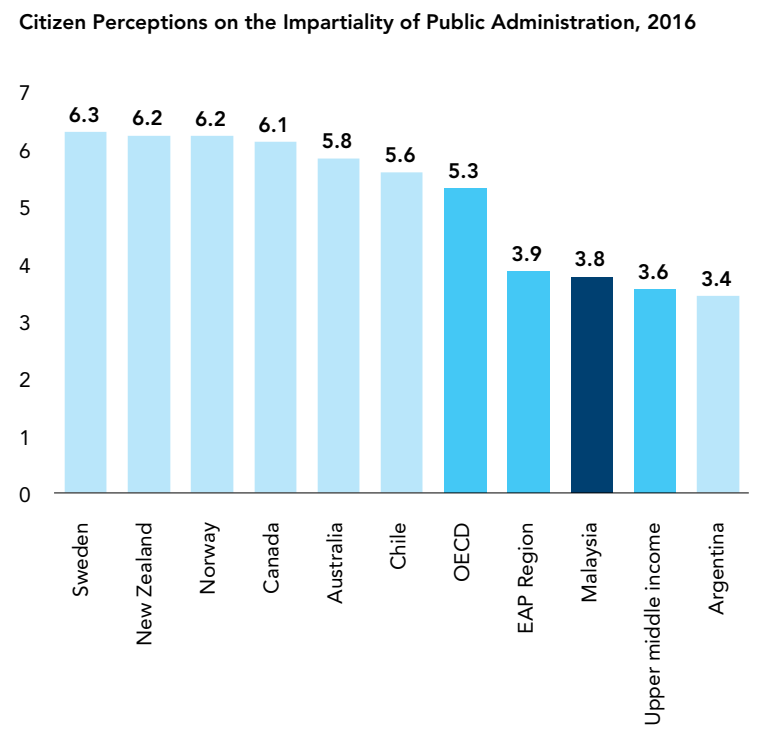

Source: Quality of Government (QoG) Expert Survey

FIGURE 41

...and in overall terms, Malaysia compares well with benchmark countries

Share of Female Employment in the Public Sector, 2016

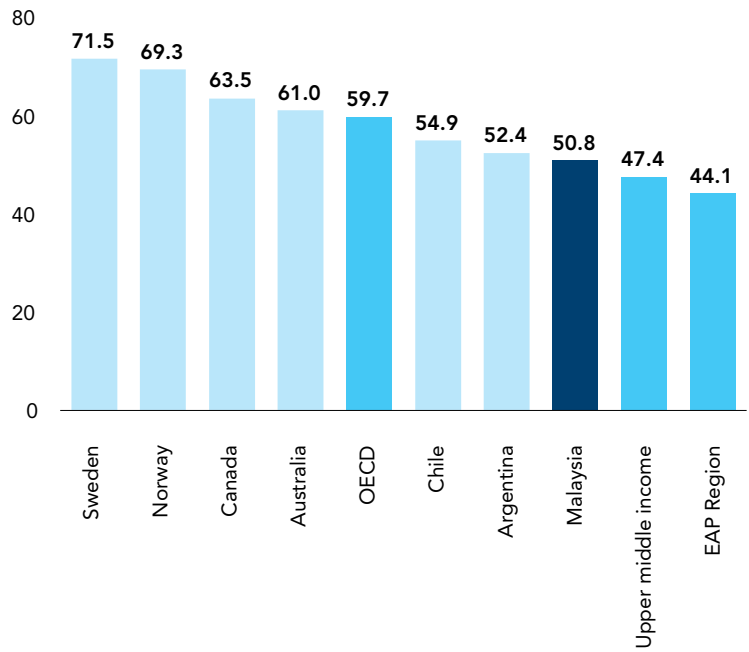

Source: World Bank staff calculations based on ILO data 
Research from around the world indicates that there is a relationship between equal opportunity and resilience, innovation and responsiveness to market demands. In turn, that relationship bears on Malaysia's overall goal of achieving high-income status. Advocates of light business regulation have long argued that anti-discrimination laws act as a brake on growth, with the argument being that such regulations constrain companies' employment decisions. However, recent research in the United States has found a positive correlation between the presence of equal employment legislation and rates of corporate innovation. This research presents evidence to suggest that such legislation spurs innovation by triggering a rebalancing of the workforce and matching pro-equality employees (who are likely to be more creative) with innovative firms. A large number of countries have implemented specific anti-discrimination legislation, usually initially relating to gender and race, but often with the addition of protections against discrimination on the basis of age and disability over the years. For example, New Zealand law recognizes that to address discrimination, positive actions may be needed to enable particular groups to achieve equal outcomes with other groups.

Given the strong relationship between HRM and organizational performance, it is important that the system is not just aligned with national priorities, but also meets the expectations of a range of stakeholder groups. The system should be based on strong principles to build and sustain the confidence of the Rakyat that the public service is clean, efficient, trustworthy and representative. To achieve this, the key principles outlined in Figure 42 can serve as useful guidance.

FIGURE 42

Four guiding principles for public service recruitment in Malaysia

Guiding Principles for Improving Fair and Neutral Employment in the Public Service

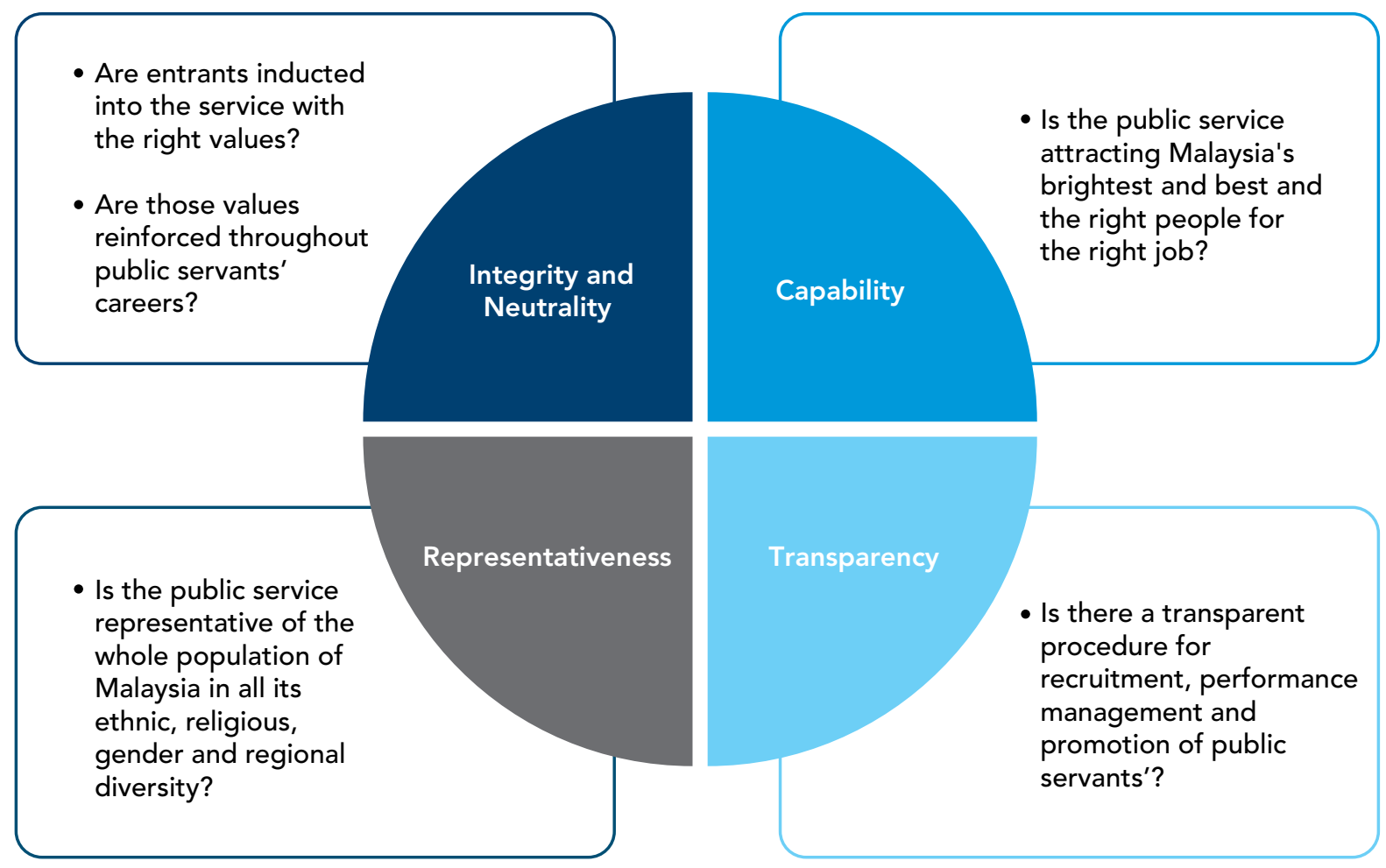


HRM reforms need to be carefully designed, and if emulated from another country, they should be adapted to the local context. ${ }^{16}$ Reform efforts, including those involving HRM, can have unanticipated consequences, which may require attention upfront. In particular, reforms should be formulated and implemented on the basis of a deep understanding of the local context and/or of the dynamics of the institutions involved in the reform efforts, amongst other matters. Each of the reforms (or the overall reform package) will need a change management plan. For example, it was necessary for the UK civil service to delay the delegation of budget responsibility to government departments in the mid-1980s because it had failed to anticipate the need for the relevant departments to have more sophisticated financial management skills and systems. Table 6 below lists some basic change management questions related to human resource management delegation.

TABLE 6

Change management questions on human resource management delegation

Theoretical framework

\begin{tabular}{|c|c|}
\hline Change management question & Example of implication for delegation \\
\hline What is the road map for change? & A road map for delegation should be developed. \\
\hline $\begin{array}{l}\text { What is the strategy for winning over stakeholders, and } \\
\text { adjusting where necessary based on their feedback? }\end{array}$ & $\begin{array}{l}\text { Concerns of central staff whose positions may be } \\
\text { affected, retraining and redeployment making best use } \\
\text { of skills. }\end{array}$ \\
\hline $\begin{array}{l}\text { What consequences, including negative ones, can be } \\
\text { anticipated at the outset? }\end{array}$ & An un-costed pension liability may be created. \\
\hline Which reforms should be piloted or phased? & $\begin{array}{l}\text { Perhaps those ministries that show ownership and already } \\
\text { have the capacity to handle the reform should be a } \\
\text { starting point. }\end{array}$ \\
\hline
\end{tabular}

What new learning needs will the reforms create, and how can they be addressed?

\section{Supporting a more open and transparent environment in the public service}

The creation of a merit-based, transparent, inclusive and citizen-centric public service needs to be supported by a broader institutional framework that encourages the emergence of an open and inclusive environment in the public sector. Such a framework promotes openness not just in terms of the relationship between the public service and citizens, but also within the public service, particularly between entities and across functions. Malaysia's Five-Year Development Plan 2016-2020 (the RMKe-11) articulates the country's intention to improve service delivery by increasing responsiveness to citizens, leveraging data to enhance outcomes, and increasing accountability through greater transparency. To achieve greater transparency, an environment that encourages proactive information and data sharing in a user-friendly and impactful manner is vital. This requires not just behavioral, technical and/or financial resources, but also measures to strengthen the institutional and legal framework to better support openness in the public service, particularly with respect to data sharing. Within this context, the Malaysian Administrative Modernization and Planning Unit (MAMPU) partnered with the World Bank in 2016-17 to assess Malaysia's readiness to successfully advance its Open Data program (see Box 10). 


\section{Reforms to improve open data would facilitate Malaysia's efforts to make government more transparent and citizen-centric}

\begin{abstract}
Many of the policy challenges of the 21st century are difficult for ministries and public servants to address if they continue to work in silos. The World Bank's report entitled "Improving Public Sector through Innovation and Inter-agency Coordination" examines the manner in which governments around the world are responding to the challenges associated with increased coordination. The report notes that the achievement of the SDGs requires a complex array of inter-relationships between ministries and departments. However, it found that the establishment of additional inter-agency committees, coordination bodies, and high-level task forces is rarely a solution. Rather, it found evidence to suggest that these efforts require a more joined-up approach, with contributions across units.
\end{abstract}

Governments are increasingly aware that effective policy actions cannot rely only on internal actors. Rather, they must involve strategies to engage citizens and the private sector to provide input. When government agencies and departments work in silos, hiding the data they hold or disclosing it only in unusable and/or cumbersome formats, it inhibits the kind of collaboration that is critical to deliver on government commitments.

An Open Data Readiness Assessment (ODRA) shows that Malaysia is well-placed to realize significant socio-economic gains from open data, but that significant further effort is needed to achieve this potential. According to this assessment, Malaysia scored "green" or "trending to green" in terms of six of the eight assessed dimensions (see Figure 43).

The ODRA found that several substantial constraints on the achievement of openness remain, including a fragmented policy environment, data management challenges, and the still-limited public engagement around data. While the current legal framework does not specifically mandate open data, neither does it actively hinder it or make it impossible. Malaysia has not yet enacted an Access to Information (ATI) law at the national level. However, two such laws exist at the state level. In addition, there has been some proactive release of data, as mandated by modern regulations, across the country. In general, the Official Secrets Act (OSA) is not used to actively prevent the release of information. The OSA explicitly prohibits the publication of only a few items of information, mostly devolving decision-making related to confidentiality to agencies, thus allowing for differences in interpretation and application. Thus, agencies have strongly devolved powers and responsibilities in terms of decisions related to the release or sharing of data. Even though this situation presents an opportunity for more open data and a bigger impact, in practice data-holders have opted to follow a case-by-case decision-making process that creates silos and uncertainties for both government and non-government requesters regarding the availability and provision of data.

In Malaysia, access to data is challenging and remains an area of concern for potential and actual data-users and other stakeholders. Data management policies and procedures to support public policy design and implementation exist in the country, but the level of interconnectedness and integration of government data is still low. While agencies are generally aware of the data they hold, with much of this data in digital format, comprehensive inventories within and/or across agencies are not generally available. There is strong demand for more internal data sharing, although requests are usually dealt with on a case-bycase basis, with data fees applying even to requests 


\section{FIGURE 43}

\section{An effective open data eco-system requires effort across a range of dimensions}

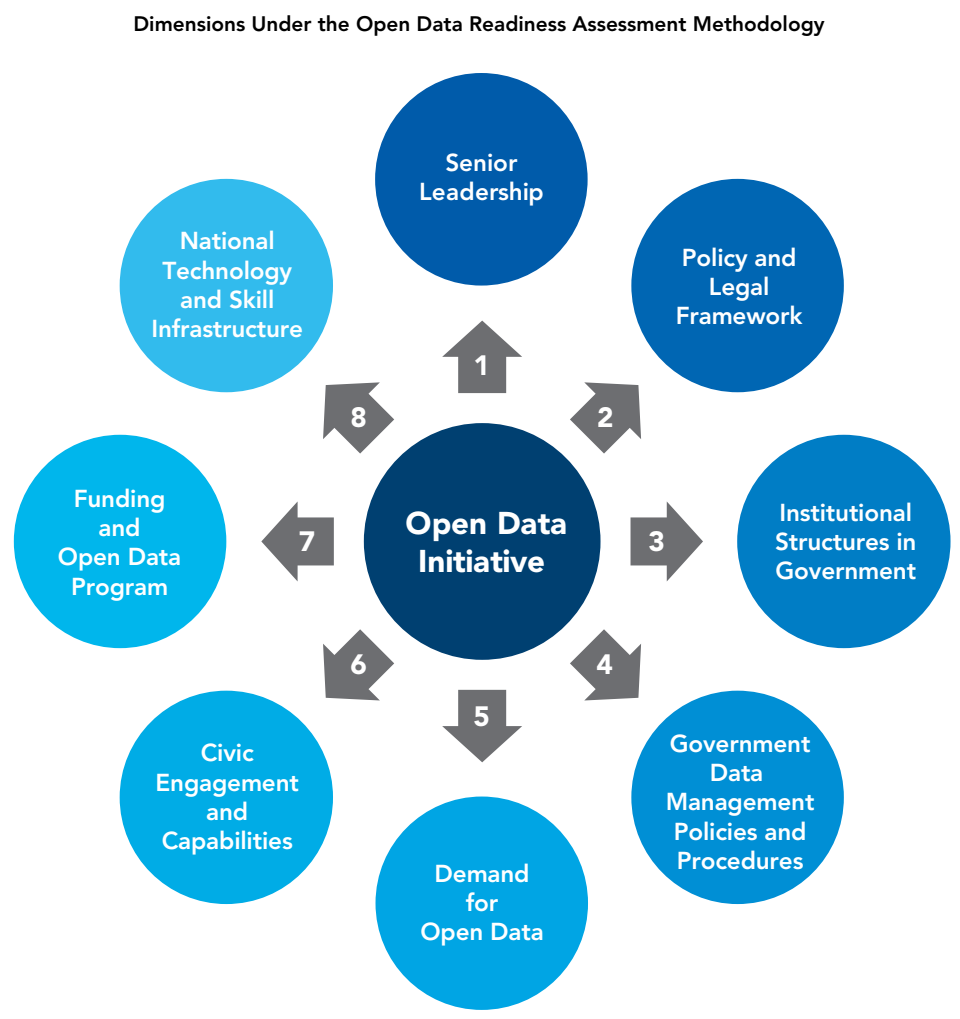

Source: World Bank (2017)

for government-to-government (G2G) data exchange. ${ }^{17}$ The external demand for open data is strong, and there is continued interest from different actors to access and use more data and to interact with data holding agencies. However, this external demand has not yet been met, despite the existence of the Open Data program, which could help to improve data quality and usefulness.

Advancing Malaysia's policy goals of facilitating the emergence of a more transparent and citizencentric government requires a number of agencies and departments to come together. MAMPU's efforts have resulted in some positive achievements, with the number of datasets on data.gov.my increasing dramatically from a modest 115 in 2014 to 12,910 by the end of 2018. In addition, the establishment of the Malaysian Open Data Users Group (MODUG) in 2018 has opened up a participatory venue for effective two-way communication with the public. Moreover, for the agency to truly fulfill its mandate, increased coordination and support from the highest levels of government is needed. While a culture of openness in the public sector may create a number of risks for public servants (data may reveal that some programs are not as effective or efficient; data is not reliable), it would go a long way towards building accountability and overall trust in the government.

\footnotetext{
${ }^{17}$ International rankings such as the Open Data Barometer (ODB) and the Open Budget Index (OBI) place Malaysia among the group of countries that must invest in opening up key datasets that people want and that affect the daily life of citizens. Malaysia scored 46 out of 100 in the latest edition of the OBI placing the country still among the group that release limited budget information. Similarly, in the ODB ranking -- which assesses that extent to which datasets on budget, spending, contracting/procurement (among others) are made available through government portals in open formats Malaysia scores 15 out 100 for the categories of "detailed government budget" and "public contracts."
} 


\section{Embracing new technologies and skills to digitalize and automate for improved public service delivery}

\begin{abstract}
Megatrends involving digitalization and automation are disrupting Malaysia's labor market and creating challenges for HRM policies. These challenges are not unique to Malaysia, but rather are affecting countries at all levels of development. Technological transformation creates opportunities for tremendous gains in productivity, performance and welfare both in the public sector and the wider economy, but it also leads to labor market disruptions. Of course, some jobs are here to stay, regardless of digitalization. But there will inevitably be many changes, partly because technological transformation alters the task content of jobs. In the process, it augments certain skills and creates new jobs, while at the same time other skills become obsolete. To take best advantage of the opportunities afforded by new technologies, it will be important that public servants have - or can be trained in - the sorts of skills needed to navigate digital technologies effectively. The public sector workforce of the future will require advanced cognitive, socio-behavioral and interpersonal skills, as well as adaptability to perform changing, nonroutine cognitive and analytical tasks. This is in stark contrast to the routine manual skills that are commonly required today.
\end{abstract}

\begin{abstract}
Quantitative estimates of the share of jobs that is susceptible to automation vary widely. The World Development Report 2016 estimates that from a purely technical level, 68 percent of the current jobs in Malaysia could potentially be automated. According to the same reference, from a purely technological standpoint, between 60 percent and 80 percent of all jobs in several East Asian countries could potentially be automated. However, the full automation of jobs takes time, especially in developing and emerging economies. Not all disruptive technologies are adopted quickly, implemented fully, or yield immediate benefits. Barriers to the adoption of technology, lower wages, and a higher prevalence of jobs based on manual dexterity in developing and emerging countries also mean that the process of automation is likely to be slower and less widespread in those countries. Adjusted for such time lags, the World Development Report estimates that 49 percent of jobs in Malaysia are susceptible to automation-a smaller share than in Thailand and China but a larger share than in Cambodia and Mongolia (see Figure 44).
\end{abstract}

FIGURE 44

A high proportion of jobs in Malaysia are susceptible to automation

Percentage of Jobs that are Susceptible to Automation, Selected Countries

100

80

60

20

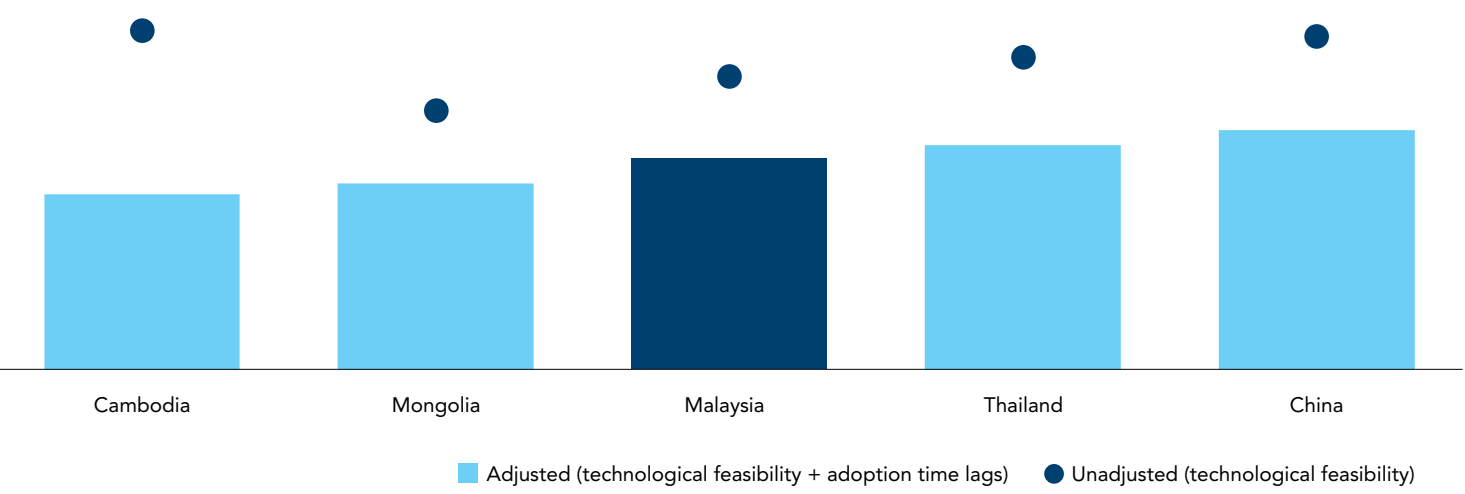

Source: World Bank (2015b) partly based on methodology of Frey and Osborne (2017) 
Malaysia's Critical Skills Committee has recently computed the likelihood that various occupations will be automated. The Committee assigns a score to each of 478 different 4-digit occupations in the Malaysia Standard Classification of Occupations (MASCO), based on an influential paper by Frey and Osborne (2017) that estimates the automatability of occupations in the United States. The authors argue that automation is possible for most tasks, except where "engineering bottlenecks to computerization" arise. ${ }^{18}$ However, there are potential constraints to automation beyond these bottlenecks. These constraints include whether firms other than globally connected top-tier firms adopt automation technologies; costs associated with adopting automation technologies; and legal, regulatory, and normative barriers to adopting automation technologies. Additionally, a number of occupations may evolve as the process of automation proceeds, rather than disappearing entirely.

Some of the ten occupations for which there is the highest probability of automation in Malaysia are widespread in today's public sector workforce. Tables 7 and 8 show the ten occupations with the highest and lowest probability of automation according to the Critical Skills Committee's analysis. Some of the occupations with the highest probability

TABLE 7

\section{Some occupations in Malaysia are likely to be} automated in the future..

Top ten occupations with the highest probability of automation

\section{Rank Title}

1 Data Entry Clerks

2 Contact Centre Salespersons

3 Photographic Products Machine Operators

4 Clearing and Forwarding Agents

$5 \quad$ Fashion and Other Models

6 Legal Secretaries

7 Packing, Bottling and Labelling Machine Operators

8 Accounting Associate Professionals

Product Graders and Testers (Excluding Foods and Beverages)

10 Woodworking-Machine Tool Setters and Operators

Source: Critical Skills Committee (2019) based on methodology of Frey and Osborne (2017) are not frequently found in the public sector but are rather routine manufacturing or services jobs (like "packing, bottling and labelling machine operator" and "contact center salespersons"). However, other occupations with a high likelihood of automation are widespread in today's public sector workforce, most particularly "data entry clerks," the occupation with the highest probability of automation among all the 478 occupations covered in the Critical Skills Committee's analysis. The public sector also relies heavily on some of the occupations with the lowest likelihood of automation, where competition for sought-after talent is likely to increase.

Occupations usually involve bundles of tasks, so certain jobs may evolve as the process of automation proceeds, with increased emphasis on some tasks and decreased emphasis on others, rather than disappearing entirely. Some jobs frequently found in the public sector may very well almost exclusively involve routine tasks that can be automated relatively easily. However, most public sector jobs involve a range of different tasks, some of which will be more easily automatable then others. Therefore, the methodology to determine the automatability of jobs by Frey and Osborne (2017) generally leads to significantly higher estimates of displacements than alternative estimates

\section{TABLE 8}

\section{...while others while likely remain relatively less affected}

Top ten occupations with the lowest probability of automation

\section{Rank Title}

1 Dieticians and Nutritionists

2 Hotel Professionals

3 Hotel Managers

4 Education Methods Specialists

$5 \quad$ Specialist Medical Practitioners

6 Audiologists and Speech Therapists

7 Social Welfare Managers

8 Psychologists

9 Education Managers

10 Health Services Managers

Source: Critical Skills Committee (2019) based on methodology of Frey and Osborne (2017)

${ }^{18}$ See Critical Skills Committee (2019) for a detailed description of the methodology adopted. 


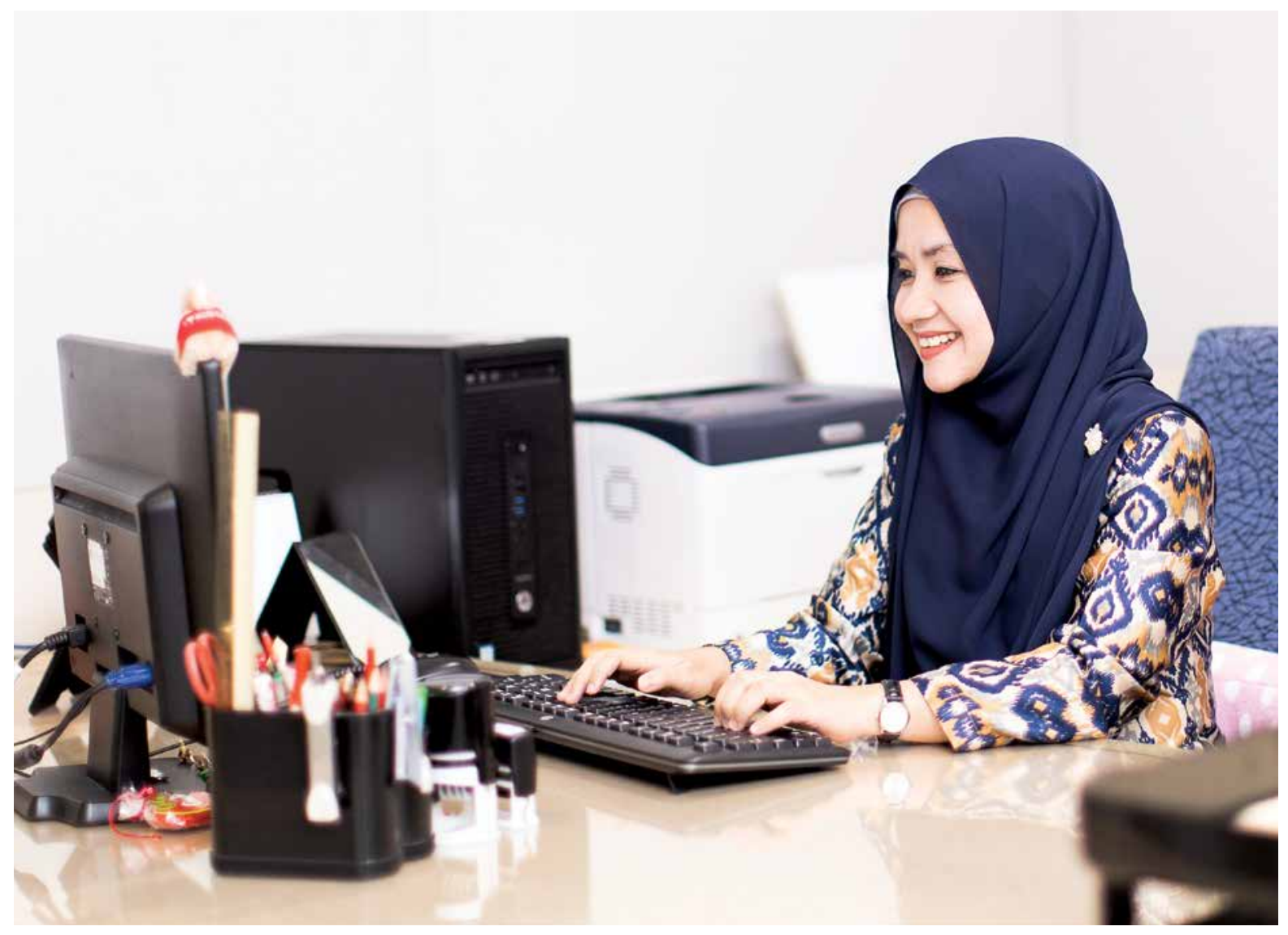

- like the one by Arnts et el. (2016) - that determine the automatability of tasks. For instance, even an occupation such as legal secretaries, with the sixth highest probability of automation in Malaysia, might not disappear completely. Instead, aspects of the occupation that can be relatively easily performed by computers (such as standardized legal research) are likely to be automated, while other aspects that require non-routine cognitive skills (like interaction with citizens) will become more prominent. The introduction of automatic teller machines (ATMs) provides an illustrative example. ATMs can handle many tasks that have historically been performed by bank tellers, such as such as facilitating cash withdrawals. As noted by Bessen (2015), following the widespread introduction of ATMs in the US, the number of tellers there did not dwindle. Instead, their function changed: dispensing cash and taking deposits became less important, and tasks involving human interaction became more so.

Technological change calls for public sector HRM policies that are more responsive and agile; that emphasize skills complementarities between machines and humans; and that enhance continuous learning. Malaysia could learn from the

\section{The public sector workforce of the future will require advanced cognitive, socio-behavioral and interpersonal skills}

experience of a number of countries that have made some headway in training their public servants to adopt new technology and to acquire the requisite skills to remain relevant in the context of evolving global megatrends. Malaysia could learn from the experience of these countries regarding the necessary design, implementation and evaluation implications, while at the same time remaining aware of the local context. For example, in the UK, the government has set up the Government Digital Services Academy to train public sector professionals in the requisite digital skills through courses on such subjects as artificial intelligence and digital services using agile principles. The main policy question from the perspective of managing the future public sector workforce is how to maximize the potential 
gains from technological change while mitigating ensuing challenges:

1. HRM policies need to adapt to fast-paced technological changes leading to the automation of a large number of tasks, potentially resulting in redundancies. At the same time, they must induct new occupations that demand new skills.

2. Public sector recruitment and workforce planning and development policies will need to systematically emphasize skills to complement new technologies (including advanced cognitive, socio-behavioral and interpersonal skills) and to ensure that the public sector remains able to attract and retain the appropriate talent in the face of increasing competition for workers with sought-after skills.
3. Enhanced opportunities for continuous learning among the public sector workforce will be necessary to encourage workers to stay engaged and to continue to participate in changing labor markets. While the public sector workforce of the future will most likely have many fewer data entry clerks than the public sector workforce of today, reskilling, upskilling and crossskilling can ensure that workers currently engaged in this occupation will have long, productive and fulfilling careers. The government plans to develop a Digital Government Competency and Capability Readiness (DGCCR) framework to provide specific upskilling in developing related digital capabilities. A sketch of future skills in the civil service developed by the OECD emphasizes professionalism, strategic and innovative aspects in the civil services to a far greater degree than in the past (see Table 9).

TABLE 9

Future skills of the civil service as Malaysia's looks towards developed country status

Typology of skills for a professional strategic and innovative civil service

\begin{tabular}{|c|c|c|c|}
\hline An effective state... & Professional & Strategic & Innovative \\
\hline $\begin{array}{l}\text {...needs civil servants who } \\
\text { are... }\end{array}$ & $\begin{array}{l}\text { - Qualified } \\
\text { - Independent } \\
\text { - Values driven } \\
\text { - Ethical }\end{array}$ & $\begin{array}{l}\text { - Outcomes driven } \\
\text { - Evidence based } \\
\text { - Future oriented } \\
\text { - Proactive } \\
\text { - Networked }\end{array}$ & $\begin{array}{l}\text { - Iterative } \\
\text { - Data literate } \\
\text { - Citizen centered } \\
\text { - Curious } \\
\text { - Storytellers } \\
\text { - Insurgent }\end{array}$ \\
\hline $\begin{array}{l}\text {...in a civil service which } \\
\text { is... }\end{array}$ & $\begin{array}{l}\text { - } \text { Merit based } \\
\text { - Capable of integrating } \\
\text { soft skills, ethics, talent } \\
\text { management (future } \\
\text { potential vs. past } \\
\text { performance) } \\
\text { - Able to structure the right } \\
\text { balance of generalize and } \\
\text { specialist professions and } \\
\text { career paths }\end{array}$ & $\begin{array}{l}\text { - Agile } \\
\text { - Attractive to skilled job } \\
\text { seekers } \\
\text { - Planned and managed } \\
\text { to ensure the right skills } \\
\text { and competencies are } \\
\text { effectively allocated } \\
\text { to areas of current and } \\
\text { emerging need } \\
\text { - Future oriented and } \\
\text { responsive }\end{array}$ & $\begin{array}{l}\text { - Open and collaborative } \\
\text { cultures, leadership and } \\
\text { management } \\
\text { - Engaged } \\
\text { - Autonomous (e.g. work } \\
\text { design) } \\
\text { - Mobile } \\
\text { - Diverse } \\
\text { - Learning oriented }\end{array}$ \\
\hline $\begin{array}{l}\text {...led by senior civil } \\
\text { servants who are... }\end{array}$ & $\begin{array}{l}\text { - Trusted policy } \\
\text { advisors and effective } \\
\text { transactional managers }\end{array}$ & $\begin{array}{l}\text { - Transformational leaders } \\
\text { and change managers }\end{array}$ & $\begin{array}{l}\text { - Collaborative leaders and } \\
\text { adaptive managers }\end{array}$ \\
\hline
\end{tabular}




\section{References}

AMRO (2019) Malaysia: Annual Consultation Report, Country Report No. ACR/19-01, Singapore: ASEAN+3 Macroeconomic Research Office.

Arnts, M., T. Gregory and U. Zerahn (2016) 'The Risk of Automation for Jobs in OECD Countries: A Comparative Analysis', OECD Social, Employment and Migration Working Paper No. 189, Paris: Organization for Economic Cooperation and Development.

Asian Development Bank and OECD (forthcoming) Governance at a Glance: Human Resources Management in ASEAN Countries, Manila: Asian Development Bank.

Bessen, J. (2015) 'Toil and Technology', Finance and Development 52: 16-19.

Bloomberg (2014) “MSCI Upgrade Unwanted as Emerging Beats Developed: Korea Markets." June 3.

BNM (2019a) Annual Report, Kuala Lumpur: Bank Negara Malaysia.

BNM (2019b) Quarterly Bulletin, Kuala Lumpur: Bank Negara Malaysia.

Critical Skills Monitoring Committee (2019) Critical Occupations List 2018/2019: Technical Report, Kuala Lumpur.

Devadas, S. and S. Pennings (2018) 'Assessing the Effect of Public Capital on Growth: An Extension of the World Bank Long-Term Growth Model' Journal of Infrastructure, Policy and Development 3(1): 22-55.

Frey, C. and M.A. Osborne (2017) 'The Future of Employment: How Susceptible Are Jobs to Computerisation?' Technological Forecasting \& Social Change 114:254-80.

Gao, H. and W. Zhang (2016) 'Non-discrimination laws make US states more innovative', Harvard Business Review, August 2016.

Ginding, T.H., Z. Hasnain, D. Newhouse and R. Shi (2019) 'Are Public Sector Workers in Developing Countries Overpaid? Evidence from a New Global Data Set', Policy Research Working Paper No.8754, Washington, DC: The World Bank.

IMF (2019) Malaysia: Article IV Consultation, Staff Report, IMF Country Report No. 19/71, Washington, DC: International Monetary Fund.

KRI (2018) The State of Households 2018: Different Realities, Kuala Lumpur: Khazanah Research Institute.

Loayza, N. and S. Pennings (2018) The Long-Term Growth Model, http://www.worldbank.org/LTGM.

McCourt, W. (2008) 'Public management in developing countries: From downsizing to governance', Public Management Review, 10: 467-79

Ministry of Finance (2018) Fiscal Outlook and Federal Government Revenue Estimates 2019. Ministry of Finance, Putrajaya: Government of Malaysia.

Ministry of Economic Affairs (2018) Mid-term Review of the 11th Malaysia Plan, Economic Planning Unit, Putrajaya: Government of Malaysia.

MSCl (2019) "MSCI Will Increase the Weight of China A Shares in MSCI Indexes." February 28.

OECD (2017) Skills for a High Performing Civil Service, OECD Public Governance Reviews, Paris: Organization for Economic Cooperation and Development.

Raddatz, C., S. Schmukler, and T. Williams (2017) 'International Asset Allocations and Capital Flows: The Benchmark Effect', Journal of International Economics, 108(C): 413-30.

Ravallion, M. (2019) 'Ethnic Inequality and Poverty in Malaysia since 1969', NBER Working Paper No.25640, Cambridge, Mass: National Bureau of Economic Research.

Reuters (2019) "Malaysia FTSE Bond Cut Cold Mean \$8 bn Outflows Morgan Stanley Warns." April 17.

Van Acker, W. and Z. Hasnain (2019) 'Wage Bill and Pay Reform: A First Glance and Look Forward', Governance Notes, Governance Global Practice. Washington, DC: The World Bank. 
Williams, T. (2018) 'Capital Inflows, Sovereign Debt, and Bank Lending: Micro-Evidence from an Emerging Market', Review of Financial Studies, forthcoming.

World Bank (2011) Transforming Government to Transform Malaysia: Expenditure Policy and Institutional Strengthening in the Context of Fiscal Adjustment, Public Expenditure Review, Washington, DC: The World Bank.

World Bank (2015a) Malaysia Economic Monitor, June 2015: Transforming Urban Transport, Washington, DC: The World Bank.

World Bank (2015b) World Development Report 2016: Digital Dividends, Washington, DC: The World Bank.

World Bank (2017) Malaysia Open Data Readiness Assessment, Malaysia Development Experience Series, Washington, DC: The World Bank.

World Bank (2018a) Malaysia Economic Monitor, December 2018: Realizing Human Potential, Washington, DC: The World Bank.

World Bank (2018b) Malaysia's Digital Economy - A New Driver of Development, Washington, DC: The World Bank. World Bank (2018c) Malaysia Economic Monitor, June 2018: Navigating Change, Washington, DC: The World Bank.

World Bank (2018d) A Resurgent East Asia, Navigating a Changing World, East Asia and Pacific Regional Report, Washington, DC: The World Bank.

World Bank (2018e) Innovating Bureaucracy for a More Capable Government, Washington, DC: The World Bank.

World Bank (2019a) Global Economic Prospects, January 2019: Darkening Skies, Washington, DC: The World Bank.

World Bank (2019b) East Asia and Pacific Economic Update, October 2018: Managing Headwinds, Washington, DC: The World Bank.

World Bank (2019c) Global Economic Prospects, June 2019: Subdued Investment, Washington, DC: The World Bank.

World Bank (forthcoming) 'Promoting Economic Opportunities for Women in Malaysia', working paper, Kuala Lumpur: The World Bank.

http://blogs.worldbank.org/governance/getting-basics-right-how-manage-civil-servants-developing-countries

http://www.nst.com.my/news/government-public-policy/2019/04/484308/171-million-civil-servants-govt-payrollmarch-2019 



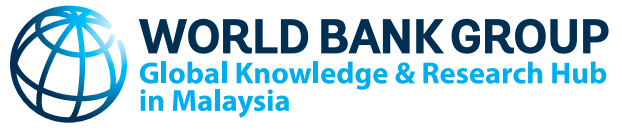

\title{
CONNECT WITH US
}

\author{
wbg.org/Malaysia
}

f@WorldBankMalaysia

@WB_AsiaPacific

http://bit.ly/WB_blogsMY 
